\title{
When Your Boo Becomes a Ghost: The Association Between Breakup Strategy and Breakup Role in Experiences of Relationship Dissolution
}

Rebecca B. Koessler, The University of Western Ontario

Supervisor: Campbell, Lorne J., The University of Western Ontario

A thesis submitted in partial fulfillment of the requirements for the Master of Science degree in Psychology

(C) Rebecca B. Koessler 2018

Follow this and additional works at: https://ir.lib.uwo.ca/etd

Part of the Social Psychology Commons

\section{Recommended Citation}

Koessler, Rebecca B., "When Your Boo Becomes a Ghost: The Association Between Breakup Strategy and Breakup Role in Experiences of Relationship Dissolution" (2018). Electronic Thesis and Dissertation Repository. 5402.

https://ir.lib.uwo.ca/etd/5402

This Dissertation/Thesis is brought to you for free and open access by Scholarship@Western. It has been accepted for inclusion in Electronic Thesis and Dissertation Repository by an authorized administrator of Scholarship@Western. For more information, please contact wlswadmin@uwo.ca. 


\begin{abstract}
Two studies examined ghosting, a unilateral breakup strategy that involves avoiding technologically-mediated contact with a partner instead of providing a verbal indication of the desire to break up. Study 1 solicited open-ended responses regarding experiences with ghosting and explored associations between ghosting and a variety of dispositional and situational variables. Study 2 investigated differences in the process of relationship dissolution and post-breakup outcomes as a function of breakup role (disengager or recipient) and breakup strategy (ghosting or direct conversation) across two samples. Recipients experienced greater distress and negative affect than disengagers, and ghosting disengagers reported the least amount of distress. Ghosting breakups were characterized by greater use of avoidance/withdrawal and distant/mediated communication tactics and less open confrontation and positive tone/self-blame tactics. Distinct differences between ghosting and direct conversation strategies suggest developments in technology have influenced traditional processes of relationship dissolution.

\section{Keywords}

Romantic relationship dissolution, breakup strategy, ghosting, technologically-mediated communication 


\section{Acknowledgments}

First, I would like to thank my advisor Dr. Lorne Campbell. The direction and support you have provided over the past two years has been invaluable, and I have been genuinely inspired by your passion for research and improving the state of psychological science. You have motivated me to critically evaluate and constantly strive to improve the quality and transparency of the research I produce, and I hope to encourage others to do the same.

Special shout out to Dr. Taylor Kohut, who acted as an essential resource during my formative first year and helped me develop and conduct my first research study. I would have floundered without your guidance, and I am very grateful to have had the opportunity to learn from you. Thank you for knowing the right time to lead gently, and when to give me a muchneeded kick in the pants.

Thank you to my examiners, Dr. Irene Cheung, Dr. Bill Fisher, and Dr. Erin Heerey for your time (and patience) during the evaluation of this thesis.

In addition, I would like to recognize the research assistants that helped code the qualitative data presented here. Alia Hussain, Suzie Blainey, Karly Mullins, Nazanin Kafaee, and Carlone Van Rooyen, thank you for volunteering your time.

I would also like to express my deepest admiration and appreciation of my fellow women in STEM who I consider to be downright badass colleagues, friends, and role models. Thank you, Alexa Clerke, Sarah Babcock, Marina Gross and Nicolyn Charlot for exemplifying what the best scholars should be: intelligent, resilient and selfless. Being around you constantly inspires me to be better. I am especially grateful for my friendship with Nicolyn--my fellow American, the cake to my wine, the zen garden to my pit, thank you for always being a shoulder to complain on. Best friends five-ever.

Finally, thank you to my family, who have offered me endless support and encouragement throughout this entire endeavor. You all mean more to me than you know. 


\section{Table of Contents}

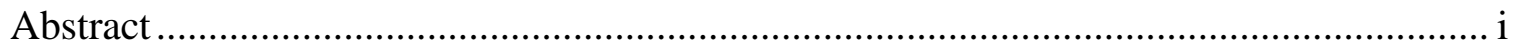

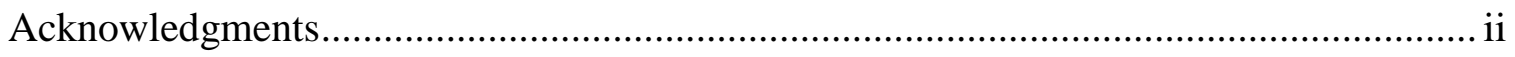

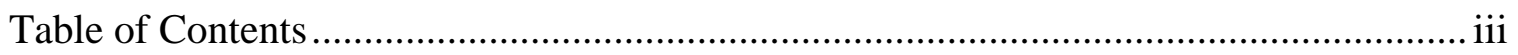

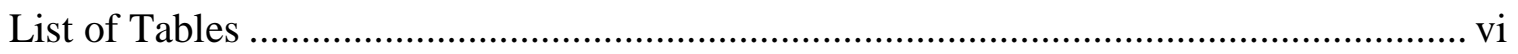

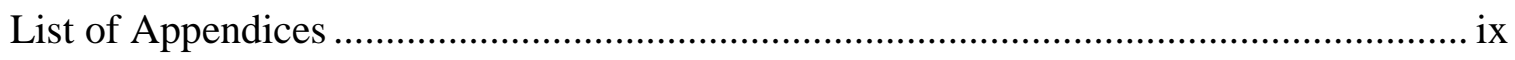

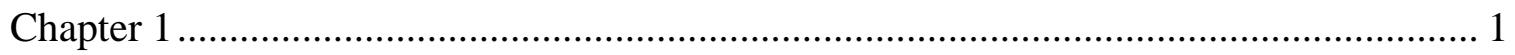

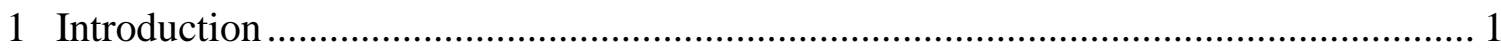

1.1 Ghosting: A Modern Breakup Strategy ....................................................... 1

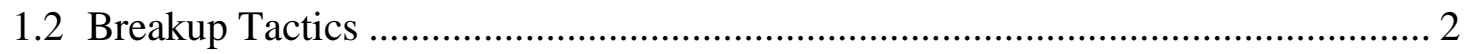

1.3 Who Ghosts? Who Gets Ghosted?........................................................... 4

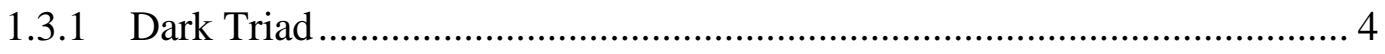

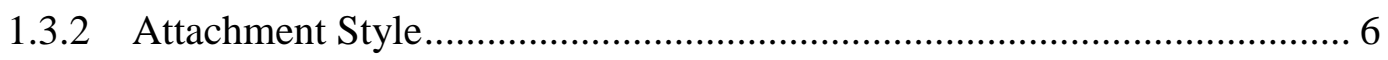

1.4 Characteristics of Relationships that End Through Ghosting ............................. 7

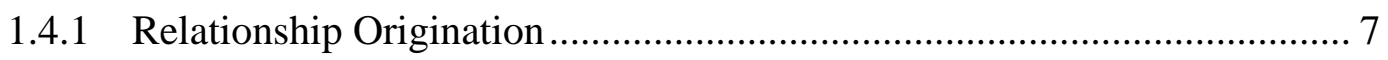

1.4.2 Relationship Length and Commitment .............................................. 8

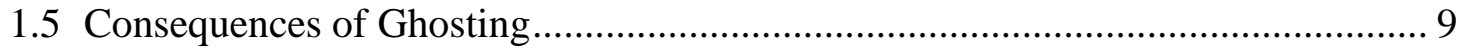

1.6 Advantages of Ghosting .......................................................................... 10

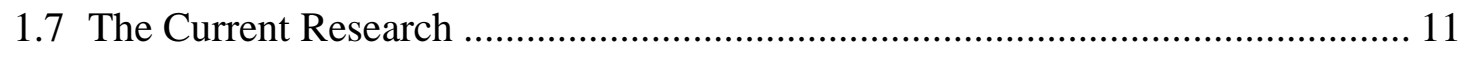

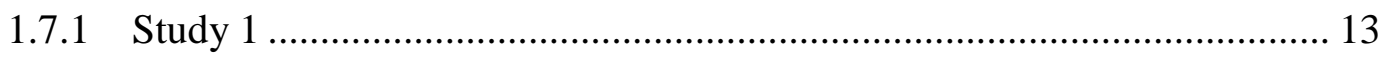

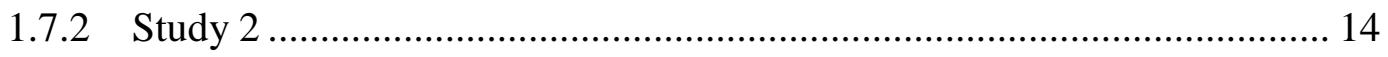

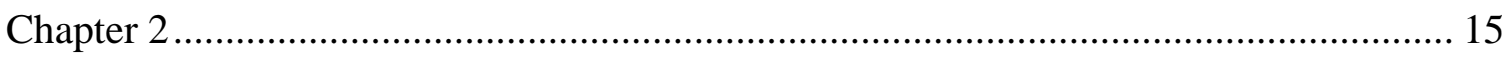

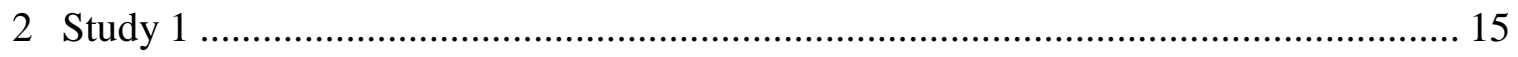

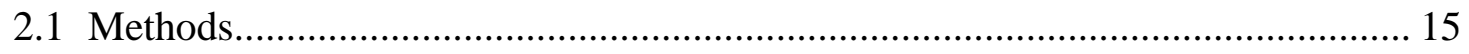

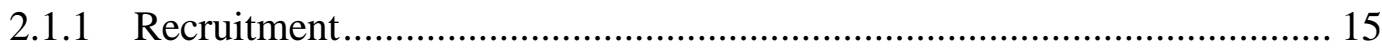




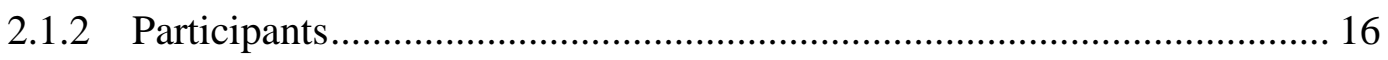

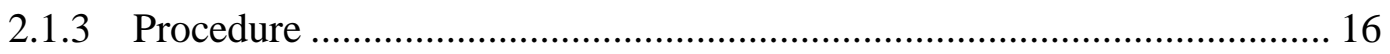

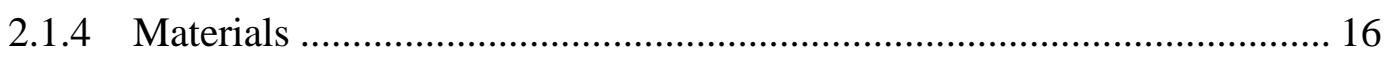

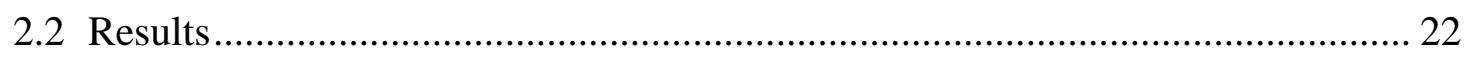

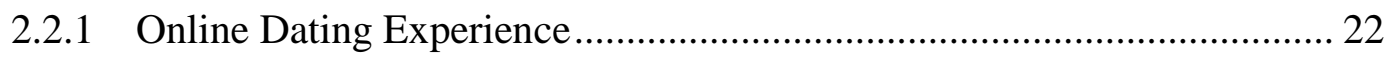

2.2.2 Base Rates and Definition of Ghosting ................................................... 22

2.2.3 Relationship Dissolution .................................................................... 25

2.2.4 Descriptions of Ghosting Experiences..................................................... 27

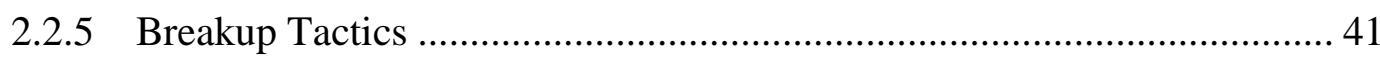

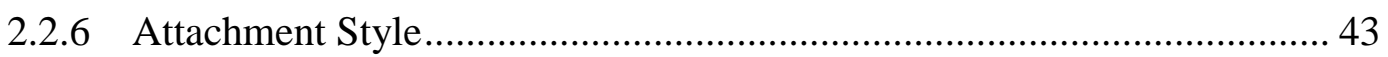

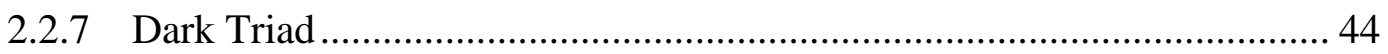

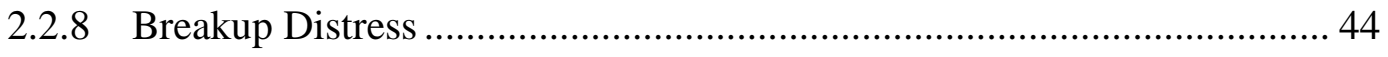

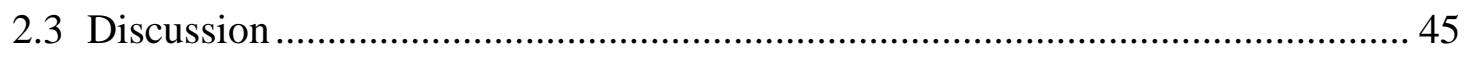

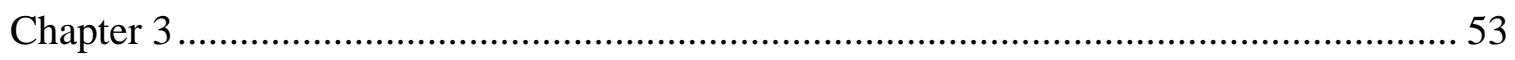

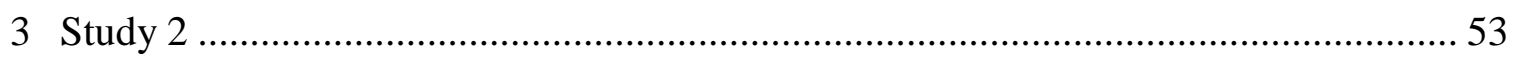

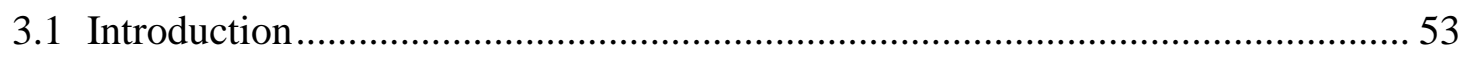

3.1.1 Breakup Role ................................................................................. 54

3.1.2 Breakup Tactics ............................................................................ 54

3.1.3 Motivations for Breakup Strategy Choice ………………………............ 55

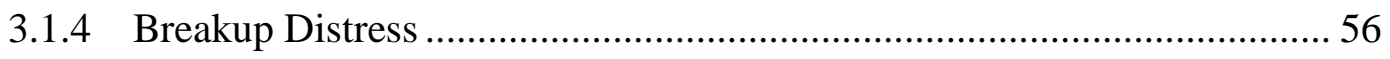

3.1.5 Positive and Negative Affect ............................................................... 56

3.1.6 Post-Breakup Recovery and Personal Growth.......................................... 57

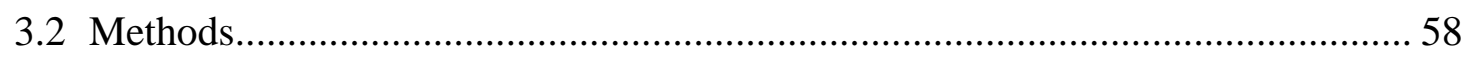

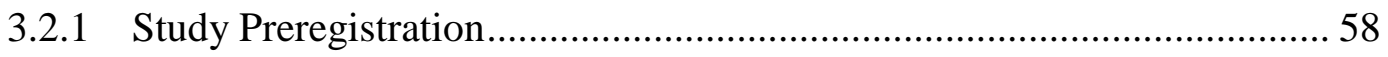

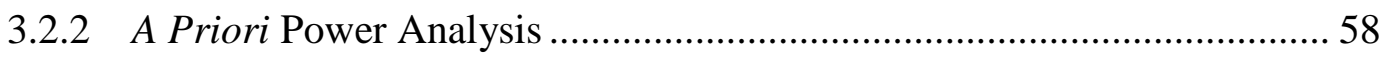

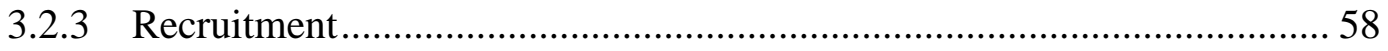




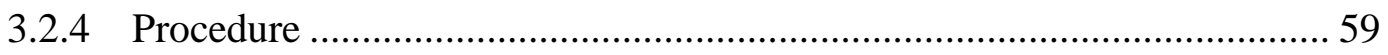

3.2.5 Participant Exclusion and Sample Division.......................................... 59

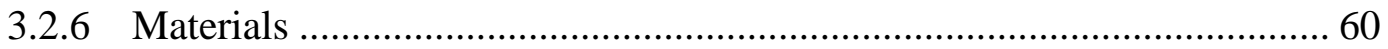

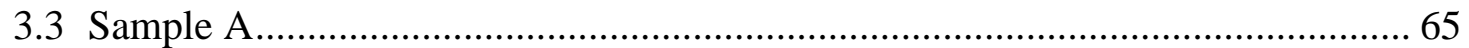

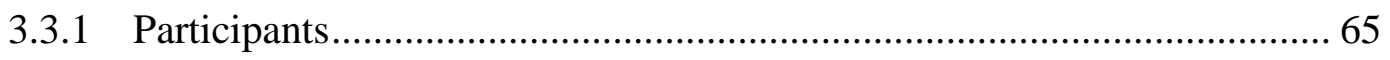

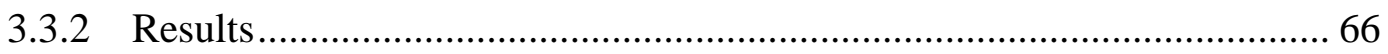

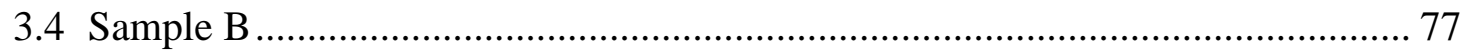

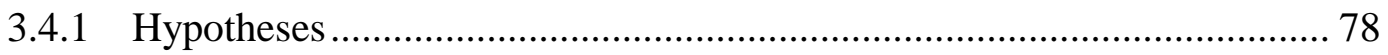

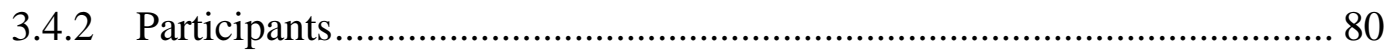

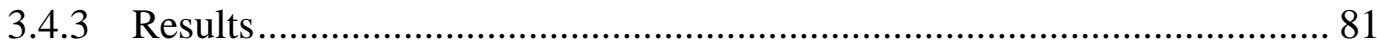

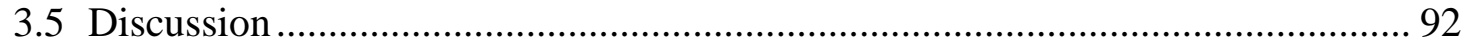

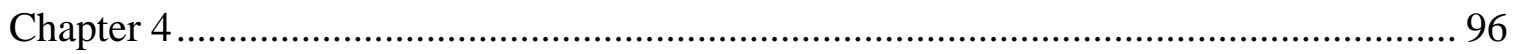

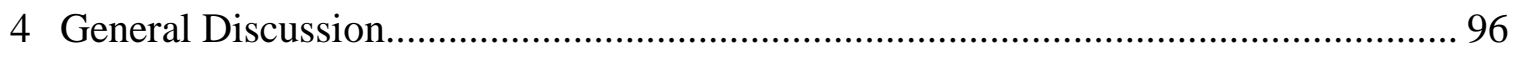

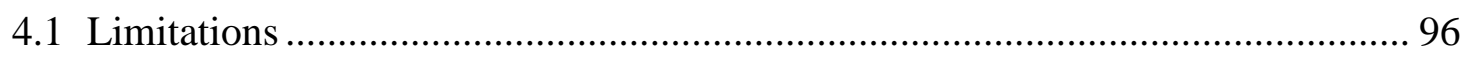

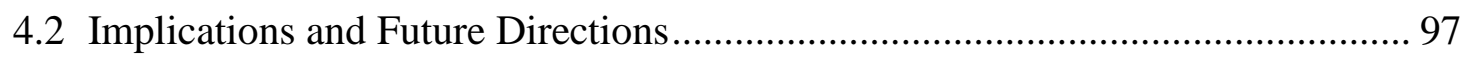

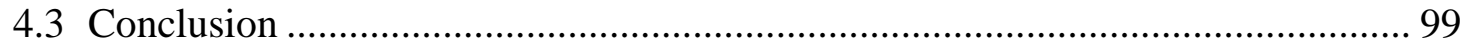

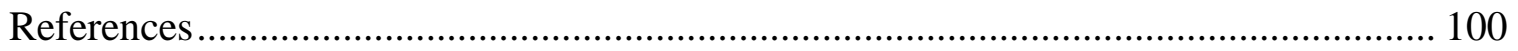

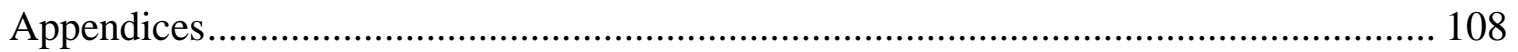

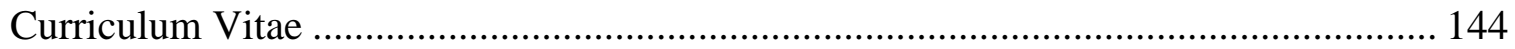




\section{List of Tables}

Table 1. Definition of ghosting ..................................................................................... 23

Table 2. How relationships originated as a function of ghosting experience. ..................... 26

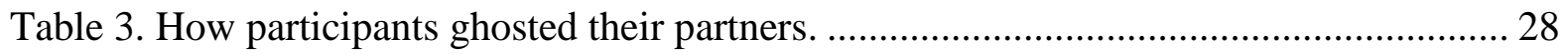

Table 4. How participants were ghosted by their partners........................................... 30

Table 5. Ghosting disengagers' motivations for ghosting. ............................................. 33

Table 6. Ghosting recipients' perceptions of disengagers' motivations for ghosting............ 36

Table 7. Ghosting recipients' responses to being ghosted.............................................. 38

Table 8. Ghosting recipients' changes in perception of ghosting disengagers. ................... 40

Table 9. Frequency of use of each breakup tactic as a function of ghosting experience....... 41

Table 10. One-way ANOVA results for frequency of use of each breakup tactic as a function

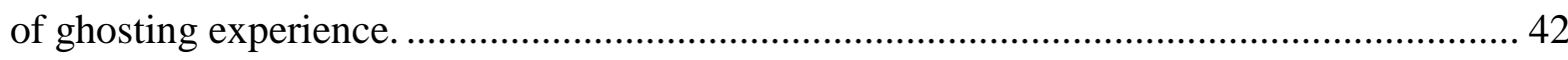

Table 11. Correlations between Dark Triad traits and number of ghosting experiences....... 44

Table 12. Cronbach's alpha for each breakup tactic subscale in Study 2.......................... 62

Table 13. Cronbach's alpha for scales and subscales of the BDS, BES, and PBRS in Study 2.

Table 14. Proportion of use or perceived use of each breakup tactic in Sample A.............. 67

Table 15. Factorial ( 2 X 2) ANOVA results for use or perceived use of each breakup tactic as a function of breakup role $(\mathrm{R})$ and breakup strategy $(\mathrm{S})$ in Sample A. .............................. 68

Table 16. Correlation coefficients for relations among the direct MBSC factors in Sample A. 70 
Table 17. Mean scores and standard deviations of the direct MBSC factors as a function of breakup role in Sample A.

Table 18. Correlation coefficients for relations among the ghosting MBSC factors in Sample

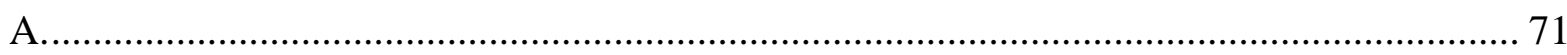

Table 19. Mean scores and standard deviations of the ghosting MBSC factors as a function of

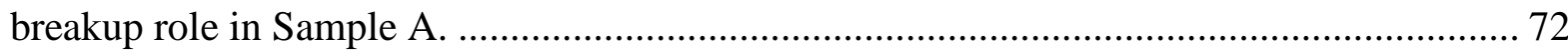

Table 20. Descriptive statistics of the BDS, BES, and PBRS in Sample A. ....................... 73

Table 21. Factorial ( 2 X 2) ANOVA results for the BDS, BES, and PBRS as a function of breakup role (R) and breakup strategy $(\mathrm{S})$ in Sample A.

Table 22. Factorial ( 2 X 2) ANOVA results without covariates and results with relationship length and commitment as covariates in Sample A.

Table 23. Proportion of use or perceived use of each breakup tactic in Sample B. 81

Table 24. Factorial ( 2 X 2) ANOVA results for use or perceived use of each breakup tactic as a function of breakup role $(\mathrm{R})$ and breakup strategy $(\mathrm{S})$ in Sample B 82

Table 25. Correlation coefficients for relations among the direct MBSC factors in Sample B. 84

Table 26. Mean scores and standard deviations of the direct MBSC factors as a function of breakup role in Sample B

Table 27. Correlation coefficients for relations among the ghosting MBSC factors in Sample B. 85

Table 28. Mean scores and standard deviations of the ghosting MBSC factors as a function of breakup role in Sample B 86

Table 29. Descriptive statistics of the BDS, BES, and PBRS in Sample B. 87 
Table 30. Factorial ( 2 X 2) ANOVA results for the BDS, BES, and PBRS as a function of breakup role $(\mathrm{R})$ and breakup strategy $(\mathrm{S})$ in Sample B

Table 31. Factorial ( 2 X 2) ANOVA results without covariates and results with relationship length and commitment as covariates in Sample B.

Table 32. Summary of Sample B hypothesis tests with Holm-Bonferroni adjusted alpha levels. 


\section{List of Appendices}

Appendix A: Study 1 MTurk Recruitment Advertisement................................................. 108

Appendix B: Study 1 Letter of Information....................................................................... 109

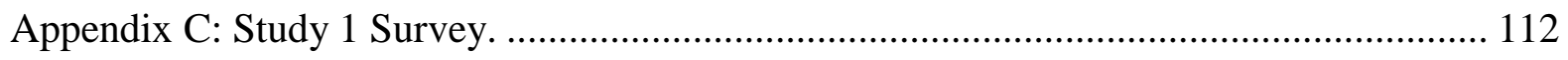

Appendix D: Study 1 Debriefing Form. ....................................................................... 120

Appendix E: Study 2 MTurk Recruitment Advertisements................................................ 121

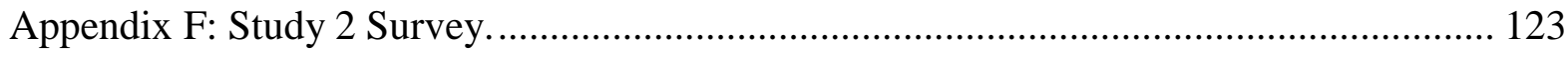

Appendix G: Study 2 Eligibility Screening Questionnaire................................................ 135

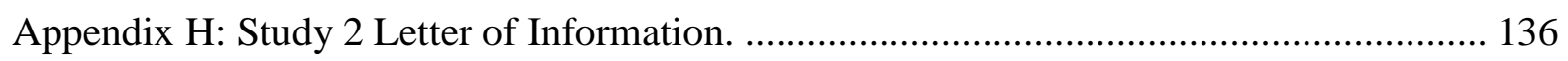

Appendix I: Study 2 Debriefing Form........................................................................ 139

Appendix J: Exploratory Factor Analyses of the Motivations for Breakup Strategy Choice

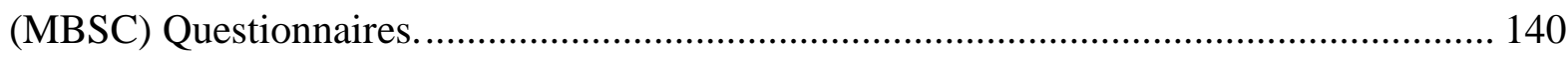




\section{Chapter 1}

\section{Introduction}

Online dating websites, dating applications, social networking sites (SNSs) and communication through technological devices have been heavily incorporated into how romantic partners connect and interact with each other (McEwan, 2013; Papp, Danielewicz \& Cayembeg, 2012). Many studies have focused on how the initiation and development of relationships has been influenced by technology, especially SNSs such as Facebook, Instagram, Snapchat and Twitter. However, as the mediums through which connections are facilitated increase, so do the mediums through which connections can be severed, and ways in which partners can be disconnected during the process of relationship dissolution. Though some past research has focused on post-breakup online and SNS behaviors as well as relationships that are terminated through text message or SNSs, little research has been done to investigate how relationship dissolution can be entirely executed by removing or preventing access to the technologically-mediated connections that once existed between partners.

\subsection{Ghosting: A Modern Breakup Strategy}

Recently, a newly recognized breakup strategy has come to the forefront of popular culture. Colloquially, "ghosting" has come to refer to instances where the disengager (partner who initiates the breakup) unilaterally dissolves a romantic relationship by avoiding online and offline contact with the recipient (partner who is broken up with). What distinguishes ghosting from other breakup strategies is the frequency with which a lack of an explicit explanation or declaration of dissolution is provided to the breakup partner. As Freedman, Powell, Le and Williams (2018) point out, this means the ghosted partner is not immediately aware of what has happened and is left to interpret on their own what this absence of communication might mean. In addition, though ending a relationship through avoidance may not be novel, the normalcy of building extensive technologically-mediated connections between partners is, meaning disconnection 
through these ubiquitous conduits may be an increasingly typical aspect of modern day relationship dissolution (LeFebvre, 2017).

Accounts of ghosting experiences have been on the rise since the term "ghosting" emerged in the popular culture discourse in 2014. A poll conducted by YouGov and Huffington Post in 2014 surveyed 1000 U.S. adults and found that approximately 13\% of the responders had previously been ghosted by a partner and $11 \%$ reported having ghosted a partner themselves (Moore, 2014). Most recently, Freedman et al. (2018) found that $25.3 \%$ of a sample of 554 participants drawn from Amazon's Mechanical Turk (MTurk) had been ghosted, and $21.7 \%$ had previously ghosted a romantic partner. In a second sample from Prolific Academic $(N=747), 23 \%$ of participants had experienced being ghosted and $18.9 \%$ reported having ghosted a romantic partner. Increasing accounts of ghosting experiences necessitates further research to understand how modern technology is affecting the way in which relationship dissolution occurs.

\section{$1.2 \quad$ Breakup Tactics}

Disengagers, the partners who initiate the termination of their relationships, have been shown to use a variety of breakup strategies in order successfully separate from their partners (Baxter, 1982, 1984; Cody, 1982). Past research that has identified different types of breakup strategies (Baxter, 1982, 1984; Cody, 1982; Collins \& Gillath, 2012) or explained the process of relationship dissolution through stage models (Knapp \& Vangelisti, 2005; Rollie \& Duck, 2006) have been conducted under the assumption that regardless of what strategy is used to dissolve a relationship, some degree of communication is involved where the recipient is verbally informed that the disengager is ending the relationship (Sprecher, Zimmerman, and Abrahams, 2010). The recent manifestation of ghosting introduced the possibility that such an instance of communication is not necessary in order for relationship dissolution to be successfully executed. Therefore, in the current research two dichotomous breakup types will be recognized, direct and indirect. A direct breakup is characterized by the disengager providing the recipient with a clear verbal indication that their relationship has ended. An indirect breakup is characterized by the disengager ending their relationship with the recipient without providing such an explicit indication of dissolution. Ghosting would 
therefore be considered an indirect breakup strategy and having a breakup conversation would be considered a direct strategy. What are referred to in the past literature as breakup strategies (Baxter, 1982; Collins \& Gillath, 2012) will be now be labeled breakup tactics. These breakup tactics are mostly descriptors of possible behaviors that lead up to either a direct breakup or an indirect breakup.

In 2012, Collins and Gillath updated Baxter's (1982) breakup tactic scale to reflect the technological advancements that had been made, including caller-ID, text-messaging, and use of SNSs. Forty-three unique breakup tactics emerged that were organized into seven factors. Avoidance/withdrawal tactics involve increasing distance from and decreasing signals of intimacy to the relationship partner, while in contrast, open confrontation tactics involve directly and honestly communicating with the relationship partner. Manipulation tactics involve intentionally manipulating third-party others in order to facilitate disengagement. Use of positive tone/self-blame tactics indicate concern for the partner's feelings, concern for their well-being, and the tendency for the disengager to take responsibility or blame for the cause of the relationship disengagement. Cost escalation involves making the partner's life difficult or costly, by initiating disagreements and being generally unpleasant. De-escalation involves the disengaging partner gradually terminating the relationship rather than ending it immediately, and distant/mediated communication tactics involve using technologically-mediated methods to inform the partner that the relationship is over (using text messaging, changing one's relationship status on Facebook, etc.).

Due to the assumption that some degree of communication exists during relationship dissolution, the unique indirectness of ghosting necessitates an exploration of the breakup tactics that are used prior to ghosting being implemented as a breakup strategy. Use of Collins and Gillath's (2012) scale should ultimately aid in identifying potential differences in the supplemental tactics used to facilitate relationship dissolution leading up to either a direct or indirect breakup. Further, the possibility that new tactics may have developed since Collins and Gillath (2012) updated the breakup tactic scale should be investigated, as the intricacies of the ghosting relationship dissolution process have not yet been empirically studied. 


\subsection{Who Ghosts? Who Gets Ghosted?}

In addition to identifying the breakup tactics used during the process of ghosting, research should aim to identify any shared characteristics that emerge within individuals who choose to utilize ghosting to end their relationships and within those who are the recipients of ghosting. Freedman et al. (2018) investigated the association between implicit theories of relationships and ghosting behaviors, intentions and perceptions. Specifically, the researchers found that individuals with greater destiny beliefs (e.g., relationships are stable and unchanging, people are either compatible or not; Knee, 1998) were more likely to have ghosted and been ghosted, to view ghosting as a socially acceptable breakup strategy, to be more likely to use ghosting in the future, and to think less poorly of those who use ghosting to end their relationships. In contrast, less associations were found for those with higher growth beliefs (e.g., relationships are dynamic, capable of developing and improving over time; Knee, 1998). Those with higher growth beliefs were less likely to think it was acceptable to use ghosting to end long-term relationships (as opposed to short-term relationships), and higher growth beliefs were negatively associated with intentions to ghost in the future. This research represents an initial investigation of the associations between attitudes towards and experiences with ghosting and various individual differences, however, many other personality orientations may be related to this behavior and are worthy of exploration.

Few studies have focused on how individual differences are related to breakup tactic and strategy choice (Brewer \& Abell, 2017). As such, associations between ghosting and attachment theory, which has been shown to be informative in the study of relational processes including romantic relationship dissolution (Bakermans-Kranenburg \& Van Ijzendoorn, 1997; Collins \& Gillath, 2012) will be explored, along with the Dark Triad, which has also been found to be useful in predicting relationship-related behavior (Jonason \& Kavanagh, 2010).

\subsubsection{Dark Triad}

The Dark Triad of personality is composed of three traits. Machiavellianism (Mach), associated with manipulation (Christie \& Geis, 1970), narcissism, characterized by grandiosity, a sense of entitlement, and superiority (Paulhus \& Williams, 2002), and 
psychopathy, related to high impulsivity, low empathy and low anxiety (Paulhus \& Williams, 2002). These traits could all potentially be related to the frequency with which ghosting is used to break up with romantic partners. Concurrently, the Dark Triad traits embody considerably negative traits that are not typically desirable in relationship partners (Ali \& Chamorro-Premuzic, 2010). As such, individuals with high expressions of Dark Triad traits may find themselves as the recipients of ghosting more often than those with lower expressions of such traits.

Few studies have explored the association between Dark Triad traits and breakup tactic preferences and frequencies of use. Brewer and Abell (2017) investigated the relationship between Mach and relationship dissolution in female participants. The authors found positive correlations between Mach and the use of Collins and Gillath's (2012) tactics of avoidance/withdrawal, cost escalation, manipulation, and distant/mediated communication, such that higher Mach individuals reported being more likely to use these tactics. These findings suggest that Mach is associated with more nonconfrontational or indirect approaches to relationship dissolution. A study by Sprecher et al. (2010) asked participants to rate the degree to which 47 breakup tactics were perceived to be compassionate. Forty tactics were adapted from Baxter (1982), six tactics were added to reflect technological developments, and one tactic was added based on data from a pilot sample. The findings revealed that avoidance/withdrawal tactics were rated as significantly less compassionate than positive tone and open confrontation, distant/mediated communication was significantly less compassionate than avoidance/withdrawal, and manipulation tactics were significantly less compassionate than distant/mediated communication tactics. Based on the aforementioned traits that individuals high on the Dark Triad express and the considerable overlap and similarity between the three constructs (McHoskey, 1995), it is likely individuals high on the Dark Triad might implement less compassionate breakup tactics more often during relationship dissolution and may be more likely to be the recipients of uncompassionate breakup strategies themselves. Partners who exude low empathy or open hostility may be difficult to have a breakup conversation with, suggesting that implementing a more indirect breakup strategy like ghosting where a conversation is entirely avoided may be a more effective strategy for dissolving relationships with Dark Triad individuals. 


\subsubsection{Attachment Style}

Hazan and Shaver (1987) suggested the three primary attachment styles in children described by Ainsworth, Blehar, Waters and Wall (1978) could be adapted to describe adult attachment styles in the context of romantic relationships. Secure individuals are comfortable depending on their partners, welcome the development of intimacy and closeness, and are not overly concerned about being abandoned. Avoidant individuals have difficulty trusting and depending on their partners and are often hesitant and nervous about getting too close. Anxious individuals often desire more closeness than their partners, are overly worried about being abandoned, and question their partner's love for them (Fraley \& Shaver, 2000; Hazan \& Shaver, 1987).

Multiple studies have documented the association between attachment style and the preferences and use of various breakup tactics (Collins \& Gillath, 2012; Krahl \& Wheeless, 1997; Pizzano, Sherblom, \& Umphrey, 2013). Avoidant individuals have been reported to be more likely to use avoidance/withdrawal and de-escalation tactics (Collins \& Gillath, 2012; Krahl \& Wheeless, 1997; Pizzano et al., 2013), which coincides with the association between attachment avoidance and greater indifference towards partner's needs for comfort and support (Collins \& Gillath, 2012). As such, avoidant individuals might be more inclined to view ghosting as an effective breakup strategy and may implement it more when dissolving their relationships. In contrast, attachment anxiety has been found to positively predict the use of positive tone and de-escalation tactics which allow for the opportunity to maintain a relationship with one's former partner, an attractive characteristic for anxious individuals who may desire to try and get their partner back in the future (Collins \& Gillath, 2012). For this reason, anxious individuals may be less likely to use ghosting as a relationship dissolution strategy, as ghosting would entail severing most or all connections that exist between partners. Like individuals high on the Dark Triad, individuals with high expressions of attachment anxiety and attachment avoidance may behave in such a way that pushes partners away. For example, anxious individuals may tend to be overbearing or clingy (Feeney \& Noller, 1990), while highly avoidant individuals may come off as uncaring or aloof (Feeney \& 
Noller, 1990). Such traits may make these individuals more likely to be ghosted by their partners.

\subsection{Characteristics of Relationships that End Through Ghosting}

\subsubsection{Relationship Origination}

The prevalence and popularity of online dating websites and applications allow for relationships between individuals to be initiated and develop online. For example, Tinder, a smartphone dating application, has 50 million users worldwide (A. Smith, 2016), and facilitates 26 million matches per day for users between the ages of 18 and 50 (C. Smith, 2016). While individuals who meet online have the ability to move their relationship offline (e.g., go on dates), much of the initial interaction between partners occurs through technologically-facilitated connections (Quiroz, 2013). In addition, though partners who meet online may live in the same city or town, the likelihood of encountering their partners serendipitously in person in their environment is probably low. Baxter (1982) found that if an individual does not expect to interact with or encounter their ex-partner in the future, less compassionate and more indirect breakup strategies may be implemented. Therefore, when relationships begin online but fizzle before significant social and environmental overlap has developed between partners, ghosting may be an effective breakup strategy and could be carried out solely online with little risk of encountering the ex-partner post-breakup. In contrast, while disconnecting from a partner online is relatively easy, relationships between partners who live, work, or socialize in close proximity to each other may represent more difficult conditions in which to successfully implement ghosting. Relatedly, Baxter (1982) suggested that when contact or interaction between romantic partners was expected to occur post-dissolution, more direct strategies of relationship dissolution would be used because uncomfortable uncertainty would be avoided, and awkwardness surrounding the breakup could be lessened if care and concern for the partner's well-being is made known during the breakup. Taking action to avoid encountering an ex-partner in person would require considerably more planning and effort, perhaps making ghosting a less optimal dissolution strategy for relationships that started offline. Operating under the assumption that differences in physical proximity 
between partners who met online versus offline differ, variance in the frequencies of ghosting experiences depending on how the relationship initially originated may exist and should be explored.

\subsubsection{Relationship Length and Commitment}

Regardless of how a relationship was initiated, as partners get to know each other the degree of contact between them should typically follow a similar pattern, with offline contact, social network overlap, commitment and exclusivity increasing as the duration of the relationship increases. Freedman et al. (2018) found ghosting was perceived to be more acceptable to end short term relationships than long term relationships, and ghosting was more acceptable to end relationships that only lasted two dates or less, or before physical intimacy occurred. Approval for the use of ghosting to end long term relationships or those in which physical intimacy occurred did not exceed $6.5 \%$ in a sample of 554 participants. Regarding more serious relationships, Davis (1973) suggested that due to the interdependent nature of close relationships, a direct conversation about dissolving a relationship is necessary to successfully "untie" partners from each other, meaning dissolving a relationship by simply fading away would be less likely to be successful. Therefore, as commitment, relationship length and interdependence increase, the more difficult and unlikely ghosting should become. In Banks, Altendorf, Greene and Cody's (1987) examination of breakup tactics and outcomes, they found avoidance tactics were usually implemented when intimacy and partner similarity were low. Similarly, Baxter (1982) found avoidance tactics were more likely to be used to disengage from a friendship as opposed to a close relationship. Accounts of ghosting experiences in the popular culture literature have described ghosting experiences at various points of a relationship ranging from relationships that had not yet moved offline (if initiated online; Hardwick, n.d.) to those that had existed for months or years (Samakow, 2014). Exploring the associations between these relationship characteristics and the occurrence of ghosting may inform whether ghosting is most commonly utilized early on in relationships before partners feel notably committed, invested, or exclusively tied to their partners. 


\subsection{Consequences of Ghosting}

Most individuals will experience relationship dissolution at some point in their lifetime, as many relationships form and fail before individuals find a partner with whom they develop a long-term pair bond (Buss, 2003; Fisher, 1989; Morris \& Reiber, 2011). While relationship dissolution is not uncommon, especially for young adults (Sprecher \& Fehr, 1998) the process nonetheless often evokes emotional reactions involving sadness, anxiety, and anger, and may evoke physical reactions such as loss of appetite and trouble sleeping (Morris \& Reiber, 2011). While the end of a romantic relationship alone can cause distress, the amount of distress may vary depending on what type of breakup strategy was used how the breakup process as a whole transpired.

As briefly mentioned above, different breakup tactics vary in degree of how compassionate they are perceived by breakup recipients. Sprecher et al. (2010) found that the breakup tactics perceived as the most uncompassionate were manipulation, distant/mediated communication, and avoidance/withdrawal. Since ghosting behaviors involve indirectly ending a relationship through avoidance and severing established technologically-mediated communication pathways, it would follow that ghosting may be perceived as an inconsiderate breakup strategy. First-hand accounts from popular culture articles support this assumption, as recipients of ghosting have reported a variety of negative outcomes spanning from rumination to anger. For example, in a blog post for XOJane, Victoria Carter wrote, "when you disappear into the ether without any indication why, all I can do is come up with a million and a half reasons why you're not into me" (Carter, 2013). A contributor for Huffington Post even went as far as to label ghosting "the coward's way of breaking up" (Spira, 2016). While these anecdotal accounts demonstrate negative feelings are harbored as a result of being the recipient of ghosting, the consequences for both recipients and disengagers following the use of ghosting as a breakup strategy have yet to be studied empirically. Furthermore, whether the use of uncompassionate breakup tactics during relationship dissolution causes more distress on behalf of the recipient has yet to be studied.

In addition to feelings of post-breakup distress, other consequences could possibly result from ghosting in terms of retaliatory actions on behalf of the recipient, perhaps including 
spreading negative perceptions of the ghosting disengager throughout shared social networks. Perilloux and Buss (2008) recognized that when couple members' social networks overlap and the couple dissolves, the partner responsible for initiating the breakup risks being regarded as rude or uncaring by their peer group who may sympathize with the other partner. Since negative traits and negative reputation/social status are detrimental to one's ability to attract future partners (Buss, 1989), rejected partners, including those who are ghosted, have the opportunity to take action in retaliation against their former partner by telling others in their social network that their ex-partner used ghosting to break up with them. With this in mind, ghosting may be less common strategy that is implemented in relationships where social network overlap between partners is large. In contrast, in early-stage relationships in which social network overlap has not yet developed, the negative opinions of the ghosting disengager held by the ghosting recipient may not negatively impact the ghosting disengager. As such, ghosting may be a more low-risk strategy for disengagers to implement in shorter, less serious relationships.

While some recipients of ghosting may simply move on without a fuss once they have realized what has occurred, others may make repeated attempts at contacting the ghosting disengager. Hypothetically, this could extend beyond attempts to reestablish contact with the disengager through technologically-mediated communication to contacting mutual friends or the disengagers' family members, or possibly even physical stalking. While post-breakup distress is valuable to study, the unique social consequences of ghosting as a breakup strategy in terms of retaliatory action on behalf of ghosting recipients and the negative perceptions of ghosting disengagers that are held by recipients and potentially disseminated to others should be explored as well.

\subsection{Advantages of Ghosting}

Though much of the focus thus far has been on the possible negative outcomes associated with ghosting, ghosting may offer benefits for the disengager. In an article for the New York Times, one individual who ghosted their partner stated, "If you disappear completely, you never have to deal with knowing someone is mad at you and being the bad guy" (Safronova, 2015). Another individual said, "I didn't know how to deal with it, 
and it was an easy way out." Though limited, these accounts demonstrate that ghosting may be a breakup strategy that can be employed where the disengager can avoid feeling like they are actively hurting the recipients' by directly communicating that they are no longer interested in a relationship. Though recipients may still be upset by being ghosted, the disengager has distanced themselves from the recipient to the point where they are not aware of or affected by the recipients' distress, perhaps making post-dissolution adjustment easier for the disengager. In addition, the ease with which ghosting can be implemented seems to be a prominent theme in popular culture articles (Coen, 2015; Crotty, 2014). Disconnecting from recipients can be done with a few button clicks, through blocking numbers, unmatching on online dating sites and unfollowing or unfriending on social media. The ease and effectiveness of ghosting may make this strategy more attractive, and perhaps more likely to be used.

Unlikely but not impossible, some breakup recipients might even prefer to be ghosted as opposed to being directly rejected online or in-person. Individuals who may not have been attached to the relationship or to the partner may not feel like a direct explanation was needed and may even interpret ghosting as a move intended to spare their feelings, or a breakup strategy that is now a normative aspect and risk of the modern dating world (Crotty, 2014; Samakow, 2014). Ghosting is a breakup strategy that has been adapted to be successful and efficient in an age of technologically-dependent communication. Further exploration of the potential advantages to both implementing ghosting and being a recipient of ghosting is necessary to gain a greater understanding of this phenomenon.

\subsection{The Current Research}

Ghosting is a new breakup strategy that has stemmed from the reliance on technologically-mediated communication for forming connections between relationship partners. Despite being able to assume associations between ghosting behaviors and variables related to the process of relationship dissolution based on existing knowledge of avoidant or withdrawal breakup tactics, much remains to be discovered. 
Existing descriptions of ghosting have only been found in non-academic sources, meaning the descriptions were not based on any sort of scientific exploration or analysis. The following are some of the definitions of ghosting found in popular media:

"The act of suddenly ceasing all communication with someone the subject is dating, but no longer wishes to date. This is done in hopes that the ghostee will just 'get the hint' and leave the subject alone, as opposed to the subject simply telling them he/she is no longer interested"-Urban Dictionary

"the ending of a relationship by one party who gradually removes him or herself from the other person's life... until eventually, all communication ceases"-Elle.com

"a legitimate way to not only convey your disinterest, but to actually break up with someone. If you were nice enough to tell [them] you weren't interested in [them] in that way and [they] keep trying, there comes a point where your best strategy is complete silence"-Bolde.com

"having someone that you believe cares about you... disappear from contact without any explanation at all" - Psychology Today

The definitions in circulation contain inconsistencies in terms of whether ghosting occurred gradually or at once, whether all contact or only partial contact was impeded, and whether an explicit explanation was given before ghosting occurred. These opposing details indicated that a clear understanding of what ghosting actually is does not yet exist.

Relatedly, how exactly ghosting is implemented has yet to be thoroughly assessed.

Freedman et al. (2018) found that out of 251 participants familiar with ghosting over $79 \%$ of participants considered not contacting or responding to the partner via phone calls or text messages and unfriending, unfollowing or blocking the partner on social media all constituted ghosting behavior. In addition, approximately 57\% of participants believed cutting off contact with mutual friends constitute ghosting behavior as well. Though informative, these items were generated by the researchers leaving the chance that other pathways or methods through which communication with a partner is severed may have been omitted by not taking into account the perspectives of those who have actually 
experienced ghosting. As such, eliciting open-ended responses from participants who have ghosted or been ghosted with regards to how that process occurred would represent a valuable contribution to existing knowledge informed by those who had experienced it first-hand.

Similarly, the motivations for choosing ghosting as a breakup strategy has yet to be investigated either. Popular sources have suggested that potential motivations include the ease with which ghosting can be implemented and avoiding actively hurting the recipients' feelings by rejecting them directly (Coen, 2015; Safronova, 2015). Though these suggestions in part are derived from sources who have experienced ghosting, they are only collated from a few individuals whose accounts may not be representative of typical ghosting breakups. As such, numerous and more diverse perspectives should be accumulated to achieve a more detailed insight into why use of this breakup strategy has been steadily increasing.

\subsubsection{Study 1}

Given that little empirical research has been conducted on ghosting and an attempt to create a data-driven approach to defining and describing the phenomenon of ghosting has not yet been undertaken, an exploratory study was conducted to accomplish this. In openended responses participants recruited from MTurk defined ghosting, explained (if applicable) how and why they chose to ghost their partners, or how and why they believe their partners ghosted them. In addition, participants who realized they had been ghosted described any retaliatory actions that were taken by them in response and how their perceptions of the ghosting partner changed. All participants then completed a number of questionnaires assessing various dispositional and situational characteristics that could be used to further our understanding of ghosting and how it is associated with a variety of social and personality constructs. Specific findings of particular interest to the researcher were selected and used to inform a follow up study that investigated certain variables in greater detail. 


\subsubsection{Study 2}

Study 2 was designed to compare the differences in breakups that occurred through the ghosting strategy (indirect breakup) to those that occurred through direct conversations (direct breakup) from the perspective of both breakup disengagers and breakup recipients on a variety of outcome measures. Types of breakup tactics used (or perceived to be used) during the process of the breakup, motivations (or perceived motivations) for selecting a specific breakup strategy (ghosting or direct conversation), breakup distress, post-breakup affect, and post-breakup recovery and personal growth were all included as outcome measures. Study 2 used a cross-validation design, meaning the total sample for Study 2 was recruited and collected through MTurk and then randomly divided in half. Sample A was used to explore the data and Sample B was used to test confirmatory hypotheses that were informed by the results found in Sample A. 


\section{Chapter 2}

\section{Study 1}

The objectives of Study 1 were to explore, define, and describe the phenomenon of ghosting as a relationship dissolution strategy with both qualitative and quantitative data, and to uncover any associations that might exist between ghosting and a variety of dispositional (e.g., attachment style, Dark Triad) and situational (e.g., relationship originated online or offline, relationship length, commitment) characteristics. In addition, base rates of experiences with ghosting were obtained to determine how often ghosting is used as a breakup strategy. The net was cast wide in Study 1, as the purpose was to identify potential variables that may be related to the phenomenon of ghosting and to design follow-up studies to investigate these relationships in greater detail. Consequently, only a subset of the total findings is reported here. All study materials are publicly available on the OSF project page (https://osf.io/bgjvz/).

\subsection{Methods}

\subsubsection{Recruitment}

Participants were recruited through MTurk, an online platform where workers complete Human Intelligence Tasks (HITs) for pay. The recruitment advertisement stated that researchers were interested in exploring, defining, and describing the phenomenon of "ghosting" as a breakup strategy in both online and offline romantic relationships. Interested participants between the ages of 18 and 35 who experienced a breakup with a romantic interest or partner in the past five years, were fluent English speakers, resided in the United States or Canada, and had an active MTurk account with at least $95 \%$ approval from previous requesters were eligible to participate. The survey took between 30 and 60 minutes to complete, and participants were compensated with \$1.00 USD for their participation. 


\subsubsection{Participants}

Of the 643 participants who started the study, 89 were excluded for only filling out the demographic portion of the survey, 115 were excluded for responding inconsistently to attention checks (e.g., reporting they ghosted a partner then reporting that same relationship ended mutually), eight participants indicated their data should not be used based on the amount of attention they paid while filling out the survey, 34 were excluded because they were over 35 years old, three were excluded for not entering their age, 11 consented but did not enter any demographic information, and 51 were excluded for reporting on a breakup that occurred over five years ago. The final sample consisted of 332 participants (149 male, 181 female, two identifying otherwise) who were between 19 and $35(M=28.26, S D=4.36)$ years of age. One hundred and thirteen participants were single at the time of the study, 155 were casually dating, 57 were married and seven were separated or divorced. In addition, 268 participants identified as heterosexual, and 64 identified as non-heterosexual. The majority of the sample identified as white (74.7\%), followed by black (7.5\%), Hispanic (6\%), Asian (4.5\%), multiracial (4.5\%), indigenous $(2.1 \%)$ and $0.6 \%$ did not specify a racial identity.

\subsubsection{Procedure}

Participants recruited from an advertisement on MTurk (Appendix A) followed a link to a Qualtrics survey that was completed entirely online. Participants read a Letter of Information (Appendix B) and gave implied consent. They were then forwarded onto the survey, where they completed a number of questionnaires (Appendix C). Once the questionnaires were finished, a debriefing form (Appendix D) was displayed along with the HIT code the participants submitted through MTurk to claim payment for completing the task.

\subsubsection{Materials}

Only a subset of the questions and scales administered in Study 1 are presented here and in Appendix C. The full survey can be found on the OSF (https://osf.io/rkude/). 


\subsubsection{Demographics}

Participants were asked to report their age, gender, English fluency, sexual orientation, relationship status, race, and religious affiliation. In addition, participants were asked about their experience with and use of online dating applications or websites.

\subsubsection{Base Rates and Definition of Ghosting}

Participants were asked if they had heard of "ghosting" in the context of dating, and if so, were asked to define ghosting in their own words. Participants who had not heard of ghosting were not given the opportunity to provide their own definition. Next, all participants were shown a vague definition of ghosting created by the researcher based on the colloquial definitions found in the popular culture articles and blog posts. Ghosting was defined as "the act of ending a relationship with a partner with whom romantic interest and attraction once existed by avoiding any type of communication and/or contact with that partner." Participants were asked to indicate how many people they had ghosted and how many people had ghosted them. Some definitions of ghosting provided by popular culture sources suggested that if a person had explicitly expressed disinterest to a partner before avoiding contact with them it was not considered ghosting because an explanation was provided. Participants were asked if they agreed or disagreed with this view.

\subsubsection{Relationship Dissolution}

Participants were asked about one to three (depending on their experiences with ghosting) of their relationships that had ended in the past five years. Eligible types of relationships could include online dating site/application matches, one-night stands, casual dating partners or serious partners. Participants were asked how long ago the relationship ended, how they met their partner, how long the relationship lasted, how committed they were to their partner on a Likert scale of 1 (not at all committed) to 7 (very committed), and how they would label the relationship they had with their partner (no relationship, just friends, casually dating, exclusively dating, engaged, etc.). Additional questions not mentioned here were asked in this section. The comprehensive version can be found in the Methods component of the OSF project page (https://osf.io/vj2af/). 


\subsubsection{Open-Ended Descriptions of Ghosting Experiences}

Participants who indicated they had previously ghosted a partner were asked to describe in an open-ended response how they did so. These participants were also asked why they ghosted their partner and to explain their reasoning in detail.

Participants who indicated they had previously been ghosted by their partners were asked to describe in an open-ended response how their partners did so, why they believe their partner chose to ghost them, what actions they took (if any) in response to being ghosted, and how (if at all) their perceptions of their partner changed after realizing they had used ghosting as a breakup strategy.

\subsection{Qualitative Analysis Method}

The guidelines of Braun and Clarke (2006) informed the analyses of the open-ended responses into codes and broader themes. This process occurred across five phases:

Phase 1: The researcher compiled the participants' responses and read through them in full. Preliminary notes or ideas for codes were generated in preparation for Phase 2.

Phase 2: Using the information gained from Phase 1, the responses were systematically analyzed by identifying and extracting interesting phrases or observations. A semantic approach was utilized to identify codes, meaning that responses were interpreted explicitly at the surface level and minimal assumptions about underlying meanings were included as part of the analysis (Braun \& Clarke, 2006). In this way, specific codes were identified that reflected "the most basic segment, or element, of the raw data or information that [could] be assessed in a meaningful way regarding the phenomenon" (Boyatzis, 1998). Once the data were thoroughly examined, the extracted codes were labelled and described along with raw text examples in the form of a codebook that was used to train reliability coders (https://osf.io/bmh68/).

Once the codes were developed, Syed and Nelson's (2015) master coder approach was used to establish reliability. 
In Phase 1 and 2 the master coder (the current researcher) read through the entirety of the responses in the data set, developed a coding scheme for each research question, and coded the responses. Five reliability coders (undergraduate research assistants) were then trained and assigned to a random $20 \%$ of the responses for each question $(20 \%$ is a common figure used in previous research; Lilgendahl \& McAdams, 2011; McLean \& Pratt, 2006). Using the coding scheme dictated by the master coder, the reliability coders coded their respective subsets of data. Interrater reliability was calculated using percentage agreement and Cohen's kappa, the indices most appropriate for categorical coding (Syed \& Nelson, 2015). To avoid inflated reliability indices a weighted average was calculated. The total number of responses categorized under a code by the reliability coders and the master coder for a single code was divided by the total number of coded responses recorded across codes for the entire research question. This proportion was then multiplied by each reliability index for that code. This was repeated for each code within a research question, with the products summed to obtain a weighted percentage agreement or Cohen's kappa, respectively, for each research question. A weighted average percentage agreement over $80 \%$ and weighted average Cohen's kappa above .70 were considered to be sufficiently reliable (Bakeman \& Gottman, 1986). If such cutoffs were satisfied, no differences needed to be reconciled between the master and reliability coders, and only the master coder's codes would be used in the final analysis. If sufficient reliability estimates were not obtained for a certain research question, the master coder reviewed the codes to check if there was a certain code or codes that had noticeably poor reliability (> 15\% disagreement between the master coder and an individual reliability coder was used as a guideline). Once problem codes were identified, the master coder met with the reliability coders to discuss discrepancies, descriptions of the codes were refined and clarified, and the reliability coders were instructed to reevaluate their old codes in accordance with the revised descriptions. The reliability indices were then recalculated, and the process repeated until the dictated cutoffs were satisfied.

Phase 3: Once adequate reliability was established the extracted codes were organized into broader levels of themes. During this process, some codes were discarded or deemed non-essential or irrelevant to providing a rich description of the phenomenon of interest. Codes were discarded when responses that made up the code were only tangentially 
related to the research question (miscellaneous or nonsensical responses) or did not represent an answer to the research question.

Phase 4: Once the codes were organized into larger themes, those themes were further refined and evaluated according to Patton's (1990) criteria for judging categories. Themes consisted of codes that were similar and related and were arguably distinct and independent from other themes. The retained themes were meant to explain a unique aspect of each respective research question and were named and described in preparation for Phase 5.

Phase 5: The fifth and final phase involved presenting the final coding schemes with broader themes along with frequency counts of each code and example responses from the data.

\subsubsection{Breakup Tactics}

Collins and Gillath (2012) conducted a factor analysis on 43 unique breakup tactics and found seven factors: avoidance/withdrawal, open confrontation, manipulation, positive tone/self-blame, cost escalation, de-escalation, and distant/mediated communication. Only a partial version of the breakup tactics questionnaire (10 total items; 1-2 highest loading items on each of the seven factors) was used to explore the frequency with which each breakup tactic was used during relationship dissolution. Participants who initiated their breakups (disengagers) were asked to self-report the frequency with which they used each tactic to facilitate the breakup with their partner. In contrast, the instructions and items were modified for participants who were broken up with (recipients), who were asked to report the frequency with which they noticed their partner using each tactic. Both disengagers and recipients rated the frequency of use of each tactic on a scale of 1 (never) to 7 (extremely often). Cronbach's alphas of the factors which had two items (avoidance/withdrawal, positive tone/self-blame, and cost escalation) were sufficient, and ranged between .72 and .94 . Reliability estimates were not obtained for open confrontation, manipulation, distant/mediated communication, or de-escalation, as only one item was included to measure each. 


\subsubsection{Breakup Distress}

Field, Diego, Pelaez, Deeds, and Delgado's (2009) 16-item Breakup Distress Scale (BDS) was used in the current study. Participants were asked to rate on a scale of 1 (not at all) to 4 (very much so) the extent to which they felt a certain way when their relationship ended. For example, "I feel that life is empty without the person." Overall breakup distress scores were calculated by averaging all 16 items, with higher scores indicating greater breakup distress at the time of the breakup $(\alpha=.96)$.

\subsubsection{Attachment Style}

The Experiences in Close Relationship Scale Short Form (ECR; Wei, Russell, Mallinckrodt, \& Vogel, 2007) was used to assess attachment style. Participants used a 7point scale $(1=$ strongly disagree, $7=$ strongly agree $)$ to indicate the extent to which they agreed with 12 statements, six of which measured attachment anxiety (e.g., "I need a lot of reassurance that I am loved by my partner") and six of which measured attachment avoidance (e.g., "I want to get close to my partner, but I keep pulling back"). Four items were reverse scored, meaning the rating scale was reversed $(1=$ strongly agree, $7=$ strongly disagree). Once respective items were reverse scored, the attachment anxiety and attachment avoidance items were averaged separately, with higher scores indicating higher anxious $(\alpha=.81)$ and avoidant orientations $(\alpha=.79)$.

\subsubsection{Dark Triad}

Jonason and Webster's (2010) Dirty Dozen 12-item scale was used to measure Dark Triad personality traits. Psychopathy (e.g., "I tend to lack remorse"), narcissism (e.g., "I tend to want others to admire me"), and Machiavellianism (e.g., "I tend to manipulate others to get my way") were each assessed with four items rated on a 7-point scale (1 = disagree strongly, 7 = agree strongly). The items for each respective trait were averaged to obtain a composite score, with higher scores indicating higher expressions of that trait $\left(\alpha_{\text {psychopathy }}=.81, \alpha_{\text {narcissism }}=.81, \alpha_{\text {Mach }}=.81\right)$. 


\subsection{Results}

An analytic plan for a subset of the following analyses was posted to the Open Science Framework (OSF) before statistical tests were conducted (https://osf.io/kyd5e/). Additional analyses were conducted after this document was posted. Regardless, all subsequent quantitative analyses are entirely exploratory in nature.

\subsubsection{Online Dating Experience}

A large majority of the participants $(90.7 \%)$ reported having used online dating sites or applications (apps) to find potential romantic partners. Of these, Tinder was the most popular, with 178 participants reporting to have used it, followed by OkCupid (149), PlentyOfFish (110), Match.com (94), eHarmony.com (53), Bumble (43), Grindr (18) and Coffee Meets Bagel (15). Approximately $30 \%$ of participants were using online dating sites/apps at the time of the study, with Tinder again being most popular (59), followed by OkCupid (28), PlentyOfFish (22), Bumble (19), Match.com (17), Grindr (8), eHarmony.com (7), and Coffee Meets Bagel (5).

\subsubsection{Base Rates and Definition of Ghosting}

Two hundred and fourteen participants (64.5\%) reported previously ghosting a partner, and $239(72 \%)$ reported previously being ghosted by a partner. Forty-seven (14.2\%) of participants had never ghosted or been ghosted, 46 (13.9\%) had ghosted a partner but never been ghosted, 71 (21.4\%) had never ghosted a partner but had been ghosted, and $168(50.6 \%)$ of the participants had both ghosted and been ghosted.

Of the 332 participants, $274(82.5 \%)$ had heard of ghosting prior to participating in the study. These participants were asked to define ghosting in their own words. Three main themes emerged: romantic relationship breakup strategy, contact interruption, and disappearing act. While asked to define ghosting in the context of dating, participant responses indicated that ghosting can apply to relationships in which the partners have "made plans", or "formed some kind of meaningful connection" with each other, meaning participants do not officially have to be dating in order to experience ghosting. In addition, some participants indicated that partners do not necessarily have to meet 
offline before ghosting can occur, suggesting that online-only relationships are susceptible to ghosting. As a breakup strategy, ghosting was characterized as being nonverbal, where $33.6 \%$ of participants reported that ghosting did not involve an explanation. The contact interruption theme elicited the highest amount of mentions from participants, such that ghosting involved at least some $(56.2 \%)$ if not all $(32.5 \%)$ communication to be impeded, with $7.3 \%$ of participants mentioning blocking phone numbers or social media access as well. Over half the sample mentioned ghosting occurs "abruptly" or "out of nowhere", while less than $10 \%$ of the sample proposed that ghosting could occur gradually (for more information see Table 1).

Table 1. Definition of ghosting.

\begin{tabular}{|c|c|c|c|}
\hline Theme & Codes & $\begin{array}{l}\text { Count } n \\
(\%)\end{array}$ & Exemplars \\
\hline \multirow{10}{*}{$\begin{array}{l}\text { Romantic } \\
\text { Relationship } \\
\text { Breakup Strategy }\end{array}$} & $\begin{array}{l}\text { Romantic } \\
\text { partner/interest }\end{array}$ & $\begin{array}{c}56 \\
(20.4)\end{array}$ & "...when you are dating someone..." \\
\hline & & & $\begin{array}{l}\text { "... someone with whom you have made plans with } \\
\text { or tlked to for awhile romantically" }\end{array}$ \\
\hline & & & $\begin{array}{l}\text { "...someone who you previously showed romantic } \\
\text { interest in..." }\end{array}$ \\
\hline & & & $\begin{array}{l}\text { "...someone you have formed some kind of } \\
\text { meaningful connection with (although not } \\
\text { necessarily in person)" }\end{array}$ \\
\hline & $\begin{array}{l}\text { Non-verbal } \\
\text { expression of } \\
\text { disinterest }\end{array}$ & $\begin{array}{c}41 \\
(14.9)\end{array}$ & $\begin{array}{l}\text { "In terms of dating, ghosting someone is basically } \\
\text { just never speaking to them in order to end a } \\
\text { relationship..." }\end{array}$ \\
\hline & & & $\begin{array}{l}\text { "Ghosting is when a person becomes disinterested } \\
\text { in the person they are dating and 'disappears' from } \\
\text { their life instead of communicating their } \\
\text { disinterest" }\end{array}$ \\
\hline & $\begin{array}{l}\text { Without } \\
\text { conversation or } \\
\text { explanation }\end{array}$ & $\begin{array}{c}92 \\
(33.6)\end{array}$ & $\begin{array}{l}\text { "one person stops communicating with the other } \\
\text { person without any explanation as to why" }\end{array}$ \\
\hline & & & $\begin{array}{l}\text { "For someone to stop talking to another with no } \\
\text { explanation as to why and not directly stating it to } \\
\text { the other person" }\end{array}$ \\
\hline & $\begin{array}{l}\text { Hope that } \\
\text { partner will } \\
\text { "get the hint" }\end{array}$ & $\begin{array}{c}13 \\
(4.7)\end{array}$ & $\begin{array}{l}\text { "When one person stops communicating in hope } \\
\text { that the other person would 'take a hint' that the } \\
\text { first person lost interest" }\end{array}$ \\
\hline & & & $\begin{array}{l}\text { "Ghosting is ignoring someone so they give up on } \\
\text { contacting you" }\end{array}$ \\
\hline
\end{tabular}




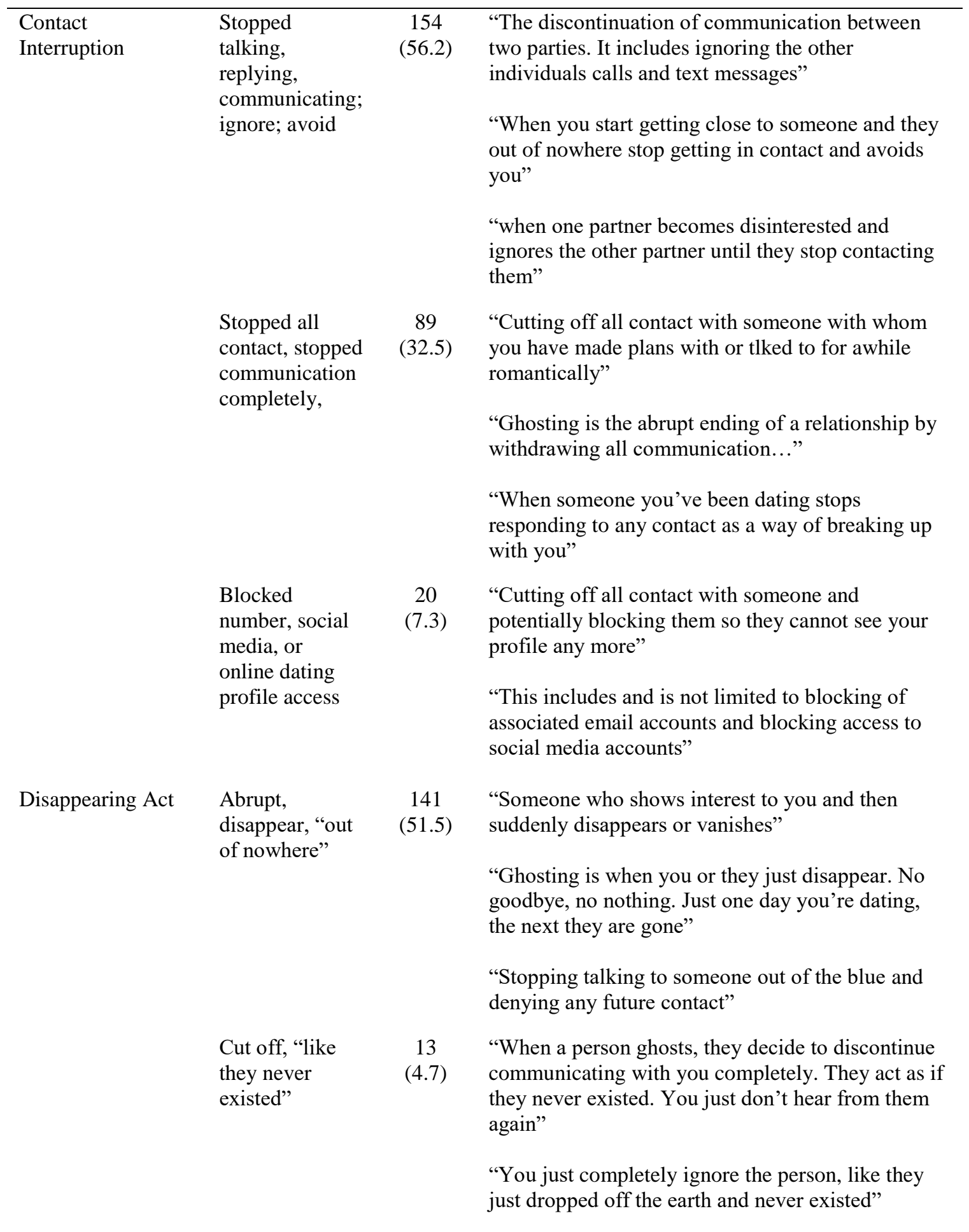




$\begin{aligned} & \text { Gradually ease } \\ & \text { out of contact }\end{aligned} \quad \begin{aligned} & \text { "Ghosting is when there's less responses until } \\ & \text { there's no response at all" }\end{aligned}$
"Ghosting would be the act of not saying anything
to them and instead keeping distance and gradually
disappearing from their life"
"...a gradual drop off in number and quality of
contacts"

Note. All typographical errors within the exemplars are from the original responses. Weighted $P_{A}=88.92 \%$. Weighted Cohen's $k=.73$.

After providing their own definitions, participants were asked whether ghosting would be an appropriate label for a breakup where one partner has explicitly expressed disinterest to the other before avoiding contact with them. The vast majority $(90.7 \%)$ of participants did not believe so, further cementing the idea that a central feature of ghosting is a lack of explanation prior to avoidant behavior.

The following definition of ghosting was constructed based on the analysis of the openended responses from the participants:

Ghosting is a strategy used to end a relationship with a partner with whom romantic interest once existed by ceasing to contact or respond to the recipient either suddenly or gradually in lieu of the disengager providing a verbal indication that they are no longer interested.

\subsubsection{Relationship Dissolution}

The following analyses (excluding the qualitative data) were conducted with participants who had either never ghosted or never been ghosted (NG/NBG; $N=47)$, participants who had ghosted a partner but had never been ghosted $(\mathrm{G} / \mathrm{NBG} ; N=46)$, and participants who had never ghosted a partner but had been ghosted (NG/BG; $N=71)$, meaning participants who reported to have previously ghosted and been ghosted $(\mathrm{G} / \mathrm{BG} ; N=168)$ were excluded. The questionnaire was designed in such a way that a single participant could report on up to three past relationships depending on their experiences with ghosting. As such, participants who had both ghosted and been ghosted were excluded to preserve the independence of the groups, as the inclusion of data from the same individual for two separate breakups would create a confound. Participants who had either only ghosted or 
only been ghosted may have provided data for a breakup that did not end through ghosting. The data from their relationships that ended through ghosting were used in the following analyses.

\subsubsection{Relationship Origination}

There was a significant association between ghosting experience and how relationship partners initially met, $\chi^{2}(2)=18.22, p<.001$, Cramer's $V=.33$. Participants whose relationships ended through ghosting were more likely to have met their partners online compared to participants who never experienced ghosting (see Table 2). Concurrently, participants who never experienced ghosting were significantly more likely to have met their partners offline compared to those who had previously experienced ghosting.

Table 2. How relationships originated as a function of ghosting experience.

\begin{tabular}{llccc}
\hline & \multicolumn{4}{c}{ Ghosting Experience Group Count (\% of Total) } \\
\cline { 2 - 5 } Origination & NG/NBG & G/NBG & NG/BG & Total \\
\hline Online & $10_{\mathrm{x}}(6.1 \%)$ & $25_{\mathrm{y}}(15.3 \%)$ & $42_{\mathrm{y}}(25.8 \%)$ & $77(47.2 \%)$ \\
Offline & $37_{\mathrm{x}}(22.7 \%)$ & $21_{\mathrm{y}}(12.9 \%)$ & $28_{\mathrm{y}}(17.2 \%)$ & $86(52.8 \%)$ \\
Total & $47(28.8 \%)$ & $46(28.2 \%)$ & $70(42.9 \%)$ & $163(100 \%)$ \\
\hline
\end{tabular}

Note. NG/NBG $=$ never ghosted partner and never been ghosted by a partner. G/NBG $=$ has ghosted a partner, never been ghosted by a partner. $\mathrm{NG} / \mathrm{BG}=$ never ghosted a partner, has been ghosted by a partner. Each subscript denotes a subset of categories whose row proportions differ significantly from each other at the .05 level.

\subsubsection{Relationship Length}

The distribution of relationship length (in weeks) emerged as slightly positively skewed (3.02) and highly leptokurtic (11.45). A log base 10 transformation was applied to the variable which resulted in values of skewness and kurtosis in a more normal range (-.204 and -.374, respectively). A one-way analysis of variance (ANOVA) was significant, $F(2$, $160)=15.17, p<.001$, and indicated a small effect size, $\omega^{2}=.046$. Relationships that did not end in ghosting $(M=85.10, S D=86.18)$ were significantly longer than relationships where the participant ghosted their partner $(M=19.43, S D=44.14)$ and relationships where the participant was ghosted by their partner $(M=52.01, S D=103.94)$. In addition, relationships of participants who ghosted their partners were significantly shorter than relationships of participants who were ghosted by their partners. 


\subsubsection{Commitment}

Levene's test of homogeneity of variance was violated for the measure of commitment. Log base 10 transformations were applied to the data which reduced the magnitude of the Levene's statistic from 13.83 to 5.77. The Levene's test, however, remained statistically significant, therefore the following results should be interpreted with caution. The oneway ANOVA was significant, $F(2,161)=22.39, p<.001$, and indicated a moderate effect size, $\omega^{2}=.060$. Post-hoc tests revealed participants who ghosted their partners $(M$ $=2.15, S D=1.33)$ to be significantly less committed than both participants who had not experienced ghosting $(M=4.72, S D=1.90)$ and participants who were ghosted by their partners $(M=4.07, S D=2.20)$. The difference in reported commitment between participants who had not experienced ghosting and participants who had been ghosted was nonsignificant.

\subsubsection{Relationship Label}

A chi-square test revealed a significant association between ghosting experience and how participants labeled their relationships, $\chi^{2}(12)=34.90, p<.001$, Cramer's $V=.33$. However, eight cells had frequency counts of less than five, therefore the results should be interpreted with caution. Examination of the contingency table revealed significant differences emerged between all three groups only for the relationship label seriously/exclusively dating, in which 25 participants who had not experienced ghosting, 18 participants who had been ghosted and only three participants who reported ghosting their partner reported such a relationship label prior to their breakups. Frequencies of participants who labeled their relationships as no relationship, just friends, friends with benefits, casually/non-exclusively dating, engaged, and other did not significantly differ between groups.

\subsubsection{Descriptions of Ghosting Experiences}

\subsubsection{How Ghosting is Implemented}

Of the 332 participants, $214(64.5 \%)$ had reported ghosting a partner (ghosting disengagers). These participants were asked how they ghosted their partners. Four 
participants did not enter a response, leaving 210 responses to be coded. The extracted themes and retained codes are shown in Table 3.

Three main themes emerged: contact interruption, disappearing act, and forewarning. Like responses elicited in the request to define ghosting, contact interruption included stopping or blocking some or all contact by phone, social media, and online messaging platforms (e.g., email, gchat, instant messenger). A code emerged that demonstrated avoidance of physical locations in which the ghosting recipient might be encountered was a measure taken by a small percent of ghosting disengagers (3.3\%). A small fraction of ghosting disengagers (1.4\%) described themselves as having "disappeared" or "vanished", while a larger percentage reported gradually ghosting their partners $(7.5 \%)$. Unlike the results found in the definition of ghosting, $14.5 \%$ of ghosting disengagers reported providing a lie, excuse or explanation to their partner prior to ghosting, and only $3.3 \%$ explicitly reported not providing an explanation.

A code that contained eight responses was eliminated. This code contained responses that indicated the relationship or interest between partners tapered off mutually. Examples included "I stopped talking, he stopped talking, we just lost touch", and "Our contact had dropped off a bit, and I think things were naturally winding down.” Because the responses in this code did not encompass a description of ghosting behavior that was intentional on behalf of one partner, it was not considered an appropriate representation of a unilateral breakup strategy and was therefore removed.

\section{Table 3. How participants ghosted their partners.}

\begin{tabular}{llcl}
\hline Theme & Code & $\begin{array}{c}\text { Count } n \\
(\%)\end{array}$ & Exemplars \\
\hline $\begin{array}{l}\text { Contact } \\
\text { Interruption }\end{array}$ & $\begin{array}{l}\text { Stopped responding } \\
\text { to calls/texts/emails }\end{array}$ & $\begin{array}{c}101 \\
(48.1)\end{array}$ & $\begin{array}{l}\text { "I simply stopped answering his calls and returning } \\
\text { his texts" } \\
\text { "I stopped contacting this person and stopped } \\
\text { responding when they reached out to me" }\end{array}$ \\
$\begin{array}{l}\text { Did not schedule } \\
\text { future dates }\end{array}$ & $\begin{array}{l}10 \\
\text { "I never texted to set up a second date" }\end{array}$ & $\begin{array}{l}\text { "He reached out to me the next day about getting } \\
\text { together again, and I just never responded" }\end{array}$ \\
\end{tabular}




\begin{tabular}{|c|c|c|c|}
\hline & Stopped all contact & $\begin{array}{c}82 \\
(39.0)\end{array}$ & $\begin{array}{l}\text { "Just stopped all methods of communication" } \\
\text { "I stopped texting them, I stopped calling or initiating } \\
\text { any contact with this person or anything or anyone } \\
\text { closely related" }\end{array}$ \\
\hline & $\begin{array}{l}\text { Blocked } \\
\text { calls/texts/emails }\end{array}$ & $\begin{array}{c}30 \\
(14.3)\end{array}$ & $\begin{array}{l}\text { "I just stopped texting her and blocked her phone } \\
\text { number" }\end{array}$ \\
\hline & & & $\begin{array}{l}\text { "he would contact me through email and changed his } \\
\text { email to gmail so that he could gchat me and I had to } \\
\text { block him from gchat" }\end{array}$ \\
\hline & $\begin{array}{l}\text { Blocked/unfriended } \\
\text { on social media }\end{array}$ & $\begin{array}{c}27 \\
(12.9)\end{array}$ & "I ended up blocking him on all social media" \\
\hline & & & "I defriended him on facebook" \\
\hline & $\begin{array}{l}\text { Blocked/unmatched } \\
\text { on dating sites/apps }\end{array}$ & $\begin{array}{c}8 \\
(3.8)\end{array}$ & $\begin{array}{l}\text { "Blocked them on grindr and deleted their contact } \\
\text { info" }\end{array}$ \\
\hline & & & "Unmatched on Tinder with no comment" \\
\hline & $\begin{array}{l}\text { Physically avoided } \\
\text { locations partner }\end{array}$ & $\begin{array}{c}7 \\
(33)\end{array}$ & "I stopped appearing places he frequented" \\
\hline & might be & & $\begin{array}{l}\text { "new email new phone no social media for months } \\
\text { and I moved. Very thorough" }\end{array}$ \\
\hline $\begin{array}{l}\text { Disappearing } \\
\text { Act }\end{array}$ & $\begin{array}{l}\text { Disappeared, } \\
\text { vanished, } \\
\text { immediate }\end{array}$ & $\begin{array}{c}3 \\
(1.4)\end{array}$ & $\begin{array}{l}\text { "I pretty much just disappeared from everyone and } \\
\text { quit answering her calls/texts" }\end{array}$ \\
\hline & $\begin{array}{l}\text { Gradually reduced } \\
\text { contact }\end{array}$ & $\begin{array}{c}16 \\
(7.6)\end{array}$ & $\begin{array}{l}\text { "I was with him for so long that I could not bring } \\
\text { myself to break up with him, so I gradually just } \\
\text { stopped talking and hanging out with him over time" }\end{array}$ \\
\hline & & & $\begin{array}{l}\text { "I just got slower and slower on responding to her } \\
\text { communications" }\end{array}$ \\
\hline Forewarning & $\begin{array}{l}\text { Explanation, } \\
\text { excuse or lie before } \\
\text { ghosting }\end{array}$ & $\begin{array}{c}31 \\
(14.8)\end{array}$ & $\begin{array}{l}\text { "I became conveniently 'busy' with work until she } \\
\text { stopped trying to initiate contact" }\end{array}$ \\
\hline & & & $\begin{array}{l}\text { "I met someone new and I wanted to pursue a } \\
\text { relationship with them, so I told this girl I was going } \\
\text { on a trip. And then I just never talked to her again." }\end{array}$ \\
\hline & No explanation & $\begin{array}{c}7 \\
(3.3)\end{array}$ & "I stopped communication without warning" \\
\hline & & & "I just vanished with no explanation" \\
\hline
\end{tabular}

Note. All typographical errors within the exemplars are from the original responses. Weighted $P_{A}=94.01 \%$. Weighted Cohen's $k=.83$.

Of the 332 participants, 239 (72\%) had reported being ghosting by a partner (ghosting recipients). These participants were asked how they were ghosted by their partners. Five 
participants did not enter a response, leaving 234 responses to be coded. The extracted themes and retained codes are shown in Table 4.

Similar to the ghosting disengagers, six instances of responses suggesting that the ghosting behavior was more mutual than one-sided were recorded. For example, "He Slowly [sic] stopped initiating calls and texts. I started to feel like I was chasing him...so, I stopped calling and texting and he didn't initiate contact after that. So I just left it alone." Since ghosting is a unilateral breakup strategy, these codes were not included in the final analysis.

The same themes that were extracted from how ghosting disengagers implemented ghosting were found for the ghosting recipients. The percent of participants who mentioned each code for contact interruption was fairly comparable between ghosting disengagers and ghosting recipients. Ghosting disengagers reported blocking their partners $(14 \%)$ more than ghosting recipients reported experiencing $(3.8 \%)$, and ghosting recipients reported not getting responses from their partners $(59.8 \%)$ more than ghosting disengagers reported not responding to their partners (47.2\%), however, these percentages were both high. While ghosting disengagers did not usually use the words “disappear" or "vanish" or similar terms that suggest ghosting happened abruptly (1.4\%), ghosting recipients did freely produce these terms more often (13.8\%). No other notable differences between ghosting disengagers and recipients were observed regarding how ghosting was implemented.

Table 4. How participants were ghosted by their partners.

\begin{tabular}{llcl}
\hline Theme & Code & $\begin{array}{c}\text { Count } n \\
(\%)\end{array}$ & Exemplars \\
\hline $\begin{array}{l}\text { Contact } \\
\text { Interruption }\end{array}$ & $\begin{array}{l}\text { Stopped responding } \\
\text { to calls/texts/emails }\end{array}$ & $\begin{array}{c}143 \\
(61.1)\end{array}$ & $\begin{array}{l}\text { "She just stopped responding to emails, and so I } \\
\text { pretty quickly stopped sending them" }\end{array}$ \\
& $\begin{array}{l}\text { Did not schedule } \\
\text { future dates }\end{array}$ & 9 & "He stopped returning my calls and messages" \\
& $(3.8)$ & "He...made less of an effort to see me" \\
& & "he just stopped asking me to hang out" \\
\hline
\end{tabular}




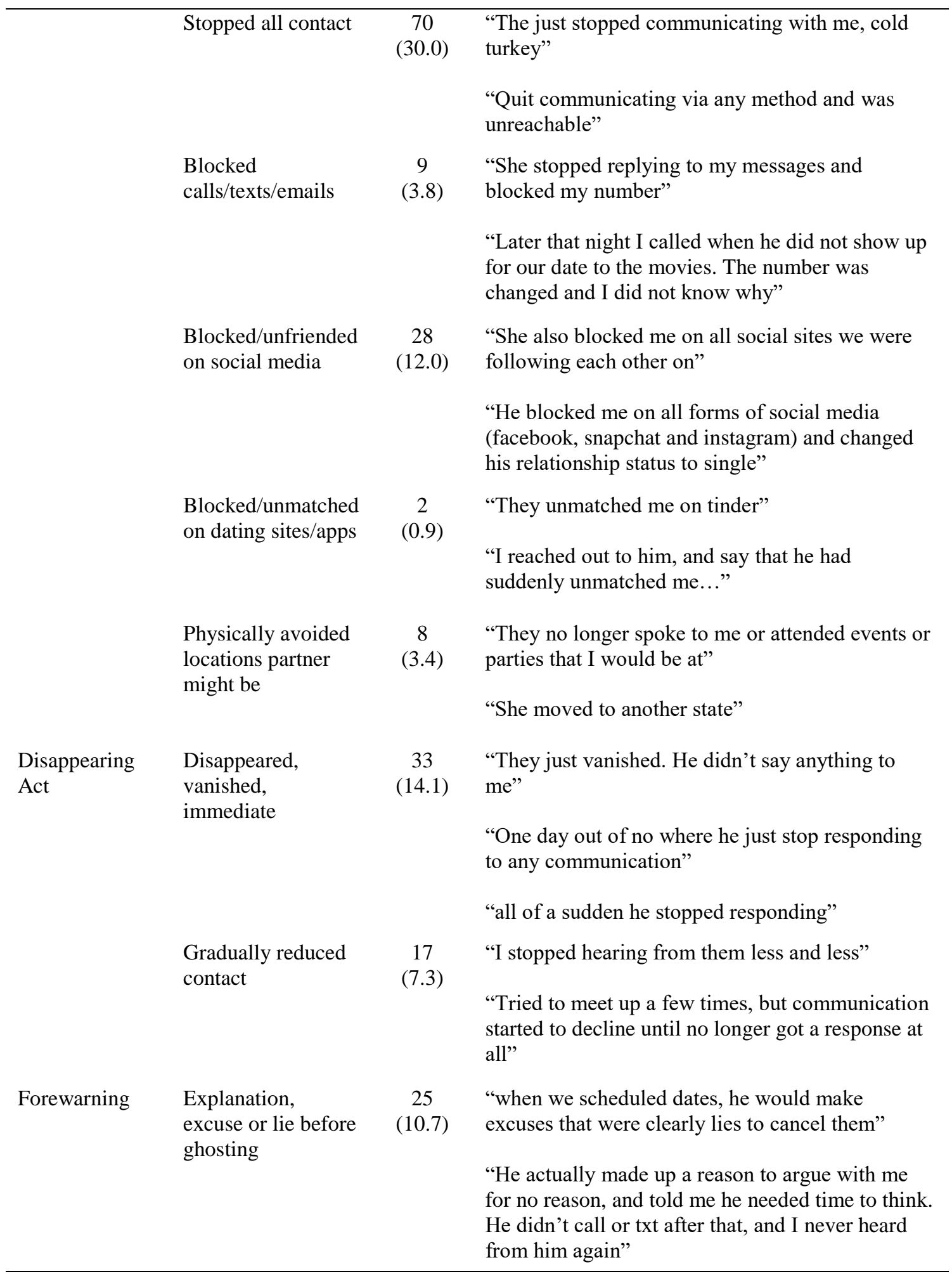


No explanation

14 "He completely just started ignoring me and

(6.0) nevergave me an answer as to why he decided to drop off the face of the earth and break things off with me"

"She simply stopped contacting me after one of our dates. I never heard from her again. I didn't receive any details, or any indication that anything was off"

Note. All typographical errors within the exemplars are from the original responses. Weighted $P_{A}=93.26 \%$. Weighted Cohen's $k=.80$.

\subsubsection{Motivations for Ghosting}

Of the 214 (64.5\%) participants who reported ghosting a partner (ghosting disengagers), four participants did not enter a response, leaving 210 responses to be coded. These participants were asked why they ghosted their partners. The extracted themes and retained codes are shown in Table 5.

Five main themes emerged from the responses: disengager-oriented motivations, recipient-oriented motivations, relationship-oriented motivations, explanation considered unnecessary, and last resort. Disengager-oriented motivations involved responses that suggested the disengager prioritized themselves and their feelings rather than their partners'. For instance, two codes involved avoiding a direct conversation because it was anticipated to require too much effort or be difficult and dramatic. The most frequently reported motivation for using ghosting was simply because the disengager had lost interest in their partner (22.9\%), and within the recipient-oriented motivations theme, $21.9 \%$ reported using ghosting as a breakup strategy because the recipient had negative qualities (e.g., rude, self-righteous, annoying, clingy). The third most frequently reported motivation involved the ghosting recipients having extreme negative qualities, such as being aggressive, controlling, or manipulative (16.2\%). Approximately equal reports of either the ghosting disengager $(2.4 \%)$ or ghosting recipient $(3.8 \%)$ dating someone else were found. Relationship-oriented motivations involved descriptions of the relationships not being serious or long enough, or feelings that the relationship had no future due to the partners being incompatible (12.9\% and $7.6 \%$ respectively). Slightly over $5 \%$ of participants did not believe that an explanation was necessary, and even fewer (2.9\%) believed the recipient did not deserve an explanation. Only $3.8 \%$ of participants reported 
utilizing ghosting as a last resort after an unsuccessful attempt was made to dissolve the relationship directly.

Two codes were not included in the final analysis. Ten participants mentioned ghosting happening naturally, mutually, or unintentionally, and with the focus being on ghosting being a unilateral and intentional breakup strategy, these responses did not appropriately reflect a specific motivation for ghosting. Additionally, there were 15 coded instances of ghosting disengagers expressing regret or guilt about ghosting. Though these responses are informational and occurred often enough to be worthy of mention, they do not reflect a motivation for ghosting.

Table 5. Ghosting disengagers' motivations for ghosting.

\begin{tabular}{|c|c|c|c|}
\hline Theme & Code & $\begin{array}{c}\text { Count } \\
(\%)\end{array}$ & Exemplars \\
\hline \multirow{12}{*}{$\begin{array}{l}\text { Disengager- } \\
\text { Oriented } \\
\text { Motivations }\end{array}$} & $\begin{array}{l}\text { Direct conversation } \\
\text { would be dramatic }\end{array}$ & $\begin{array}{c}26 \\
(12.4)\end{array}$ & $\begin{array}{l}\text { "They would be too emotional and make me feel } \\
\text { guilty if I tried to be just friends" }\end{array}$ \\
\hline & & & $\begin{array}{l}\text { "Because it was easy and avoided conflict and } \\
\text { saved me from having to do anything additional" }\end{array}$ \\
\hline & $\begin{array}{l}\text { Direct conversation } \\
\text { would be too much } \\
\text { effort }\end{array}$ & $\begin{array}{c}21 \\
(10.0)\end{array}$ & $\begin{array}{l}\text { "I was not interested in them and I didn't have the } \\
\text { energy to explain as to why I didn't want to be with } \\
\text { them" }\end{array}$ \\
\hline & & & "It's just easier to move on with my life" \\
\hline & $\begin{array}{l}\text { Did not know how } \\
\text { to approach direct } \\
\text { conversation }\end{array}$ & $\begin{array}{c}9 \\
(4.3)\end{array}$ & $\begin{array}{l}\text { "I didn't feel comfortable bringing it up and it was } \\
\text { too awkward" }\end{array}$ \\
\hline & & & "I just didn't know how to handle it" \\
\hline & $\begin{array}{l}\text { Direct conversation } \\
\text { would hurt }\end{array}$ & $\begin{array}{c}9 \\
(4.3)\end{array}$ & "I didn't want to hurt his feelings" \\
\hline & recipient's feelings & & $\begin{array}{l}\text { "I was not interested, and I felt bad telling them } \\
\text { that" }\end{array}$ \\
\hline & $\begin{array}{l}\text { Lost interest in } \\
\text { recipient }\end{array}$ & $\begin{array}{c}48 \\
(22.9)\end{array}$ & $\begin{array}{l}\text { "I became disinterested when I learned more about } \\
\text { her personality" }\end{array}$ \\
\hline & & & $\begin{array}{l}\text { "She was nice, and I had a good time with her. But I } \\
\text { didn't feel any kind of romantic connection" }\end{array}$ \\
\hline & $\begin{array}{l}\text { Started dating } \\
\text { someone else }\end{array}$ & $\begin{array}{c}5 \\
(2.4)\end{array}$ & "I started dating another guy seriously" \\
\hline & & & "Also I had another relationship in the pocket" \\
\hline
\end{tabular}




\begin{tabular}{|c|c|c|c|}
\hline \multirow[t]{9}{*}{$\begin{array}{l}\text { Recipient- } \\
\text { Oriented } \\
\text { Motivations }\end{array}$} & $\begin{array}{l}\text { Recipient cheated or } \\
\text { started dating } \\
\text { someone else }\end{array}$ & $\begin{array}{c}8 \\
(3.8)\end{array}$ & $\begin{array}{l}\text { "I found out he had been cheating from the } \\
\text { beginning" } \\
\text { "I ghosted this person because she went and got } \\
\text { herself a boyfriend" }\end{array}$ \\
\hline & $\begin{array}{l}\text { Recipient was } \\
\text { getting too attached }\end{array}$ & $\begin{array}{c}21 \\
(10.0)\end{array}$ & $\begin{array}{l}\text { "He kept trying to make the relationship happen but } \\
\text { I was tired of talking to him about it so I just } \\
\text { ignored him" }\end{array}$ \\
\hline & & & $\begin{array}{l}\text { "She had shown signs that she wanted to lock me } \\
\text { down and I didn't want to have that conversation" }\end{array}$ \\
\hline & $\begin{array}{l}\text { Recipient had } \\
\text { negative qualities or } \\
\text { behaviors }\end{array}$ & $\begin{array}{c}46 \\
(21.9)\end{array}$ & $\begin{array}{l}\text { "I was annoyed by what I perceived to be her } \\
\text { selfish self-centered behavior" }\end{array}$ \\
\hline & & & "He acted rudely and self-righteously" \\
\hline & & & $\begin{array}{l}\text { "He was HORRIBLE at communicating. Texting } \\
\text { him was like talking to a grapefruit" }\end{array}$ \\
\hline & $\begin{array}{l}\text { Recipient had severe } \\
\text { negative qualities or } \\
\text { behaviors }\end{array}$ & $\begin{array}{c}34 \\
(16.2)\end{array}$ & $\begin{array}{l}\text { "their behavior was scaring me and made me realize } \\
\text { they weren't the kind of person I wanted to get } \\
\text { closer to. They were more aggressive than I thought } \\
\text { and they were also already attempting to control my } \\
\text { actions" }\end{array}$ \\
\hline & & & "I was scared of being harmed by them" \\
\hline & $\begin{array}{l}\text { Disengager just } \\
\text { needed to "get } \\
\text { away" from } \\
\text { recipient }\end{array}$ & $\begin{array}{c}9 \\
(4.3)\end{array}$ & $\begin{array}{l}\text { "I just wanted it over" } \\
\text { "I needed a clean break for my own health" }\end{array}$ \\
\hline \multirow{4}{*}{$\begin{array}{l}\text { Relationship- } \\
\text { Oriented } \\
\text { Motivations }\end{array}$} & $\begin{array}{l}\text { Relationship not } \\
\text { going anywhere }\end{array}$ & $\begin{array}{c}16 \\
(7.6)\end{array}$ & "We just weren't compatible" \\
\hline & & & $\begin{array}{l}\text { "He was very boring, we had nothing in common. } \\
\text { He just wasn't the right fit for me" }\end{array}$ \\
\hline & $\begin{array}{l}\text { Relationship was } \\
\text { not long or serious }\end{array}$ & $\begin{array}{c}27 \\
(12.9)\end{array}$ & $\begin{array}{l}\text { "The relationship was short enough that I didn't } \\
\text { think I owed him an explanation" }\end{array}$ \\
\hline & & & $\begin{array}{l}\text { "Since it was a casual situation I didn't feel it would } \\
\text { be all that big a deal to them" }\end{array}$ \\
\hline \multirow[t]{2}{*}{$\begin{array}{l}\text { Explanation } \\
\text { Considered } \\
\text { Unnecessary }\end{array}$} & $\begin{array}{l}\text { Disengager did not } \\
\text { feel the need to } \\
\text { explain }\end{array}$ & $\begin{array}{l}15 \\
(7.1)\end{array}$ & $\begin{array}{l}\text { "Because it was someone at the club. I didn't feel } \\
\text { like I owed him anything, and since I didn't really } \\
\text { care about him at all, it was just easiest to ghost } \\
\text { him" }\end{array}$ \\
\hline & & & $\begin{array}{l}\text { "I had a lot going on at the time and I didn't feel } \\
\text { that things were so serious that I needed to explain } \\
\text { anything to her" }\end{array}$ \\
\hline
\end{tabular}




\begin{tabular}{|c|c|c|c|}
\hline & $\begin{array}{l}\text { Partner did not } \\
\text { deserve an } \\
\text { explanation }\end{array}$ & $\begin{array}{c}6 \\
(2.9)\end{array}$ & $\begin{array}{l}\text { "They said some rude things and I did not think } \\
\text { they deserved to not be ghosted" } \\
\text { "We had an understanding that we were not going } \\
\text { to get serious. He started acting jealous and } \\
\text { controlling...I didn't feel he deserved any } \\
\text { explanation" }\end{array}$ \\
\hline Last Resort & $\begin{array}{l}\text { Direct conversation } \\
\text { failed, so ghosted }\end{array}$ & $\begin{array}{c}8 \\
(3.8)\end{array}$ & $\begin{array}{l}\text { "they would not listen when I had tried to break up } \\
\text { in the past and I felt this was the only was [sic] to } \\
\text { not have to hear about what happened to them after } \\
\text { the fact" }\end{array}$ \\
\hline
\end{tabular}

Note. All typographical errors within the exemplars are from the original responses. Weighted $P_{A}=95.20 \%$. Weighted Cohen's $k=.75$.

Of the 239 participants (72\%) who had reported being ghosting by a partner, five participants did not enter a response, leaving 234 responses to be coded. These participants were asked how they were ghosted by their partners. The extracted themes and retained codes are shown in Table 6.

Four themes emerged from the responses: no idea, disengager-oriented motivations, recipient-oriented motivations, and relationship-oriented motivations. Approximately $13 \%$ of participants reporting having no idea or clue as to why their partners chose to ghost them. Similar to the motivations elicited by the ghosting disengagers, the ghosting recipients acknowledged that avoidance of a direct conversation for a variety of reasons (e.g., avoid drama, easier than breakup conversation) influenced the disengagers' decision to ghost. In addition, the belief that the disengager lost interest in the recipient or became more interested in someone else was the perceived motivation that elicited the highest frequency of mentions (19.7\% and $21.4 \%$ respectively), consistent with the disengagers' highest reported motivation. A smaller percentage of recipients $(4.3 \%)$ than disengagers (12.9\%) reported the relationship not being long or serious enough as a motivation for ghosting. Fewer recipients $(5.1 \%)$ than disengagers $(21.9 \%)$ blamed their own negative qualities as responsible for driving their partners to ghost. Recipients also attributed ghosting behavior to the disengagers' negative qualities (12\%), which was not a reason that emerged from the disengagers themselves. Finally, partners being 
incompatible or wanting different types of relationships were attributed as motivations more frequently in the recipient responses.

Table 6. Ghosting recipients' perceptions of disengagers' motivations for ghosting.

\begin{tabular}{|c|c|c|c|}
\hline Theme & Code & $\begin{array}{c}\text { Count } \\
(\%)\end{array}$ & Exemplars \\
\hline \multirow[t]{2}{*}{ No idea } & No idea & $\begin{array}{c}31 \\
(13.2)\end{array}$ & $\begin{array}{l}\text { "I have no idea I thought things were going good in the } \\
\text { relationship" }\end{array}$ \\
\hline & & & "I still to this day have no idea as to why she ghosted me" \\
\hline \multirow{15}{*}{$\begin{array}{l}\text { Disengager- } \\
\text { Oriented } \\
\text { Motivations }\end{array}$} & $\begin{array}{l}\text { Direct } \\
\text { conversation }\end{array}$ & $\begin{array}{c}7 \\
(3.0)\end{array}$ & $\begin{array}{l}\text { "Because they weren't interested in me and didn't want } \\
\text { drama" }\end{array}$ \\
\hline & dramatic & & $\begin{array}{l}\text { "Because he didn't have the courage to tell me he was no } \\
\text { longer interested, or didn't want to deal with my } \\
\text { reaction" }\end{array}$ \\
\hline & $\begin{array}{l}\text { Direct } \\
\text { conversation }\end{array}$ & $\begin{array}{c}12 \\
(5.1)\end{array}$ & "I feel they were just being lazy and inconsiderate" \\
\hline & $\begin{array}{l}\text { would be too } \\
\text { much effort }\end{array}$ & & $\begin{array}{l}\text { "It's just a lot easier to do that, instead of explaining to } \\
\text { someone that your [sic] not into them" }\end{array}$ \\
\hline & $\begin{array}{l}\text { Did not know } \\
\text { how to approach } \\
\text { direct }\end{array}$ & $\begin{array}{c}13 \\
(5.6)\end{array}$ & $\begin{array}{l}\text { "Because they were uncomfortable stating their } \\
\text { disinterest" }\end{array}$ \\
\hline & conversation & & $\begin{array}{l}\text { "I think he felt like he wasn't able to communicate his } \\
\text { needs/wants effectively" }\end{array}$ \\
\hline & $\begin{array}{l}\text { Direct } \\
\text { conversation } \\
\text { would hurt }\end{array}$ & $\begin{array}{c}6 \\
(2.6)\end{array}$ & $\begin{array}{l}\text { "Things hadn't gone very far, and this was probably just } \\
\text { easier than saying things that might have been hurtful" }\end{array}$ \\
\hline & $\begin{array}{l}\text { recipient's } \\
\text { feelings }\end{array}$ & & "Because he was worried about hurting my feelings" \\
\hline & $\begin{array}{l}\text { Disengager lost } \\
\text { interest }\end{array}$ & $\begin{array}{c}46 \\
(19.7)\end{array}$ & "They just weren't interested any more" \\
\hline & & & "They were over the relationship" \\
\hline & & & "I guess he didn't feel any chemistry" \\
\hline & $\begin{array}{l}\text { Disengager was } \\
\text { interested or }\end{array}$ & $\begin{array}{c}50 \\
(21.4)\end{array}$ & \\
\hline & $\begin{array}{l}\text { started dating } \\
\text { someone else }\end{array}$ & & "I think he found someone he liked better" \\
\hline & $\begin{array}{l}\text { Disengager had } \\
\text { negative qualities }\end{array}$ & $\begin{array}{c}28 \\
(12.0)\end{array}$ & "They have issues" \\
\hline & or behaviors & & $\begin{array}{l}\text { "He was a coward who couldn't tell me to my face that it } \\
\text { was over" }\end{array}$ \\
\hline
\end{tabular}




\begin{tabular}{|c|c|c|c|}
\hline & $\begin{array}{l}\text { Disengager used } \\
\text { recipient, then } \\
\text { ghosted }\end{array}$ & $\begin{array}{c}5 \\
(2.1)\end{array}$ & $\begin{array}{l}\text { "I was professionally useful to her in the beginning; then, } \\
\text { because of changes in my own career, I was no longer } \\
\text { useful to her" } \\
\text { "Because he got what he wanted, which was a hook up. } \\
\text { That's all he wanted the whole time" }\end{array}$ \\
\hline \multirow{3}{*}{$\begin{array}{l}\text { Recipient- } \\
\text { Oriented } \\
\text { Motivations }\end{array}$} & $\begin{array}{l}\text { Recipient } \\
\text { cheated }\end{array}$ & $\begin{array}{c}1 \\
(0.4)\end{array}$ & "He was angry that I slept with someone else" \\
\hline & $\begin{array}{l}\text { Recipient had } \\
\text { negative qualities } \\
\text { or behaviors } \\
\text { (blames } \\
\text { themselves) }\end{array}$ & $\begin{array}{c}12 \\
(5.1)\end{array}$ & $\begin{array}{l}\text { "Because I betrayed them and said things that were not } \\
\text { favorable" } \\
\text { "They felt maybe I was possessive, or needy or not } \\
\text { attractive" }\end{array}$ \\
\hline & & & "I asked him to many personal questions I think" \\
\hline \multirow{6}{*}{$\begin{array}{l}\text { Relationship- } \\
\text { Oriented } \\
\text { Motivations }\end{array}$} & $\begin{array}{l}\text { Relationship not } \\
\text { going anywhere }\end{array}$ & $\begin{array}{c}6 \\
(2.6)\end{array}$ & $\begin{array}{l}\text { "I honestly feel he thought maybe the relationship wasn't } \\
\text { going anywhere, and decided to split." }\end{array}$ \\
\hline & & & $\begin{array}{l}\text { "We didn't really have a relationship. Our agreement was } \\
\text { strictly fwb, and that we would stop if either of us had a } \\
\text { shot at something real. So, perhaps he found someone" }\end{array}$ \\
\hline & $\begin{array}{l}\text { Relationship was } \\
\text { not long or } \\
\text { serious }\end{array}$ & $\begin{array}{c}10 \\
(4.3)\end{array}$ & $\begin{array}{l}\text { "We weren't in a serious relationship, so he probably } \\
\text { didn't think it was a big deal" } \\
\text { "It was really just a one time thing I was not shocked she } \\
\text { didn't get back to me" }\end{array}$ \\
\hline & $\begin{array}{l}\text { Disengager } \\
\text { thought recipient } \\
\text { was too serious } \\
\text { about } \\
\text { relationship }\end{array}$ & $\begin{array}{c}12 \\
(5.1)\end{array}$ & $\begin{array}{l}\text { "They probably thought I wanted a serious relationship" } \\
\text { "I think I contacted him too frequently and it probably } \\
\text { got annoying or made him think I wanted a serious } \\
\text { relationship (I didn't)" }\end{array}$ \\
\hline & $\begin{array}{l}\text { Recipient was } \\
\text { not as serious } \\
\text { about } \\
\text { relationship as } \\
\text { disengager }\end{array}$ & $\begin{array}{c}3 \\
(1.3)\end{array}$ & $\begin{array}{l}\text { "She wanted a serious relationship and I didn't" } \\
\text { "I'm sure she could tell I wasn't very serious about her } \\
\text { and I" }\end{array}$ \\
\hline & $\begin{array}{l}\text { Partners were not } \\
\text { compatible }\end{array}$ & $\begin{array}{c}20 \\
(8.5)\end{array}$ & $\begin{array}{l}\text { "We were looking for different things" } \\
\text { "I think we did not connect socially. I was too quiet and } \\
\text { reserved and she was much more active and social than } \\
\text { me" }\end{array}$ \\
\hline
\end{tabular}

Note. All typographical errors within the exemplars are from the original responses. Weighted $P_{A}=97.79 \%$. Weighted Cohen's $k=.83$.

\subsubsection{Ghosting Recipients' Responses to Being Ghosted}

Of the 239 (72\%) participants who had reported being ghosting by a partner, seven participants did not enter a response, leaving 232 responses to be coded. These 
participants were asked how they were ghosted by their partners. The extracted themes and retained codes are shown in Table 7.

No action taken in response to being ghosted elicited the highest count of all the codes (29.3\%). A similarly frequent response of "moving on" or "letting it go" (19.4\%) was also reported. Comparably, however, reports of attempting to get in contact with the partner before giving up (19.4\%) and making persistent attempts at contacting the disengager with no indication that the recipient gave up (19\%) were found as well. Less commonly reported actions involved retaliation, in the form of preventing the disengager from contacting the recipient (e.g., blocking their number or blocking them on social media), sending aggressive or angry messages, and telling others about the disengagers' behavior. The least common responses included changes in the recipients' relationship status or approach to initiating new relationships, with three participants reporting being able to successfully contact and break up with their partners, six reported looking for new partners, and two participants reporting a decrease or cessation of online dating use.

\section{Table 7. Ghosting recipients' responses to being ghosted.}

\begin{tabular}{|c|c|c|c|}
\hline Theme & Code & $\begin{array}{c}\text { Count } \\
(\%)\end{array}$ & Exemplars \\
\hline \multirow[t]{4}{*}{ None, moved on } & No action taken & $\begin{array}{c}68 \\
(29.3)\end{array}$ & "Zero action" \\
\hline & & & "Nothing can be done" \\
\hline & Let it go, moved on & $\begin{array}{c}45 \\
(19.4)\end{array}$ & "I kinda just let it be" \\
\hline & & & "Shrugged my shoulders and went on" \\
\hline \multirow[t]{2}{*}{$\begin{array}{l}\text { Attempted } \\
\text { Contact Then } \\
\text { Gave Up }\end{array}$} & $\begin{array}{l}\text { Attempted contact } \\
\text { without success, then } \\
\text { gave un }\end{array}$ & $\begin{array}{c}45 \\
(19.4)\end{array}$ & $\begin{array}{l}\text { "I tried a couple more times to contact } \\
\text { them, then gave up" }\end{array}$ \\
\hline & & & $\begin{array}{l}\text { "After contacting him a few times, I } \\
\text { realized what was happening and left } \\
\text { him alone" }\end{array}$ \\
\hline \multirow[t]{2}{*}{$\begin{array}{l}\text { Persistent Contact } \\
\text { Attempts }\end{array}$} & $\begin{array}{l}\text { Persistent contact } \\
\text { attempts (ambiguous } \\
\text { about whether }\end{array}$ & $\begin{array}{c}44 \\
(19.0)\end{array}$ & $\begin{array}{l}\text { "I kept messaging them to see what } \\
\text { happened" }\end{array}$ \\
\hline & recipient gave up) & & $\begin{array}{l}\text { "tried to contact them repeatedly and } \\
\text { asked why" }\end{array}$ \\
\hline
\end{tabular}




\begin{tabular}{|c|c|c|c|}
\hline & $\begin{array}{l}\text { Contacted } \\
\text { disengager's friends } \\
\text { or family }\end{array}$ & $\begin{array}{c}7 \\
(3.0)\end{array}$ & $\begin{array}{l}\text { "Tried to call him repeatedly, and talk to } \\
\text { his friends" } \\
\text { "I tried to call, text, email, reach out to } \\
\text { friends to find out if he was ok or what } \\
\text { was going on" }\end{array}$ \\
\hline \multirow[t]{2}{*}{ Retaliation } & $\begin{array}{l}\text { Blocked, unmatched } \\
\text { or unfollowed } \\
\text { disengager }\end{array}$ & $\begin{array}{c}20 \\
(8.6)\end{array}$ & $\begin{array}{l}\text { "I deleted their number, and unmatched } \\
\text { them on Tinder" } \\
\text { "blocked them back where I could" }\end{array}$ \\
\hline & $\begin{array}{l}\text { Acted aggressively } \\
\text { towards disengager }\end{array}$ & $\begin{array}{c}18 \\
(7.8)\end{array}$ & $\begin{array}{l}\text { "I sent him a glitter bomb in the mail" } \\
\text { "I sent him a strongly worded email" } \\
\text { "I posted on social media about him and } \\
\text { warned other women about he treats } \\
\text { people. I told everyone I knew he was a } \\
\text { fake loser" }\end{array}$ \\
\hline \multirow[t]{3}{*}{$\begin{array}{l}\text { Changes in } \\
\text { Personal } \\
\text { Relationships }\end{array}$} & $\begin{array}{l}\text { Looked for a } \\
\text { different romantic } \\
\text { partner, rebounded }\end{array}$ & $\begin{array}{c}6 \\
(2.6)\end{array}$ & $\begin{array}{l}\text { "looked for new people to talk to I had } \\
\text { more in common with" } \\
\text { "Moved on to other romantic } \\
\text { relationships" }\end{array}$ \\
\hline & $\begin{array}{l}\text { Dissolved } \\
\text { relationship with } \\
\text { disengager }\end{array}$ & $\begin{array}{c}3 \\
(1.3)\end{array}$ & $\begin{array}{l}\text { "I initiated a complete breakup" } \\
\text { "I just gave up and ended the fake } \\
\text { relationship" }\end{array}$ \\
\hline & $\begin{array}{l}\text { Used online dating } \\
\text { less }\end{array}$ & $\begin{array}{c}2 \\
(0.9)\end{array}$ & $\begin{array}{l}\text { "It was the final nail in the coffin for my } \\
\text { interest in online dating" } \\
\text { "I used dating sites less" }\end{array}$ \\
\hline
\end{tabular}

Note. All typographical errors within the exemplars are from the original responses. Weighted $P_{A}=97.80 \%$. Weighted Cohen's $k=.92$.

\subsubsection{Perceptions of Ghosting Disengagers}

Of the 239 (72\%) participants who had reported being ghosting by a partner, seven participants did not enter a response, leaving 232 responses to be coded. These participants were asked how they were ghosted by their partners. The extracted themes and retained codes are shown in Table 8 .

A sizeable percentage of participants reported no change in their perception of their partners after realizing they had been ghosted (24.1\%), and 3\% of participants even reported positive perceptions that included the desire to remain friends with or an increased interest in their partners who ghosted them. However, the majority of responses 
to this question demonstrated ghosting disengagers were perceived negatively by ghosting recipients. While most descriptions suggested generally mild negative perceptions (e.g., rude, cold, mean, immature), 19.8\% of responses indicated severe negative perceptions which included name calling, use of profanity, and loaded language (e.g., hate, horrible, awful, jerk, etc.).

Table 8. Ghosting recipients' changes in perception of ghosting disengagers.

\begin{tabular}{|c|c|c|c|}
\hline Theme & Code & $\begin{array}{c}\text { Count } n \\
(\%)\end{array}$ & Exemplars \\
\hline \multirow[t]{3}{*}{ No Change } & $\begin{array}{l}\text { Perceptions } \\
\text { stayed the same }\end{array}$ & $\begin{array}{c}56 \\
(24.1)\end{array}$ & "They remained more or less the same" \\
\hline & & & "I thought they were fine. It's not a big deal" \\
\hline & & & "My opinion of this person didn’t change at all" \\
\hline \multirow[t]{13}{*}{$\begin{array}{l}\text { Negative } \\
\text { Change }\end{array}$} & $\begin{array}{l}\text { Disengager was } \\
\text { not what }\end{array}$ & $\begin{array}{c}25 \\
(10.8)\end{array}$ & $\begin{array}{l}\text { "I realized that he was...nothing like how he } \\
\text { presented himself to be originally" }\end{array}$ \\
\hline & they were & & $\begin{array}{l}\text { "realized this person wasn't as nice as I thought } \\
\text { they were" }\end{array}$ \\
\hline & $\begin{array}{l}\text { Lost trust or } \\
\text { respect for } \\
\text { disengager }\end{array}$ & $\begin{array}{l}15 \\
(6.5)\end{array}$ & $\begin{array}{l}\text { "I lost respect for him because the least he could do } \\
\text { was be honest" }\end{array}$ \\
\hline & & & "I felt like he was a less trustworthy person" \\
\hline & $\begin{array}{l}\text { Lost interest in } \\
\text { disengager }\end{array}$ & $\begin{array}{c}21 \\
(9.1)\end{array}$ & "I realized I didn't want to be with him" \\
\hline & & & "I lost interest in her as well" \\
\hline & $\begin{array}{l}\text { Childish or } \\
\text { immature }\end{array}$ & $\begin{array}{c}17 \\
(7.3)\end{array}$ & "Just felt they acted very childish" \\
\hline & & & "They appeared irresponsible and immature" \\
\hline & Coward & $\begin{array}{c}8 \\
(3.4)\end{array}$ & $\begin{array}{l}\text { "There was no other way for me to interpret that } \\
\text { but cowardice" }\end{array}$ \\
\hline & & & "It made me see him as a coward" \\
\hline & $\begin{array}{l}\text { Various negative } \\
\text { perceptions }\end{array}$ & $\begin{array}{c}57 \\
(24.6)\end{array}$ & "It lowered my opinion of her somewhat" \\
\hline & & & $\begin{array}{l}\text { "I was really irritated at him and thought he was } \\
\text { immature and rude" }\end{array}$ \\
\hline & & & $\begin{array}{l}\text { "I thought it was rather cold hearted of them to do } \\
\text { that" }\end{array}$ \\
\hline
\end{tabular}




\begin{tabular}{|c|c|c|c|}
\hline & $\begin{array}{l}\text { Various severe } \\
\text { negative } \\
\text { perceptions } \\
\text { (profanity or } \\
\text { loaded language) }\end{array}$ & $\begin{array}{c}46 \\
(19.8)\end{array}$ & $\begin{array}{l}\text { "I realized he's a terrible human being" } \\
\text { I hated him" } \\
\text { "They're a piece of human garbage and I hope they } \\
\text { rot in hell" }\end{array}$ \\
\hline \multirow[t]{2}{*}{$\begin{array}{l}\text { Positive } \\
\text { Change }\end{array}$} & $\begin{array}{l}\text { Interest sustained } \\
\text { or piqued in } \\
\text { disengager }\end{array}$ & $\begin{array}{c}7 \\
(3.0)\end{array}$ & $\begin{array}{l}\text { "I hoped we would remain friends" } \\
\text { "I still think she's a great person and would love to } \\
\text { start things back up with her" }\end{array}$ \\
\hline & & & "They became more attractive" \\
\hline
\end{tabular}

Note. All typographical errors within the exemplars are from the original responses. Weighted $P_{A}=94.33 \%$. Weighted Cohen's $k=.78$.

\subsubsection{Breakup Tactics}

A series of one-way ANOVAs were conducted to investigate whether mean differences in the frequency of use of various breakup tactics were reported between participants with different experiences with ghosting and those who had not experienced ghosting. Of participants who had not previously experienced ghosting, only those who reported a unilateral breakup were included $(N=21)$ and coincidentally, all were responsible for initiating their breakups. Descriptive statistics for the breakup tactics are in Table 9 and results of the ANOVAs are in Table 10.

Table 9. Frequency of use of each breakup tactic as a function of ghosting experience.

\begin{tabular}{llccccc}
\hline & \multicolumn{2}{c}{ NG/NBG } & \multicolumn{2}{c}{ G/NBG } & \multicolumn{2}{c}{ NG/BG } \\
\cline { 2 - 7 } Tactic & $M$ & $S D$ & $M$ & $S D$ & $M$ & $S D$ \\
\hline Avoidance/Withdrawal & 3.60 & 1.71 & 3.87 & 1.95 & 3.26 & 1.84 \\
Open Confrontation & $4.81_{\mathrm{a}}$ & 1.99 & $2.17_{\mathrm{b}}$ & 1.98 & $1.58_{\mathrm{b}}$ & 1.18 \\
Distant/Mediated Communication & 2.67 & 2.15 & 2.04 & 1.93 & 1.87 & 1.66 \\
De-escalation & $2.75_{\mathrm{a}}$ & 2.00 & $2.07_{\mathrm{a}}$ & 1.69 & $1.58_{\mathrm{b}}$ & 1.21 \\
Positive Tone/Self-Blame & $3.45_{\mathrm{a}}$ & 1.33 & $3.22_{\mathrm{a}}$ & 2.00 & $2.08_{\mathrm{b}}$ & 1.55 \\
Cost Escalation & $3.29_{\mathrm{a}}$ & 2.11 & $1.52_{\mathrm{b}}$ & 0.94 & $1.80_{\mathrm{b}}$ & 1.38 \\
Manipulation & $2.86_{\mathrm{a}}$ & 1.80 & $1.98_{\mathrm{a}}$ & 1.64 & $1.52_{\mathrm{b}}$ & 1.15 \\
\hline
\end{tabular}

Note. Descriptive statistics were computed with the data before transformations were applied for ease of interpretation. $\mathrm{NG} / \mathrm{NBG}=$ never ghosted partner and never been ghosted by a partner. $\mathrm{G} / \mathrm{NBG}=$ ghosted a partner, never been ghosted by a partner. $\mathrm{NG} / \mathrm{BG}=$ never ghosted a partner, has been ghosted by a partner. Each subscript denotes a subset of categories whose row means differ significantly from each other at the .05 level. 
Open confrontation, de-escalation, positive tone/self-blame, cost escalation, and manipulation violated Levene's test of homogeneity of variance. Each was transformed by taking the square root of the raw scores, and the results below were computed using the transformed values. The results should be interpreted with caution, however, because the assumption of homogeneity of variance remained violated after the transformations.

A significant difference was found between participants who did not experience a ghosting breakup and those who did experience a ghosting breakup, such that reported use of open confrontation was greater in breakups that did not end through ghosting. A significant difference was found for de-escalation such that participants who dissolved their relationships without ghosting reported greater use of de-escalation than participants who were ghosted reported perceiving their partners to have used. In addition, participants who were ghosted perceived their partners to have used significantly less positive tone/self-blame tactics than participants who broke up with their partners reported to have used, regardless of whether the breakup involved ghosting. Participants who did not use ghosting to break up with their partners reported using significantly more cost escalation tactics than either participants who ghosted their partners and participants who were ghosted perceived their partners to use. Finally, participants who broke up with their partners without ghosting reported using significantly more manipulation than participants who had been ghosted reported their partners to have used, and a similar difference approached statistical significance between participants whose breakups did not involve ghosting and those who ghosted their partners. No significant group differences were observed for avoidance/withdrawal or distant/mediated communication.

Table 10. One-way ANOVA results for frequency of use of each breakup tactic as a function of ghosting experience.

\begin{tabular}{lccc}
\hline Tactic & $N$ & $F$ & $\omega^{2}$ \\
\hline Avoidance/Withdrawal $^{2}$ & 137 & 1.53 & .002 \\
Open Confrontation $^{\dagger}$ & 136 & $31.37 * * *$ & .193 \\
Distant/Mediated Communication $^{\dagger}$ & 136 & 1.52 & .003 \\
De-escalation $^{\dagger}$ & 135 & $4.88^{* *}$ & .036 \\
Positive Tone/Self-blame $^{\dagger}$ & 136 & $10.21^{* * *}$ & .061 \\
Cost Escalation $^{\dagger}$ & 136 & $11.04 * * *$ & .075 \\
Manipulation $^{\dagger}$ & 136 & $7.25^{* *}$ & .059 \\
\hline
\end{tabular}


Note. $* * p<.01 . * * * p<.001 .{ }^{\dagger}$ Levene's test remained violated after a square root transformation. Omega squared effect sizes can be interpreted as follows: $.01=$ small, .06 $=$ medium, and $.14=$ large.

\subsubsection{Attachment Style}

Pearson's $r$ correlations were conducted between the anxious and avoidant attachment orientations and frequency of ghosting experiences. Only one significant positive correlation emerged between attachment anxiety $(M=3.91, S D=1.37)$ and frequency of being ghosted by partners $(M=2.10, S D=2.11), r(320)=.23, p<.001, R^{2}=.052$. The correlation between attachment anxiety and frequency of ghosting partners $(M=1.90, S D$ $=2.07)$ was not significant, and attachment avoidance $(M=3.03, S D=1.21)$ was not significantly correlated with either type of ghosting experience.

A one-way ANOVA which included participants who had both ghosted others and been ghosted $(N=168)$ revealed a significant difference in attachment anxiety as a function of experience with ghosting, $F(3,318)=8.70, p<.001, \omega^{2}=.007$. Specifically, participants who had not experienced ghosting $(M=3.39, S D=1.32)$ had significantly less anxious attachment orientations than participants who had been ghosted but had not ghosted others $(M=4.08, S D=1.22)$ and participants who had both ghosted and been ghosted $(M$ $=4.18, S D=1.35)$. Participants who had ghosted others but not been ghosted $(M=3.27$, $S D=1.40$ ) had significantly less anxious attachment orientations than participants who had only ever been ghosted, and participants who had both ghosted and been ghosted.

Levene's test was violated for the one-way ANOVA conducted to investigate differences in attachment avoidance. Values of skewness and kurtosis were well within an acceptable range, so a transformation was not applied to the data. The one-way ANOVA revealed no significant differences between participants who had never ghosted or been ghosted $(M=$ 2.94, $S D=1.24)$, participants who had ghosted others but had never been ghosted $(M=$ $2.99, S D=1.47)$, participants who had never ghosted but had been ghosted $(M=2.90, S D$ $=1.22)$, and participants who had both ghosted and been ghosted $(M=3.13, S D=1.11)$. 


\subsubsection{Dark Triad}

Pearson's $r$ correlations were conducted between the Dark Triad traits and reported number of partners ghosted and number of times the participants had been ghosted by others (see Table 11). Machiavellianism $(M=3.08, S D=1.47)$ and psychopathy $(M=$ $3.01, S D=1.50$ ) were both significantly positively correlated with the number of times participants had ghosted others $(M=1.90, S D=2.07)$ and Machiavellianism and narcissism $(M=3.42, S D=1.45)$ were both significantly positively correlated with the number of times the participant had been ghosted by others $(M=2.10, S D=2.11)$.

Table 11. Correlations between Dark Triad traits and number of ghosting experiences.

\begin{tabular}{lccc}
\hline & \multicolumn{3}{c}{ Dark Triad Traits } \\
\cline { 2 - 4 } Number of ghosting experiences & Machiavellianism & Psychopathy & Narcissism \\
\hline Ghosted partners & $.218^{* *}$ & $.203^{* *}$ & .098 \\
Ghosted by partners & $.164^{* *}$ & .084 & $.143^{*}$ \\
\hline
\end{tabular}

Note. ${ }^{*} p<.05 . * * p<.01 . N=322$.

A one-way ANOVA revealed a significant difference in Machiavellianism as a function of experience with ghosting, $F(3,318)=6.53, p<.001, \omega^{2}=.009$. Specifically, participants who had only ever been ghosted $(M=2.54, S D=1.17)$ scored significantly lower than participants who had both ghosted and been ghosted $(M=3.39, S D=1.54)$.

The one-way ANOVA for psychopathy was also significant, $F(3,318)=3.53, p=.015$, $\omega^{2}=.005$, such that participants who had only ever been ghosted $(M=2.53, S D=1.33)$ scored significantly lower than participants who had both ghosted and been ghosted $(M=$ $3.22, S D=1.53)$. No significant differences in narcissism as a function of ghosting experience emerged, $F(3,318)=2.34, p=.07$.

\subsubsection{Breakup Distress}

A one-way ANOVA revealed a significant difference in breakup distress as a function of ghosting experience, $F(2,160)=9.86, p<.001, \omega^{2}=.016$. Post hoc tests revealed participants who did not experience a ghosting breakup and who either initiated their breakup or reported a mutual breakup $(N=47, M=1.50, S D=0.67)$ experienced significantly greater distress than participants who ghosted their partners $(M=1.15, S D=$ 
$0.35)$. In addition, participants who were ghosted $(M=1.68, S D=0.73)$ experienced significantly greater distress than participants who ghosted their partners. The difference in distress between participants who did not experience a ghosting breakup and participants who were ghosted was not significant. To summarize, participants who ghosted their partners experienced significantly less distress than participants who were ghosted or participants whose relationships did not end through ghosting.

\subsection{Discussion}

The present study reflects the first broad-scale investigation into the phenomenon of ghosting. Experiences with ghosting were common in the present sample, with over $60 \%$ of participants having reported previously ghosting a romantic partner, and over $70 \%$ reported having previously been ghosted by a romantic partner.

Over $80 \%$ of participants who reported being familiar with the concept of ghosting provided definitions which were qualitatively analyzed and collated to construct an empirically-based definition of ghosting which resolved some of the inconsistencies in the existing definitions provided in popular culture media. While some participants considered avoidant behavior that occurred after an explicit expression of disinterest was given to the recipient to be considered ghosting and a few mentioned using ghosting as a last resort after a direct breakup had failed, the overwhelming majority of participants believed if an explanation was given to the recipient, the breakup strategy should not be considered ghosting. This indicated that the lack of explanation prior to avoidant behavior is a unique and defining feature of the ghosting breakup strategy. Mentions of ghosting occurring immediately and gradually were apparent in open-ended responses for both the definition of ghosting as well as for how ghosting was implemented. As such, at this time more information is needed to further clarify whether popular opinion dictates a cessation of contact should only be considered ghosting if it happens immediately. Other accounts of similar distancing or breakup behavior has been found in the popular culture literature and is colloquially referred to as the "slow fade" (Carter, 2013; Crotty, 2014). While the only essential difference between the slow fade and ghosting is the speed at which the processes occur, whether or not these are worthy of being considered distinct phenomena remains up for debate. 
A remaining ambiguity is whether some or all contact is severed between partners. While many responses indicated ghosting disengagers "ignored" or "stopped talking" to the recipients, the nuances of these contact interruptions remain to be understood. While unprompted responses from participants regarding how ghosting is implemented were valuable, future investigations should use the responses provided by the participants of the current study to inform and specify the types of contact that can be interrupted in a check-all-that-apply format. Participants should be asked to indicate whether contact through each medium was completely halted or not in order to explicitly determine which means of communication are most often disrupted when ghosting is implemented as a breakup strategy.

The rich descriptive information elicited from participants who reported on their ghosting experiences provided key insights into why ghosting is implemented. Prominent themes emerged from both ghosting disengagers and recipients, such that the desire of disengagers to avoid a direct conversation played a large part in their selection of this strategy. Disengagers frequently reported that negative qualities of the recipient influenced their decision to ghost, and both disengagers and recipients acknowledged that the disengagers' loss of interest in the recipient and the overall qualities of the relationship or situation (e.g., short length, not serious/exclusive, low partner compatibility) motivated disengagers' decisions as well. Preliminary conclusions that can be drawn from this data are that ghosting occurs because of loss of interest in or low perceived compatibility with the relationship partner, and that ghosting is often selected as a breakup strategy because the disengager benefits by being able to avoid a direct conversation with the recipient, which minimizes the amount of expended effort and emotional energy involved in the breakup.

In terms of the possible consequences of ghosting, a minimal percent of ghosting recipients reported taking active action in attempt to retaliate against the ghosting disengager. While approximately $40 \%$ of recipients reported attempting to reestablish contact with the disengager, half of them explicitly indicated that they gave up after being unsuccessful in their attempts. In fact, the most frequently reported post-ghosting response was that no action was taken; the recipients either recognized that nothing could 
be done, or they decided to let it go and move on. These results suggest that ghosting does not have severe consequences that require a cause for immediate concern or intervention, however, the extent to which the consequences of ghosting differ from the consequences of breakups that occur in a more direct manner is yet to be known and presents a question that future research should address.

Hostile descriptions of ghosting disengagers in the popular culture discourse prompted the exploration of how ghosting disengagers are perceived by ghosting recipients. Unsurprisingly the majority of the accounts involved negative perceptions of the disengagers that ranged from mild reflections about insensitivity and rudeness to more dramatic descriptions of disengagers being assholes and pieces of human garbage. The conclusion can be drawn that individuals who choose to ghost their partners will most likely not be perceived positively by their ex-partners, however, as discussed above, whether these perceptions vary from recipients' perceptions of their partners who ended their relationships directly remains unknown. While mostly negative perceptions emerged, almost a quarter of the sample reported that their perceptions of their partners were unaffected despite their partners using ghosting to end their relationships. Possible explanations for this can be found in the popular culture discourse, with a few sources suggesting that the nature of online dating has turned "dating into something disposable, in which we ultimately view one another as just another match in a long list of matches" (Coen, 2015). While only applicable to individuals who participate in online dating, the immense availability of alternate partners and the potential ease of developing another romantic connection may make rejection less debilitating, as individuals may adopt the attitude that they can simply "go onto the next one" (Coen, 2015) rather than spending time ruminating about their breakup.

Participants who had breakups involving ghosting were more likely to have met their partners online, however, participants who met their partners offline reported experiences with ghosting as well. Therefore, while ghosting can be carried out mainly through technologically-mediated communication, it is not a phenomenon that is unique to online relationships or relationships that started through online platforms (e.g., online dating sites or apps). Ghosting occurred more often in shorter relationships, and participants 
who ghosted their partners were significantly less committed than participants who were ghosted or those whose relationships did not end through ghosting. Reported commitment between participants who were ghosted and those who did not experience ghosting did not significantly differ. These findings suggest ghosting may be a strategy implemented mostly in casual dating relationships, where partners have not yet become overly "tied" (Davis, 1973) to each other.

Participants whose breakups did not involve ghosting reported using more open confrontation and cost escalation tactics than participants who ghosted and participants who were ghosted perceived their partners to have used. Higher use of open confrontation tactics in non-ghosting breakups reinforce the sentiment that ghosting breakups are unique because of the lack of explanation from the disengaging partner. Lower use of cost escalation in ghosting breakups suggests that a reduction or prevention of contact between partners may lessen the tendency to make a relationship more unpleasant in order to compel a partner to consider dissolution. Withdrawing access to means of communication is a passive act and could be considered by some individuals who use ghosting as a gentler way of dissolving a relationship as opposed to implementing cost escalation tactics, which may be perceived as a more active and aggressive way to achieve the same goal. Participants whose relationships did not end through ghosting reported using more de-escalation and manipulation tactics than participants who were ghosted reported perceiving. De-escalation tactics represent actions on behalf of the disengager to find the right time to breakup, indicating care and concern for the recipient. As considerably more effort and consideration are put into finding the right time and the right words to say during a breakup conversation, it is logical that non-ghosting disengagers report using this tactic more often, especially since ghosting breakups do not culminate in such a direct conversation. Similarly, if ghosting is often implemented in more casual relationships or relationships where partners interact mostly online, consideration of the recipient's feelings may not be a high priority for a ghosting disengager. Both participants whose relationships did not end through ghosting and those who did ghost their partners reported using more positive-tone/self-blame tactics than participants who were ghosted reported perceiving. Differences here suggest that inconsistencies in accounts of breakup processes between disengagers and recipients 
may exist, such that recipients do not perceive disengagers to have acted in as much of a considerate manner as disengagers believed they had. Considering that the item for distant/mediated communication reflected informing a partner about the intention to end the relationship through technologically-mediated communication methods, it is not surprising that no differences emerged between groups. While relationships that ended through ghosting would likely not involve an explanation at all, non-ghosting breakups may occur more often in face-to-face conversations, making the use of distant/mediated communication tactics non-essential or less common during the dissolution process. Quite surprisingly however, no significant differences between groups emerged for avoidance/withdrawal. While use of avoidance/withdrawal tactics in non-ghosting relationships is not unexpected, the central feature of ghosting is avoidance, so a discernable difference between ghosting and non-ghosting breakups should emerge.

This finding suggests that the scale used in the breakup tactic questionnaire (Collins \& Gillath, 2012) may not be the most appropriate for assessing differences between direct and indirect breakups. For instance, upon closer inspection of the avoidance/withdrawal distributions, participants who ghosted their partners and participants who were ghosted reported very low frequencies of avoidance/withdrawal use. Assessing the frequency of use, then, may not be the most accurate measure, as cutting off a partner's access could happen in a single instance, resulting in a lower frequency of use despite the reality of complete and total withdrawal from the relationship. This questionnaire offers great utility in identifying the various types of tactics that can be used during relationship dissolution, however, whether a certain tactic is used or not may be more informative, as a frequency scale assumes that certain tactics that are used more often throughout the breakup process are the most essential to achieving relationship dissolution. In addition to issues with the original scale, less than a third of the total breakup tactics and only one or two items for each factor were used in the present investigation and future studies should include the full scale.

There were no significant differences in breakup distress between participants whose relationships did not end through ghosting and those in which the participant was ghosted, however, both groups experienced significantly more distress than participants 
who ghosted their partners. This suggests that by avoiding their partners ghosting disengagers are also avoiding feeling more distressed after the breakup, fueling the idea that ghosting may be an adaptive breakup strategy for disengagers. In contrast, ghosting recipients experiencing similar levels of distress as individuals who experienced nonghosting breakups suggest that being on the receiving end of a ghosting breakup is not much different than breaking up with a partner or experiencing a mutual breakup through more direct means. So, while ghosting may embody an uncompassionate and indirect breakup strategy, the amount of distress it causes the recipient may not be more than what would be experienced in a more direct breakup. However, of the participants who had not ghosted or been ghosted, none were the recipients of their non-ghosting breakups. Therefore, the amount of distress experienced between ghosting recipients and nonghosting recipients has yet to be quantified and necessitates further exploration. While post-breakup distress was assessed, other possible post-breakup emotions like positive affect were not measured. Future investigations should attempt to assess a more comprehensive span of possible post-breakup emotions.

More anxiously attached participants reported being ghosted more frequently. Anxiously attached individuals' desire to be close to their partners may result in frequent monitoring of their partners' online activity, perhaps being more alert and sensitive to signs of distancing or disconnection. Similarly, anxious individuals may overestimate the seriousness of their relationships more so than their partners, perhaps creating increased sensitivity to thinking they were ghosted when their partner's may not have believed they were in a relationship at all. The association between anxious attachment and experiences of being ghosted was also found when comparing the four ghosting conditions, such that participants whose relationships did not end through ghosting and those who ghosted their partners were significantly less anxiously attached than participants who had reported being ghosted in the past and those who had both previously ghosted and been ghosted. This suggests that being anxiously attached is associated with either actually being ghosted more often than less anxiously attached individuals, or the tendency of anxious individuals to be oversensitive to signals of disconnection, perhaps resulting in an overestimation of the frequency with which they have been ghosted by others. 
Machiavellianism and psychopathy both showed positive correlations with frequency of ghosting others. The correlation between Mach and the use of ghosting coincides with Brewer and Abell's (2017) finding that Mach was associated with higher usage of avoidance/withdrawal breakup tactics. The possibility of ending a relationship instantaneously through ghosting may coincide with psychopathic individuals' tendency to be highly impulsive. In addition, the characteristic lack of empathy may contribute to their preference to ghost rather than have a direct conversation with the partners they reject, as ghosting does not provide an opportunity or an obligation to provide support to the rejected partner. Mach and narcissism were positively associated with being ghosted more frequently by others, indicating that perhaps partners of Dark Triad individuals find it easier to disappear than to have to navigate a breakup conversation with manipulative or entitled partners. This finding is supported by responses found in the qualitative data, with ghosting disengagers reporting their partners to have had negative qualities including being controlling, manipulative and aggressive. Participants who had both ghosted and been ghosted scored significantly higher on Mach and psychopathy than participants who had only been ghosted. Lower expressions of Dark Triad traits found in individuals who had only ever been ghosted may suggest they may be more susceptible to being broken up with through ghosting and less likely to use ghosting to dissolve their relationships. Though the Dirty Dozen (Jonason \& Webster, 2010) was appropriate for use in the current study because of its short length, the construct validity of this scale has been questioned in the past (Carter, Campbell, Muncer, \& Carter, 2015; Kajonius, Persson, Rosenberg, \& Garcia, 2016). Reliability estimates for the three Dark Triad subscales in the current study were acceptable $(\alpha=.81)$, however, further investigations into the Dark Triad personality traits should use a scale that has less disagreement concerning its utility.

This study was the first data-driven investigation of ghosting, a novel breakup strategy which involves dissolving a relationship indirectly through ceasing contact with a relationship partner instead of providing them with a direct explanation. Open-ended responses that were collected provided descriptive first-hand accounts of how ghosting is implemented, why ghosting is implemented, and the consequences that result from its 
implementation in terms of retaliatory action and perceptions of the ghosting disengager. Qualitative analysis of these responses allowed for the creation of an empirically derived definition of ghosting and provided a breadth of information which can act as an anchor for future researchers interesting in studying this phenomenon further. Quantitative analyses demonstrated relationships between ghosting experiences and a variety of individual difference variables including attachment style and the Dark Triad traits of personality. Similarly, relationship characteristics were found to differ between relationships that ended through ghosting and those that did not end through ghosting, including relationship origination (online or offline), relationship length, and commitment. Finally, measures of breakup distress indicated that while being ghosted is comparably distressing to breaking up with a partner in more direct ways or experiencing a mutual breakup, ghosting disengagers experienced the least amount of post-breakup distress, which suggests ghosting may have evolved to as an adaptive and effortless breakup strategy within modern culture. 


\section{Chapter 3}

\section{Study 2}

Study 2 compared the motivations for, processes by which, and consequences of two breakup strategies (direct conversations and ghosting) between disengagers (those who initiated their breakups) and recipients (those who were broken up with) in terms of specific breakup tactics used during the breakup process, breakup distress, positive and negative affect, and post-breakup recovery and personal growth. New variables were included with which the relation to ghosting was unknown, therefore, Study 2 was designed as a cross-validation study. A large sample was collected (based on an a priori power analysis detailed below) and randomly split into two halves. Exploratory analyses were conducted in Sample A. Hypotheses informed by the results of Sample A were tested in Sample B, in which a more stringent alpha level was adopted in order to contain the experiment-wise error rate to $5 \%$. A series of 2 (breakup role: disengager or recipient) X 2 (breakup strategy: ghosting or direct conversation) factorial ANOVAs and two multivariate analyses of variance (MANOVAs) were used to test the preregistered hypotheses in both samples (https://osf.io/t6q4s/).

\subsection{Introduction}

Results from Study 1 suggested that ghosting breakups differed from non-ghosting breakups in terms of how the relationships originated, levels of commitment, relationship length, breakup distress, and use and perceived use of various breakup tactics. While differences in breakup strategy were observed, differences also emerged between ghosting disengagers and ghosting recipients, suggesting that breakup role might contribute to differences in outcome variables in meaningful ways. The size of the nonghosting comparison group in Study 1 was small and did not include non-ghosting breakup recipients, which exposed the inability to make comparisons between recipients and disengagers within the non-ghosting breakup group and comparisons between recipients and disengagers between breakup strategy groups. Therefore, Study 2 prioritized a more focused approach to determining differences in breakup processes, 
motivations, and outcomes as a function of breakup strategy and breakup role before moving on to further investigations of the associations between ghosting experiences and individual differences. While associations between ghosting and individual differences are not the focus of this initial follow-up study, an increase in our knowledge of the shared traits that exist in individuals who choose to end their relationships through ghosting, and in individuals who find themselves being ghosted by their partners would aid in our understanding of whether certain individuals experience ghosting more often than others.

\subsubsection{Breakup Role}

Multiple studies have found that most relationships dissolve at the request of one partner, rather than both partners (Drigotas \& Rusbult, 1992; Helgeson, 1994; Hill et al., 1976), and past research has shown that differences exist between disengagers and recipients in various post-breakup emotional outcomes (Davis, Shaver \& Vernon, 2003; Field et al., 2009; Hill, Rubin, \& Peplau, 1976; Sprecher, Felmlee, Metts, Fehr, \& Vanni, 1998). Study 1 found differences between ghosting disengagers and ghosting recipients in commitment, the positive tone/self-blame breakup tactic, and breakup distress. Commitment characterizes the relationship pre-breakup, positive tone/self-blame is a tactic that is used during the process of dissolution, and breakup distress is a post-breakup outcome. These preliminary findings suggest that differences in experiences of a breakup between disengagers and recipients may be observed throughout the entire process of relationship dissolution.

\subsubsection{Breakup Tactics}

Results from Study 1 indicated the frequency of use or perceived use of certain breakup tactics differed between ghosting and non-ghosting breakups and between ghosting disengagers and ghosting recipients. Despite only one or two items representing each tactic, differences were observed between strategies for open confrontation, deescalation, cost escalation, and manipulation, and differences emerged between ghosting disengagers and ghosting recipients for positive tone/self-blame. To address the limitations of the adapted breakup tactic scale (Collins \& Gillath, 2012) from Study 1, the 
entire set of items was used in Study 2 and the rating scale was changed from assessing frequency to dichotomously assessing whether or not each tactic was used.

\subsubsection{Motivations for Breakup Strategy Choice}

Collins and Gillath (2012) remarked that research on predictors of breakup strategy choice was relatively limited. Existing literature on the topic focuses on relationshipspecific factors like intimacy and closeness, partner similarity, reasons for the breakup, social network overlap, and intentions to maintain a friendship with the ex-partner after the breakup (Banks et al., 1987; Baxter, 1982; Cody, 1982; Metts, Cupach, \& Bejlovec, 1989; Sprecher et al. 2010). In general, direct breakups that involve explicit and honest expressions of emotion and intents to dissolve often occur in relationships where intimacy, partner similarity, and social network overlap are high (Banks et al., 1987; Baxter, 1982; Cody, 1982) and in contrast, indirect tactics involving more avoidance rather than communication are used when intimacy is low (Banks et al., 1987; Baxter, 1982). However, the motivations that stimulate disengagers to choose a certain breakup strategy over another may extend beyond the predictors examined in past research. For example, direct statements explaining the reason for dissolution is associated with more intimate relationships, however, whether the disengager was motivated to use that direct strategy because they considered their relationship to be highly intimate remains unknown. Qualitative data from Study 1 demonstrated that ghosting disengagers were motivated to ghost by a variety of reasons that centered around the self, the partner, and the relationship situation. In addition, ghosting recipients suggested a variety of similar motivations that they believe stimulated their partners to ghost. While qualitative similarities were observed between ghosting disengagers and recipients, differences were also observed in the number of reports of each motivation between the two breakup roles, which suggested that disengagers may report being motivated by certain reasons to a different extent than what recipients perceive. As such, the relationship between breakup role and attributions of motivations for breakup strategy choice represent a research path worthy of attention. Additionally, while similar qualitative data was not collected for non-ghosting breakups, to the researcher's knowledge Study 1 represented the first effort to gather data-driven motivations for selecting a certain breakup strategy. The qualitative 
responses from Study 1 were used to inform the creation of items for a motivation for breakup strategy choice scale for both ghosting and non-ghosting breakups which were used to investigate differences in motivations and perceived motivations between disengagers and recipients.

\subsubsection{Breakup Distress}

When an individual feels they have control over certain events, those events are perceived as less distressing than events that seem, or are, uncontrollable (Fiske \& Taylor, 1984; Frazier \& Cook, 1993). Thus, when individuals experience a breakup, the severity of the reaction to the breakup may be partially predicted by whether they initiated the breakup or whether they were the partner being broken up with. Multiple studies have found that disengagers report less breakup distress than recipients (Davis et al., 2003; Field et al., 2009; Hill et al., 1976; Morris, Reiber, \& Roman, 2015; Perilloux \& Buss, 2008; Sprecher, 1994, 1998), and that individuals involved in relationships dissolved mutually reported less distress than those who were broken up with (Morris et al., 2015). However, Simpson (1990) found no differences between the amount of breakup distress reported by disengagers and recipients, and Fine and Sacher (1997) found greater reported distress only for males who believed their partners initiated the breakup. Study 1 revealed a difference in breakup distress such that ghosting disengagers reported significantly less distress than ghosting recipients and participants whose relationships did not end through ghosting. The distress experienced by those who were ghosted and those who experienced non-ghosting breakups did not significantly differ. These findings suggest breakup distress could be influenced by both breakup strategy and breakup role.

\subsubsection{Positive and Negative Affect}

Sprecher (1994) investigated differences in post-breakup positive and negative affect between partners within the same relationship, catching a rare perspective of both sides of a breakup. Unsurprisingly, negative emotions were experienced more intensely than positive emotions, especially hurt, frustration, depression and loneliness, however, the positive emotions of love and relief were also experienced. The assessment of breakup 
distress and negative affect have been prioritized in many studies that have investigated relationship dissolution with less attention being paid to potential positive outcomes (Sprecher, 1994; Tashiro \& Frazier, 2003). Though Sprecher (1994) had data from both partners and assessed on a continuous scale the extent to which each participant was responsible for their breakup $(1=I$ did, $4=$ we both did, $7=$ my partner did $)$, her analyses focused on gender differences rather than differences in breakup role. Sprecher (1994) cited Cupach's (1992) dialectical approach to relationships which suggests that oppositional propensities can exist within various stages of relationships. Specifically,

during dissolution, individuals may feel independent from their ex-partner and that sense of autonomy can be associated with positive emotions. However, despite these feelings, the desire to feel connected to one's partner may also remain which could lead to more negative feelings (Cupach, 1992). Study 1 only included a post-breakup measure of distress which precluded the assessment of a greater range of emotions that may be experienced after a romantic relationship ends. The inclusion of a scale that measures positive and negative affect in the current investigation should allow the differences in these emotions as a function of breakup role and the type of breakup strategy used during relationship dissolution to be revealed.

\subsubsection{Post-Breakup Recovery and Personal Growth}

Similarly, few studies have focused on the positive life changes that can result from romantic relationship dissolution (Buehler, 1987; Helgeson, 1994; Tashiro \& Frazier, 2003). While breakups have been described as one of life's most distressing events (Sprecher, 1994; Tashiro \& Frazier, 2003), breakups also provide the opportunity for individuals to develop and change in constructive ways, including positive changes in self-perception and interpersonal priorities (Tashiro \& Frazier, 2003). Past research has looked at the relationship between breakup role and post-breakup positive experiences and personal growth and found mixed results. Buehler (1987) found participants who initiated a divorce were more likely to report experiences of personal growth than recipients of divorce. Tashiro \& Frazier (2003) used the Post-Traumatic Growth Inventory (Tedeschi \& Calhoun, 1996) to investigate differences as a function of breakup role and found no significant differences between disengagers and recipients, and no 
significant interaction between gender and breakup role. While literature on breakup role and post-breakup personal growth is mixed, the current study will offer another opportunity to see if any differences emerge. Prior research has not investigated possible differences in post-breakup personal growth as a function of breakup strategy. As such, the inclusion of this measure may reveal whether the occurrence of a direct conversation during a breakup may offer more of an opportunity to process and reflect on the dissolution, perhaps increasing the chances or speed at which the partners could recover and adjust post-breakup. Relatedly, as ghosting does not involve a breakup conversation, whether personal growth and recovery is significantly hindered as a result of this strategy would be important to determine.

\subsection{Methods}

\subsubsection{Study Preregistration}

Study 2 was preregistered on the OSF. All materials and documents created during the course of the study for Sample A and Sample B can be found at https://osf.io/t6q4s/.

\subsubsection{A Priori Power Analysis}

An a priori power analysis was conducted using the $\mathrm{G}^{*}$ Power application (Version 3.1.9.2). The determined smallest effect size of interest (Lakens, 2014) was Cohen's $f=$ .20. Alpha was set to .01 to account for the multiple significance tests that were anticipated to be conducted. As most planned analyses would be 2 X 2 factorial ANOVAs meaning there were four conditions in the study, the numerator degrees of freedom were equal to 1 . With these input parameters, a sample size of 296 was needed to detect the smallest effect of interest with $80 \%$ power. This sample size was then doubled, so both Sample A and Sample B would have at least 296 participants, and at least 74 participants in each condition.

\subsubsection{Recruitment}

Participants were recruited through MTurk. Interested participants between the ages of 18 and 35 had to have experienced a non-mutual breakup with a romantic partner in the past six months that ended through either a direct conversation or through ghosting, be fluent 
English speakers, reside in the United States or Canada, and have an active MTurk account with at least $97 \%$ approval from previous requesters. In addition, participants must not have indicated they participated in a similar study on ghosting (Study 1) in August 2017. The survey took between 15 and 30 minutes to complete, and participants were compensated with $\$ 0.50$ USD for their participation.

\subsubsection{Procedure}

Four recruitment ads were posted to MTurk, one for each condition (direct disengager, direct recipient, ghosting disengager, ghosting recipient; Appendix E). Participants recruited from MTurk followed a link to a Qualtrics survey (Appendix F) that was completed entirely online. Participants were first shown the Eligibility Screening Questionnaire (Appendix G), which consisted only of questions meant to assess whether participants satisfied the inclusion criteria of the study. Participants who did not pass eligibility screening were excluded from participating and were not compensated. Participants who satisfied the eligibility criteria were shown a Letter of Information then gave implied consent (Appendix H). Participants answered demographic questions followed by questions about how their breakup occurred. Participants were then shown the breakup tactics questionnaire (Collins \& Gillath, 2012), and the motivation for breakup strategy choice questionnaire (created by the researchers for the current study), the Breakup Distress Scale (BDS; Field et al., 2009), the Breakup Emotions Scale (BES; Sprecher, 1994), the Post-Breakup Personal Recovery and Personal Growth questionnaire (PBRS; Tedeschi \& Calhoun, 1996), and asked whether they remembered participating in Study 1 . Once the questionnaires were finished, a debriefing form (Appendix I) was displayed along with the HIT code the participants submit through MTurk to claim payment for completing the task.

\subsubsection{Participant Exclusion and Sample Division}

Of the 1697 participants who started the study, 1021 were excluded for either not passing the Eligibility Screening Questionnaire or not indicating whether they had participated in Study 1, 34 were excluded for reporting on a relationship that ended over six months ago, 16 were excluded for reporting their relationship ended mutually, 20 participants were 
excluded for being over 35 years old, one was excluded for not being fluent in English, two were excluded for missing information on at least one item needed to determine eligibility, five were excluded for indicating their relationships ended in a way other than a direct conversation or ghosting, and three participants were excluded for missing responses on $25 \%$ or more of the items of any single questionnaire. The final total sample consisted of 595 participants.

The data set was split in half using a random number generator. Each of the case numbers in the SPSS file for each of the four groups (direct disengagers, direct recipients, ghosting disengagers, ghosting recipients) were entered separately into a website that generates random groups (Random Lists). Each case in each group was then randomly assigned to either the exploratory or confirmatory sample. Sample A contained 299 participants, and Sample B contained 296 participants.

\subsubsection{Materials}

A comprehensive and detailed document explaining the how each scale was adjusted or crafted and scored can be found in the "Adopted Instruments" document on the OSF (https://osf.io/tdvke/).

\subsubsection{Eligibility Screening Document}

Participants were shown six questions meant to assess whether participants met the inclusion criteria of the study. Participants were asked to report their age, their English fluency, how long ago their relationship ended, how the relationship ended (one-sided or mutual), and how they broke up with their partner or how their partner broke up with them (ghosting or direct conversation).

\subsubsection{Demographics}

Participants were asked to report their age, gender, English fluency, sexual orientation, current relationship status, race, and religious affiliation. 


\subsubsection{Relationship Dissolution}

Participants were asked about their dissolved relationship and ex-partner. Specifically, participants were asked to report how long ago their relationship ended and how they met their partner (online dating site/app, by chance in person, through a friend or family member, at school or work, or other). In addition, participants were asked how long their relationship lasted, how committed they were to their partner on a scale of 1 (not at all committed) to 7 (very committed), and how they characterized their relationship with their partner at the time of the breakup (friend with benefits, casually/non-exclusively dating, seriously/exclusively dating, or other). Finally, participants were asked who initiated the breakup (self/disengager or partner/recipient) and how that breakup occurred (ghosting or direct conversation).

\subsubsection{Breakup Tactics}

The full 7-factor breakup tactics questionnaire (Collins \& Gillath, 2012) was used to assess whether each breakup tactic was used during the process of relationship dissolution. Due to issues with the original rating scale which assessed frequency of tactic use in Study 1, the scale was changed to offer a dichotomous choice, either 1 indicating "yes, this strategy was used" or 0 indicating "no, this strategy was not used." Participants who initiated their breakups (disengagers) were asked to self-report whether they used each tactic to facilitate the breakup with their partner. In contrast, the instructions and items were modified for participants who were broken up with (recipients), who were asked to report whether they noticed their partner using each tactic. Item 24, "I verbally blamed my partner for causing the breakup, even if I thought they were not totally to blame" was reverse scored in the original questionnaire and was not included in the questionnaire for Study 2, making the total number of items 42. Each of the seven factors did not have the same number of items, therefore, total number of tactics used (or perceived to be used) within a certain factor were summed and divided by the total number of items in that factor, resulting in an average that indicated the proportion of use of tactics that represented a certain factor. Proportions ranged from 0 to 1 , with higher proportions indicating greater use of tactics within a factor. See Table 12 for reliability estimates. 
Table 12. Cronbach's alpha for each breakup tactic subscale in Study 2.

\begin{tabular}{|c|c|c|c|c|c|}
\hline \multirow[b]{2}{*}{ Tactic } & \multirow[b]{2}{*}{ Items } & \multicolumn{2}{|c|}{$\begin{array}{l}\text { Sample A } \\
(N=299)\end{array}$} & \multicolumn{2}{|c|}{$\begin{array}{l}\text { Sample B } \\
(N=296)\end{array}$} \\
\hline & & DIS & REC & DIS & REC \\
\hline Avoidance/Withdrawal & 11 & .81 & .76 & .84 & .82 \\
\hline Open Confrontation & 4 & .85 & .81 & .88 & .85 \\
\hline Distant/Mediated Communication & 4 & .66 & .63 & .59 & .72 \\
\hline De-escalation & 5 & .62 & .60 & .61 & .65 \\
\hline Positive tone/Self-blame & 9 & .83 & .86 & .83 & .81 \\
\hline Cost Escalation & 4 & .66 & .67 & .65 & .61 \\
\hline Manipulation & 5 & .63 & .76 & .68 & .67 \\
\hline
\end{tabular}

Note. DIS = disengager. $\mathrm{REC}=$ recipient.

\subsubsection{Motivation for Breakup Strategy Choice (MBSC)}

Motivations (and perceived motivations) for why a breakup occurred through a direct conversation or through ghosting were of particular interest, and potential motivations for choosing each breakup strategy were crafted by the researchers, with items reflecting motivations for ghosting informed by the open-ended responses provided by participants in Study 1. The motivation scale for direct conversation breakups contained 16 items $(\alpha=$ .78), for example, "I wanted to explain why I wanted to breakup." The motivation scale for ghosting breakups contained 21 items $(\alpha=.83)$, for example, "It was too much effort to explain why I wanted to breakup." Seven items were shown to all participants regardless of breakup strategy. These items reflected motivations that might have applied to either breakup strategy, for example, "I wanted to have control over the breakup" and "Our relationship was not very serious." Participants rated the extent to which each motivation affected the decision to use a certain breakup strategy on a scale of 1 (did not affect my/my partner's decision at all) to 7 (extremely affected my/my partner's decision). For each breakup strategy two versions of the scale were created, one for disengagers and one for recipients. Disengagers were instructed to indicate to what extent each motivation affected their decision to breakup with their partner through direct conversation/ghosting, while recipients were asked to indicate to what extent they believed each of the motivations affected their partner's decision to breakup up with them through direct conversation/ghosting. In addition, disengagers were asked to focus on what motivated their decision to break up with their partner in the way that they did, rather than why they 
no longer wanted to be in a relationship with their partner in general. Recipients were given a similar reminder.

Breakup strategy motivation scales were analyzed with exploratory factor analysis (EFA) using the full sample size $(N=595)$ and both the disengager and recipient responses for each strategy. As the aim was to identify differences in motivations and perceived motivations between disengagers and recipients for each strategy, to make comparisons between disengagers and recipients the factor structure needed to be identical, therefore conducting separate EFAs for disengagers and recipients for each strategy was not appropriate. Similarly, in order to compare results from Sample A to Sample B, the factor structure had to be identical between samples, therefore conducting separate EFAs for Sample A and Sample B for each strategy was not appropriate.

Results of the direct MBSC revealed three factors: gentle breakup, clarity and understanding, and done with relationship. The gentle breakup factor, composed of six items $\left(\alpha_{\text {disengager }}=.79, \alpha_{\text {recipient }}=.83\right)$, is characterized by concern of the disengager for the recipient's feelings during the breakup, for example, "I wanted to try and support my partner even though I was breaking up with them." The clarity and understanding factor contained four items $\left(\alpha_{\text {disengager }}=.82, \alpha_{\text {recipient }}=.81\right)$ and is characterized by the desire of the disengagers to be clear, honest, and explain why they wanted to separate from their partners, for example, "I wanted to make my intentions/desire for separation clear." The done with relationship factor had three items $\left(\alpha_{\text {disengager }}=.70, \alpha_{\text {recipient }}=.55\right)$ and was characterized by dwindling interest in the relationship or relationship partner, for example, "I became bored with the relationship."

Results of the ghosting MBSC revealed four factors: avoidance, done with relationship, guilt, and anticipated a difficult breakup. The avoidance factor, composed of six items $\left(\alpha_{\text {disengager }}=.84, \alpha_{\text {recipient }}=.82\right)$, is characterized by the unwillingness or hesitancy on the part of the disengager to facilitate a breakup conversation, for example, "It was too much effort to explain why I wanted to break up." The done with relationship factor contained three items $\left(\alpha_{\text {disengager }}=.76, \alpha_{\text {recipient }}=.45\right)$ and is characterized by the belief that the relationship with the recipient was not working out, for example, "I did not think my 
partner and I were compatible." The guilt factor had two items $\left(\alpha\right.$ disengager $=.63, \alpha_{\text {recipient }}=$ .49) and is characterized by guilt or concern about potentially hurting the recipient's feelings, for example, "I felt bad telling them I wanted to breakup." The anticipated a difficult breakup factor had two items $\left(\alpha_{\text {disengager }}=.68, \alpha_{\text {recipient }}=.51\right)$ and is characterized by the expectation that the recipient would not accept the breakup easily, for example, "My partner would overreact/be dramatic about the breakup."

Detailed explanations of the EFAs for the ghosting and direct MBSC scales can be found in Appendix J. The items within the extracted and retained factors were averaged to create an overall score for that motivation factor. Higher averages indicated that motivation factor was more influential in the decision to use a certain breakup strategy.

\subsubsection{Breakup Distress (BDS)}

The 16-item breakup distress scale (Field et al., 2009) that was used in Study 1 was used in Study 2. Participants were asked to rate on a scale of 1 (not at all) to 4 (very much so) to what extent they felt a certain way when their relationship ended. Overall breakup distress scores were calculated by averaging all 16 items, with higher scores indicating greater breakup distress at the time of the breakup. Reliability estimates for both samples are found in Table 13.

Table 13. Cronbach's alpha for scales and subscales of the BDS, BES, and PBRS in

\section{Study 2.}

\begin{tabular}{lccc}
\hline Measure & Items & $\begin{array}{c}\text { Sample A } \\
(N=299)\end{array}$ & $\begin{array}{c}\text { Sample B } \\
(N=296)\end{array}$ \\
\hline BDS & 16 & .96 & .96 \\
BES & 15 & .72 & .74 \\
Negative Emotions Index & 9 & .89 & .91 \\
Positive Emotions Index & 6 & .88 & .86 \\
PBRS & 21 & .95 & .96 \\
\hline
\end{tabular}

Note . BDS = Breakup Distress Scale. BES = Breakup Emotions Scale. PBRS = PostBreakup Recovery and Personal Growth Scale.

\subsubsection{Breakup Emotions (BES)}

Sprecher's (1994) breakup emotions scale included nine negative valence items (e.g., anger, frustration) and six positive valence items (e.g., relief, satisfaction). Participants 
were instructed to rate on a 7 -point scale $(1=$ not at all, $7=$ extremely $)$ the degree to which they experienced each emotion initially after the breakup. Negative valence items were averaged to obtain the Negative Emotions index. Positive valence items were averaged to obtain the Positive Emotions index. The Breakup Emotions index was calculated by taking the difference between the Positive Emotions Index and the Negative Emotions Index, with positive scores indicating negative emotions were experienced to a greater degree, and negative scores indicating that positive emotions were experienced to a greater degree. Table 13 shows reliability estimates for each index for both samples.

\subsubsection{Post-Breakup Recovery and Personal Growth (PBRS)}

Tedseschi and Calhoun (1996) created the 21-item Posttraumatic Growth Inventory to measure the type and extent of personal life changes experienced after the occurrence of a traumatic event. Tashiro and Frazier (2003) modified the instructions of the scale to assess how much life change had been experienced in different areas as a result of a romantic relationship breakup. Example items include "I'm more likely to try to change things which need changing" and "Having compassion for others." Items were rated on a scale of 1 (I did not experience this) to 6 (I experienced this to a very great degree). All items were averaged to obtain an overall post-breakup recovery and growth score, with higher scores indicating greater experiences of or greater variety of benefits resulting from the process of post-breakup recovery and growth. Table 13 shows reliability estimates of the PBRS scale for both samples.

\subsection{Sample A}

\subsubsection{Participants}

Sample A contained 299 participants $\left(M_{\text {age }}=25.87, S D_{\text {age }}=4.13\right)$, with 131 identifying as male, 166 identifying as female, and two identifying otherwise. The direct disengager, ghosting disengager, and ghosting recipient groups each had 75 participants, and the direct recipient group had 74 participants. The majority of participants identified as heterosexual (83.6\%), with 14\% identifying as lesbian, gay or bisexual, and $2.3 \%$ identifying otherwise. 
Of the breakups used to inform the participants' responses, 117 (39.1\%) ended between 3 and 6 months before the time of study completion, 110 (36.8\%) ended between a month and 3 months before, 53 (17.7\%) ended between a week and a month before, and 19 (6.4\%) ended within a week prior to completing the study. Online dating sites or applications were how $106(35.5 \%)$ participants met their partners, and 191 (63.9\%) met offline, either meeting by chance in person (70), being introduced through a friend or family member (58), or meeting at school or work (63). One participant met their partner online (not a dating site), and another participant's response was ambiguous as to whether they met their partner online or offline. The majority of relationships before the breakups were characterized as serious or exclusively dating relationships $(65.2 \%)$, with $27.4 \%$ being casual or non-exclusively dating relationships and $5.4 \%$ being friends-with-benefits or casual sex relationships. On average, participants self-reported commitment to their partners before the breakup was relatively high $(M=5.08, S D=1.61)$, and the length of the relationships ranged from less than a week to more than a year $\left(M_{\text {weeks }}=31.12\right.$, $\left.S D_{\text {weeks }}=25.68\right)$.

\subsubsection{Results}

All of the following analyses were conducted with SPSS (version 25.0.0.0). A series of 2 $\mathrm{X} 2$ factorial ANOVAs were conducted to assess whether use of certain breakup tactics, breakup distress, positive and negative emotions, and post-breakup recovery and personal growth could be predicted from breakup strategy (direct conversation or ghosting), breakup role (disengager or recipient) and the interaction between strategy and role. Two MANOVAs (and subsequently, Welch's robust tests of equality of means) were conducted to assess differences between self-reported (disengagers) and perceived (recipients) motivations for breakup strategy choice for relationships that ended through direct conversations and through ghosting.

Preliminary data screening was done to assess whether the assumptions of factorial ANOVA or MANOVA were seriously violated prior to conducting the following analyses, respectively. Histograms of all the dependent variables were obtained, and skewness and kurtosis values that exceeded -1.5 or 1.5 (cutoffs for normally distributed variables; Tabachnick \& Fidell, 2007) were noted, however, no adjustments were made 
unless Levene's test of homogeneity of variance (factorial ANOVA) or Box's $M$ test (MANOVA) were also violated. For the following analyses all assumptions were satisfied, unless otherwise specified. The adjustments made to account for violations of assumptions are described where necessary.

\subsubsection{Breakup Tactics: Avoidance/Withdrawal}

A significant main effect of breakup strategy emerged with a large effect size, such that relationships dissolved through ghosting incurred higher reports of avoidance/withdrawal tactics than relationships dissolved directly. In addition, a significant main effect of breakup role emerged, such that disengagers reported utilizing avoidance/withdrawal tactics more often than recipients reported perceiving, however, the effect size was small. The interaction between breakup strategy and role was non-significant (see Table 14 for means and standard deviations, and Table 15 for ANOVA summary statistics).

Table 14. Proportion of use or perceived use of each breakup tactic in Sample A.

\begin{tabular}{|c|c|c|c|c|c|c|}
\hline \multirow[b]{3}{*}{ Tactic } & \multicolumn{4}{|c|}{ Breakup Strategy } & \multirow{2}{*}{\multicolumn{2}{|c|}{ Total }} \\
\hline & \multicolumn{2}{|c|}{$\begin{array}{c}\text { Direct } \\
\text { Conversation }\end{array}$} & \multicolumn{2}{|c|}{ Ghosting } & & \\
\hline & $M$ & $S D$ & $M$ & $S D$ & $M$ & $S D$ \\
\hline \multicolumn{7}{|c|}{ Avoidance/Withdrawal } \\
\hline Disengager & .417 & .268 & .679 & .250 & .548 & .290 \\
\hline Recipient & .403 & .270 & .560 & .242 & .482 & .267 \\
\hline Total & .410 & .268 & .619 & .252 & .515 & .280 \\
\hline \multicolumn{7}{|c|}{ Open Confrontation } \\
\hline Disengager & .790 & .285 & .203 & .304 & .497 & .416 \\
\hline Recipient & .713 & .283 & .160 & .278 & .435 & .394 \\
\hline Total & .752 & .285 & .182 & .291 & .466 & .405 \\
\hline \multicolumn{7}{|c|}{ Distant/Mediated Communication } \\
\hline Disengager & .193 & .277 & .513 & .305 & .353 & .332 \\
\hline Recipient & .220 & .292 & .547 & .290 & .384 & .333 \\
\hline Total & .206 & .284 & .530 & .297 & .369 & .332 \\
\hline \multicolumn{7}{|c|}{ De-escalation } \\
\hline Disengager & .365 & .300 & .405 & .303 & .385 & .301 \\
\hline Recipient & .287 & .259 & .267 & .295 & .277 & .277 \\
\hline Total & .326 & .282 & .336 & .306 & .331 & .294 \\
\hline \multicolumn{7}{|c|}{ Positive Tone/Self-Blame } \\
\hline Disengager & .517 & .304 & .270 & .277 & .393 & .315 \\
\hline Recipient & .479 & .312 & .218 & .281 & .348 & .323 \\
\hline Total & .498 & .307 & .244 & .279 & .371 & .319 \\
\hline
\end{tabular}




\section{Cost Escalation}

Disengager

$\begin{array}{lll}.247 & .271 & .420\end{array}$

Recipient

$\begin{array}{lll}.362 & .347 & .287\end{array}$

.347

$.333 \quad .322$

Total

.304

.315

.353

.307

$.324 \quad .328$

Manipulation

Disengager

.189

.170

.248

.317

.333

$.329 \quad .325$

Recipient

.180

.268

.279

$.253 \quad .271$

Total

.258

.221

.293

$.196 \quad .281$

Note. Cost escalation descriptive statistics are not transformed for ease of interpretation.

Table 15. Factorial ( 2 X 2) ANOVA results for use or perceived use of each breakup tactic as a function of breakup role $(R)$ and breakup strategy $(S)$ in Sample A.

\begin{tabular}{lcccccc}
\hline Tactic & $F_{\text {Role }}$ & $\omega^{2}$ & $F_{\text {Strategy }}$ & $\omega^{2}$ & $F_{R x S}$ & $\omega^{2}$ \\
\hline Avoidance/Withdrawal & $4.96^{*}$ & .011 & $49.36^{* * *}$ & .137 & 3.09 & .006 \\
Open Confrontation & 3.28 & .004 & $293.58^{* * *}$ & .491 & 0.26 & -.001 \\
Distant/Mediated Communication & 0.78 & -.001 & $92.27^{* * *}$ & .282 & 0.01 & -.003 \\
De-escalation & $10.53^{* *}$ & .031 & 0.09 & -.003 & 0.80 & -.001 \\
Positive Tone/Self-blame & 1.75 & .002 & $56.12^{* * *}$ & .156 & 0.04 & -.003 \\
Cost Escalation $\dagger$ & 0.13 & -.003 & 0.95 & -.000 & $9.14 * *$ & .026 \\
Manipulation & 3.33 & .008 & $8.06^{* *}$ & .023 & 1.49 & .002 \\
\hline
\end{tabular}

Note. $* p<.05 . * * p<.01 . * * * p<.001 . \dagger$ A square root transformation was applied to the variable.

\subsubsection{Breakup Tactics: Open Confrontation}

A main effect of breakup strategy was found such that breakups facilitated by direct conversations elicited higher use of open confrontation tactics than relationships that ended through ghosting. The effect size was very large (see Table 15). In contrast, a main effect of breakup role was not found. Disengagers reported greater use of open confrontation than recipients, however, the difference did not reach significance (see Table 14). The interaction between breakup strategy and role was not statistically significant.

\subsubsection{Breakup Tactics: Distant/Mediated Communication}

A significant difference was found for breakup strategy such that relationships that ended through ghosting reported greater use of distant/mediated communication tactics than relationships that ended directly (see Table 14). The effect size was large. No significant difference was found for breakup role, nor the interaction between breakup strategy and role (see Table 15). 


\subsubsection{Breakup Tactics: De-escalation}

A main effect of strategy was not found for de-escalation tactics. A main effect of role was found with a small effect size, such that disengagers reported significantly higher use of de-escalation tactics than recipients reported perceiving (see Table 14). The interaction between strategy and role was not significant (see Table 15).

\subsubsection{Breakup Tactics: Positive Tone/Self-Blame}

Only a main effect of breakup strategy was found for positive tone/self-blame, which showed a large effect size (see Table 15). Direct breakups elicited greater reported use of positive tone/self-blame tactics than ghosting breakups (see Table 14).

\subsubsection{Breakup Tactics: Cost Escalation}

Levene's test of homogeneity of variance was violated for cost escalation. According to recommendations from Tabachnick and Fidell (2007) the skewness was evaluated and was found to be moderately positively skewed. To correct for this violation, a square root transformation was applied to the variable. The 2 X 2 ANOVA was rerun using the transformed data, and Levene's test was shown to be non-significant.

Results showed a significant interaction between breakup strategy and role with a small effect size (see Table 15), such that ghosting disengagers reported using cost escalation tactics significantly more than ghosting recipients perceived (see Table 14). No significant difference emerged between direct disengagers and direct recipients.

\subsubsection{Breakup Tactics: Manipulation}

Results showed a main effect of breakup strategy with a small effect size, such that relationships that ended through ghosting elicited greater reports of manipulation tactic use than relationships that ended directly (see Table 14). No support was found for a main effect of breakup role nor an interaction between strategy and role (see Table 15). 


\subsubsection{Breakup Motivations: Direct Conversation Strategy}

A MANOVA was planned to analyze the differences in the motivation factors of the direct MBSC as a function of breakup role. Preliminary data screening indicated that Box's $M$ test was non-significant, meaning the assumption of homogeneity of variance/covariance matrices across conditions was satisfied. Intercorrelations between the factors ranged from .083 to .332 and were deemed not sufficiently large enough to raise concern about multicollinearity (see Table 16). Though Box's $M$ test was not significant, the third factor done with relationship violated Levene's test of homogeneity of variance. As a conservative measure, the MANOVA was abandoned in favor of a series of one-way Welch's robust tests of equality of means which are more resilient when data violates assumptions (Field, 2013).

Table 16. Correlation coefficients for relations among the direct MBSC factors in Sample A.

\begin{tabular}{lcc}
\hline Factors & Clarity and Understanding & Done with Relationship \\
\hline Gentle Breakup & $.332^{* *}$ & .083 \\
Clarity and Understanding & -- & $-.225^{* *}$ \\
\hline
\end{tabular}
Note. $* * p<.01$.

Disengagers reported clarity and understanding motivations to be the most influential in their decision to choose to have a direct conversation to facilitate their breakups followed by gentle breakup motivations and then done with relationship motivations. An identical pattern was also perceived by recipients (see Table 17).

Specifically, no significant difference emerged between disengagers and recipients in terms of self-reported or perceived motivations to have a direct breakup in order to facilitate a gentle separation, Welch's $F(1,144.86)=1.50, p>.05$. However, a significant difference did emerge for the second factor, clarity and understanding, such that disengagers reported these items as more influential in their decision to have a direct breakup than recipients believed, Welch's $F(1,143.41)=10.50, p=.001$, est. $\omega^{2}=.060$. For the third factor, results indicated disengagers and recipients similarly rated the influence of the disengager feeling done with the relationship, Welch's $F(1,143.61)=$ $0.04, p>.05$. 
Table 17. Mean scores and standard deviations of the direct MBSC factors as a function of breakup role in Sample A.

\begin{tabular}{lcccccc}
\hline & \multicolumn{6}{c}{ Factors } \\
\cline { 2 - 7 } & Gentle Breakup & \multicolumn{1}{c}{ Clarity and Understanding } & Done with Relationship \\
\cline { 2 - 7 } Role & $M$ & $S D$ & $M$ & $S D$ & $M$ & $S D$ \\
\hline Disengagers & 4.23 & 1.35 & 5.29 & 1.27 & 3.02 & 1.54 \\
Recipients & 3.94 & 1.51 & 4.56 & 1.47 & 3.07 & 1.30 \\
\hline
\end{tabular}

\subsubsection{Breakup Motivations: Ghosting Strategy}

A MANOVA was planned to analyze the differences in the motivation factors of the ghosting MBSC as a function of breakup role. Preliminary data screening indicated that intercorrelations between the factors ranged from .051 to .325 and were deemed not sufficiently large enough to raise concern about multicollinearity (see Table 18).

However, Box's $M$ test was significant, meaning the assumption of homogeneity of variance/covariance matrices across conditions was not satisfied. In addition, the second factor done with relationship violated Levene's test of homogeneity of variance. A series of one-way Welch's robust tests of equality of means were conducted for each factor to account for the inequality of variances.

Table 18. Correlation coefficients for relations among the ghosting MBSC factors in Sample A.

\begin{tabular}{lccc}
\hline Factors & $\begin{array}{c}\text { Done with } \\
\text { Relationship }\end{array}$ & Guilt & $\begin{array}{c}\text { Anticipated a } \\
\text { Difficult Breakup }\end{array}$ \\
\hline Avoidance & $.235^{* *}$ & $.325^{* *}$ & .051 \\
Done with Relationship & -- & $.211^{* *}$ & .148 \\
Guilt & -- & -- & .115 \\
\hline Note. ${ }^{* *} p<.01$. & & &
\end{tabular}

Disengagers reported the motivation factors of avoidance, done with the relationship, and anticipated a difficult breakup were similarly influential in their decision to ghost their partner, with the guilt factor not attaining as much importance. Recipients' perceptions of influential motivations of the disengagers' decision to ghost were more sporadic. Avoidance and done with relationship were also perceived as most influential by recipients, and a similar level of influence as the disengagers was attributed to guilt, 
however, recipients perceived the least influential motivation to be anticipated a difficult breakup, while disengagers reported this as more moderately influential (see Table 19).

The reported influence of avoidance motivations contributing to the disengagers' decision to ghost their partners was consistent between disengagers and recipients, Welch's $F(1,147.82)=0.64, p>.05$. A significant inconsistency regarding the influence of the disengager feeling done with the relationship was found, such that disengagers reported these motivations to be more influential than recipients perceived them to be, Welch's $F(1,133.77)=7.21, p=.008$, est. $\omega^{2}=.040$. No significant difference emerged between disengagers and recipients in terms of the motivation factor of guilt, Welch's $F(1,147.74)=1.25, p>.05$. Motivations representing the anticipated a difficult breakup factor were rated as significantly different between disengagers and recipients, such that disengagers reported these items as more influential in their decision to ghost their partners than recipients believed, Welch's $F(1,147.73)=29.58, p<.001$, est. $\omega^{2}=.160$.

Table 19. Mean scores and standard deviations of the ghosting MBSC factors as a function of breakup role in Sample A.

\begin{tabular}{lcccccccc}
\hline & \multicolumn{1}{c}{ Factors } \\
\cline { 2 - 9 } & \multicolumn{1}{c}{$\begin{array}{c}\text { Avoidance } \\
\text { Role }\end{array}$} & \multicolumn{1}{c}{$\begin{array}{c}\text { Done with } \\
\text { Relationship }\end{array}$} & \multicolumn{2}{c}{ Guilt } & \multicolumn{2}{c}{$\begin{array}{c}\text { Anticipated a } \\
\text { Difficult Breakup }\end{array}$} \\
\cline { 2 - 10 } & $M$ & $S D$ & $M$ & $S D$ & $M$ & $S D$ & $M$ & $S D$ \\
\hline Disengagers & 4.62 & 1.33 & 4.64 & 1.58 & 3.84 & 1.58 & 4.25 & 1.56 \\
Recipients & 4.79 & 1.38 & 4.04 & 1.12 & 3.55 & 1.64 & 2.90 & 1.49 \\
\hline
\end{tabular}

\subsubsection{Breakup Distress}

A main effect of breakup strategy was found with direct breakups eliciting greater distress than ghosting breakups, however, the effect size was small. A main effect of breakup role with a large effect size was found, with recipients reporting significantly greater distress than disengagers. An interaction between strategy and role was also found, albeit with a small effect size (see Table 21). Recipients experienced similar amounts of breakup distress across breakup strategy, however, direct disengagers experienced significantly greater distress than ghosting disengagers (see Table 20). 
Table 20. Descriptive statistics of the BDS, BES, and PBRS in Sample A.

\begin{tabular}{|c|c|c|c|c|c|c|}
\hline \multirow[b]{3}{*}{ Measure } & \multicolumn{4}{|c|}{ Breakup Strategy } & & \\
\hline & \multicolumn{2}{|c|}{$\begin{array}{c}\text { Direct } \\
\text { Conversation } \\
\end{array}$} & \multicolumn{2}{|c|}{ Ghosting } & \multicolumn{2}{|c|}{ Total } \\
\hline & $M$ & $S D$ & $M$ & $S D$ & $M$ & $S D$ \\
\hline \multicolumn{7}{|l|}{ BDS } \\
\hline Disengager & 2.12 & 0.75 & 1.77 & 0.69 & 1.94 & 0.74 \\
\hline Recipient & 2.74 & 0.76 & 2.73 & 0.73 & 2.73 & 0.74 \\
\hline Total & 2.42 & 0.81 & 2.25 & 0.86 & 2.34 & 0.84 \\
\hline \multicolumn{7}{|l|}{ BES } \\
\hline Disengager & -0.12 & 1.88 & -0.98 & 1.89 & -0.55 & 1.92 \\
\hline Recipient & 2.35 & 1.83 & 2.45 & 1.99 & 2.40 & 1.90 \\
\hline Total & 1.11 & 2.22 & 0.73 & 2.59 & 0.92 & 2.42 \\
\hline \multicolumn{7}{|l|}{ PBRS } \\
\hline Disengager & 3.58 & 1.07 & 3.41 & 1.07 & 3.50 & 1.07 \\
\hline Recipient & 3.39 & 1.08 & 3.28 & 1.26 & 3.34 & 1.17 \\
\hline Total & 3.49 & 1.07 & 3.35 & 1.17 & 3.42 & 1.12 \\
\hline
\end{tabular}

Note. BDS = Breakup Distress Scale, BES = Breakup Emotions Scale, PBRS = PostBreakup Recovery and Personal Growth Scale. Negative scores on the BES represent more positive emotions. Positive scores on the BES represent more negative emotions.

Table 21. Factorial ( $2 \times$ 2) ANOVA results for the BDS, BES, and PBRS as a function of breakup role (R) and breakup strategy (S) in Sample A.

\begin{tabular}{lrrlrrr}
\hline Measure & $F_{\text {Role }}$ & $\omega^{2}$ & $F_{\text {Strategy }}$ & $\omega^{2}$ & $F_{R x S}$ & $\omega^{2}$ \\
\hline BDS & $85.91^{* * *}$ & .217 & $4.22^{*}$ & .008 & $3.92^{*}$ & .007 \\
BES & $181.13^{* * *}$ & .371 & 3.09 & .004 & $4.77^{*}$ & .008 \\
PBRS & 1.50 & .002 & 1.16 & .001 & 0.05 & -.003 \\
\hline
\end{tabular}

Note. $* p<.05 . * * * p<.001$.

\subsubsection{Positive and Negative Affect}

No significant difference emerged between breakups that ended directly and breakups that ended through ghosting in terms of positive and negative affect. However, a main effect of breakup role was significant with a large effect size, such that recipients reported much greater negative affect than disengagers. An interaction was also found with a small effect size (see Table 21). Recipients experienced similar amounts of negative affect, however, direct disengagers experienced significantly more negative affect than ghosting disengagers (see Table 20). 


\subsubsection{Post-Breakup Recovery and Personal Growth}

No main effects or interactions were significant for post-breakup recovery and personal growth (see Table 20 and Table 21).

\subsubsection{Exploration of Covariates: Relationship Length and Commitment}

A significant main effect of breakup strategy emerged when relationship length was treated as a dependent variable, such that breakups that ended through ghosting $\left(M_{\text {weeks }}=\right.$ $\left.25.16, S D_{\text {weeks }}=25.46\right)$ were significantly shorter than relationships that ended directly $\left(M_{\text {weeks }}=37.16, S D_{\text {weeks }}=24.54\right), F(1,294)=17.10, p<.001, \omega^{2}=.051$.

When commitment was treated as a dependent variable a main effect of breakup strategy was found, such that direct relationships $(M=5.58, S D=1.46)$ had significantly higher reported commitment than relationships that ended through ghosting $(M=4.57, S D=$ 1.59), $F(1,294)=35.08, p<.001, \omega^{2}=.096$. In addition, a main effect of breakup role was significant, such that recipients $(M=5.44, S D=1.39)$ reported significantly greater commitment prior to the breakup than disengagers $(M=4.71, S D=1.72), F(1,295)=$ $18.36, p<.001, \omega^{2}=.049$.

When relationship length and commitment were independently added as covariates to the 2 X 2 factorial ANOVAs above, a few notable changes in statistical significance emerged.

The significant main effect of breakup strategy and the interaction between breakup role and breakup strategy on breakup distress became non-significant when relationship length and commitment were added as covariates.

The interaction between breakup strategy and breakup role for positive and negative affect remained statistically significant when relationship length was added as a covariate but became non-significant when commitment was added as a covariate.

No significant main effects or interactions were found for post-breakup personal growth when there were no covariates or when relationship length was added as a covariate, 
however, a significant main effect of breakup role emerged when commitment was added as a covariate, such that disengagers reported significantly greater post-breakup personal growth than recipients.

All other main effects and interactions were not affected by adding relationship length or commitment as covariates (see Table 22).

Table 22. Factorial ( 2 X 2) ANOVA results without covariates and results with relationship length and commitment as covariates in Sample A.

\begin{tabular}{|c|c|c|c|c|c|c|}
\hline \multirow[b]{3}{*}{ Measure } & \multicolumn{6}{|c|}{ Covariates } \\
\hline & \multicolumn{2}{|c|}{ No Covariates } & \multicolumn{2}{|c|}{ Length } & \multicolumn{2}{|c|}{ Commitment } \\
\hline & $F$ & $\omega^{2}$ & $F$ & $\omega^{2}$ & $F$ & $\omega^{2}$ \\
\hline \multicolumn{7}{|c|}{ Avoidance/Withdrawal } \\
\hline Role (R) & $4.96^{*}$ & .011 & $4.88 *$ & .011 & $6.07 *$ & .014 \\
\hline Strategy $(\mathrm{S})$ & $49.36 * * *$ & .137 & $49.94 * * *$ & .137 & $49.72 * * *$ & .137 \\
\hline Interaction R X S & 3.09 & .006 & 3.37 & .007 & 3.53 & .007 \\
\hline \multicolumn{7}{|c|}{ Open Communication } \\
\hline Role & 3.28 & .004 & 3.52 & .004 & 3.27 & .004 \\
\hline Strategy & $293.58 * * *$ & .491 & $273.02 * * *$ & .473 & $259.17 * * *$ & .461 \\
\hline Interaction $\mathrm{R} \mathrm{X} \mathrm{S}$ & 0.26 & -.001 & 0.28 & -.001 & 0.23 & -.001 \\
\hline \multicolumn{7}{|l|}{ Cost Escalation } \\
\hline Role & 0.13 & -.003 & 0.14 & -.003 & 0.56 & -.001 \\
\hline Strategy & 0.95 & -.000 & 3.51 & .008 & 2.14 & .004 \\
\hline Interaction $\mathrm{R} \mathrm{X} \mathrm{S}$ & $9.14 * *$ & .026 & $11.23 * *$ & .033 & $10.16 * *$ & .030 \\
\hline \multicolumn{7}{|l|}{ Distant/Mediated } \\
\hline \multicolumn{7}{|l|}{ Communication } \\
\hline Role & 0.78 & -.001 & 0.85 & -.000 & 0.05 & -.002 \\
\hline Strategy & $92.27 * * *$ & .282 & $92.84 * * *$ & .234 & $100.88 * * *$ & .251 \\
\hline Interaction R X S & 0.01 & -.003 & 0.98 & -.001 & 0.03 & -.002 \\
\hline \multicolumn{7}{|l|}{ Manipulation } \\
\hline Role & 3.34 & .008 & 3.27 & .007 & 2.81 & .006 \\
\hline Strategy & 8.06** & .023 & $12.49 * * *$ & .037 & $6.55 *$ & .018 \\
\hline Interaction R X S & 1.49 & .002 & 2.22 & .004 & 1.38 & .001 \\
\hline \multicolumn{7}{|l|}{ De-escalation } \\
\hline Role & $10.53 * *$ & .031 & $10.35 * *$ & .030 & $10.95 * *$ & .032 \\
\hline Strategy & 0.09 & -.003 & 0.78 & -.001 & 0.25 & -.002 \\
\hline Interaction R X S & 0.80 & -.001 & 1.24 & .001 & 0.92 & -.000 \\
\hline \multicolumn{7}{|l|}{ Positive Tone/Self- } \\
\hline \multicolumn{7}{|l|}{ Blame } \\
\hline Role & 1.75 & .002 & 1.95 & .003 & 1.75 & .002 \\
\hline
\end{tabular}




\begin{tabular}{lcccccc}
\hline Strategy & $56.12 * * *$ & .156 & $50.59 * * *$ & .142 & $49.25 * * *$ & .139 \\
Interaction R X S & 0.04 & -.003 & 0.04 & -.003 & 0.05 & -.003 \\
Breakup Distress & & & & & & \\
Role & $85.91 * * *$ & .217 & $94.15 * * *$ & .236 & $64.03 * * *$ & .174 \\
Strategy & $\mathbf{4 . 2 2} *$ & $\mathbf{. 0 0 8}$ & $\mathbf{0 . 4 4}$ & $\mathbf{- . 0 0 1}$ & $\mathbf{0 . 0 4}$ & $\mathbf{- . 0 0 3}$ \\
Interaction R X S & $\mathbf{3 . 9 2} *$ & $\mathbf{. 0 0 7}$ & $\mathbf{2 . 8 3}$ & $\mathbf{. 0 0 5}$ & $\mathbf{1 . 9 3}$ & $\mathbf{. 0 0 3}$ \\
Breakup Emotions & & & & & & \\
Role & $181.13 * * *$ & .371 & $180.21 * * *$ & .371 & $154.93 * * *$ & .338 \\
Strategy & 3.09 & .004 & 1.75 & .002 & 0.27 & -.002 \\
Interaction R X S & $\mathbf{4 . 7 7 *}$ & $\mathbf{. 0 0 8}$ & $\mathbf{4 . 3 0 *}$ & $\mathbf{. 0 0 7}$ & $\mathbf{3 . 3 8}$ & $\mathbf{. 0 0 5}$ \\
Post-Breakup Personal & & & & & & \\
Growth & & & & & & \\
Role & $\mathbf{1 . 4 9}$ & $\mathbf{. 0 0 2}$ & $\mathbf{1 . 6 0}$ & $\mathbf{. 0 0 2}$ & $\mathbf{6 . 9 8} * *$ & $\mathbf{. 0 2 0}$ \\
Strategy & 1.16 & .001 & 0.31 & -.002 & 0.65 & -.001 \\
Interaction R X S & 0.05 & -.003 & 0.92 & -.003 & 0.13 & -.003 \\
\hline
\end{tabular}

Note. ${ }^{*} p<.05 . * * * p<.001$. Bolded rows indicate a change in statistical significance with the addition of a covariate.

\subsubsection{Results Summary}

Multiple main effects of breakup strategy emerged, with avoidance/withdrawal, distant/mediated communication, and manipulation breakup tactics being used significantly more often in breakups that ended through ghosting as compared to those that ended directly. In contrast, open confrontation and positive tone/self-blame strategies were implemented more often in direct breakups. Direct breakups had also lasted longer, involved partners who were more committed to each other, and were characterized by greater post-breakup distress than ghosting breakups.

Differences in breakup role were observed as well, with disengagers reporting greater use of avoidance/withdrawal and de-escalation breakup tactics than recipients perceived. Recipients also reported significantly greater breakup distress, negative affect, and commitment than disengagers. Direct disengagers reported that the motivation to ensure clarity and understanding during the breakup influenced their decision to have a direct breakup more than direct recipients believed. For ghosting breakups, ghosting disengagers reported being done with the relationship and the anticipation that a direct breakup would be difficult as greater influences in their decision to ghost than ghosting recipients perceived. 
Interactions between breakup role and breakup strategy were found for cost escalation, breakup distress and positive and negative affect, however all had minimal effect sizes. Ghosting disengagers reported significantly greater use of cost escalation than ghosting recipients perceived, but direct recipients perceived greater use of cost escalation than direct disengagers reported, however this difference did not reach significance. For breakup distress and positive and negative affect, regardless of breakup strategy, recipients reported similar levels of distress, while ghosting disengagers reported significantly less distress and significantly more positive affect than direct disengagers.

\subsection{Sample B}

Sample A was intended as a focused exploration of the influence of breakup strategy and breakup role on a variety of dependent variables relevant to the experience of a romantic relationship breakup. As the purpose of the exploration was to observe what differences emerged, the experiment-wise alpha level was not controlled, meaning Type I error was left unrestrained. The purpose of Sample B was to construct hypotheses based on select findings the researchers were willing to "bet on" and subject these hypotheses to a more stringent test to increase the confidence in the existence and strength of the results that were found in both in the first and second sample.

The Holm-Bonferroni correction method (Cramer et al., 2016; Hartley, 1955) was implemented to maintain an experiment-wise Type I error rate of 5\%. Following the Holm-Bonferroni method, all the $p$ values for each confirmatory analysis were ordered from smallest to largest. The alpha level (.05) was divided by the total number of tests (15) and compared to the smallest of the $p$ values. Obtained p-values lower than the predetermined alpha level for each respective analysis indicated statistical significance. If the $p$ value was smaller than the alpha, the null hypothesis was rejected, and the alternative hypothesis was accepted. The next smallest $p$ value was then compared to alpha (.05) divided by one less test than before $(15-1=14)$. Again, the obtained $p$ value was compared to that alpha level and the null hypothesis was either rejected or retained. Each subsequent hypothesis was tested in this manner until a hypothesis was unable to be rejected. At this point, no other hypotheses were tested, and it was concluded that the remaining hypotheses had inadequate support to reject the null. A summary of the 
hypotheses, the obtained $p$ values, the Holm-Bonferroni adjusted critical values, and whether or not the hypotheses were supported can be found in the results summary in section 3.4.3.14 (see Table 32). Explorations of relationships not explicitly hypothesized about in a confirmatory manner are described as well. Exploratory findings are interpreted without controlling for Type I error, meaning exploratory findings that attained a $p$ value of less than .05 were considered significant and interpreted as such.

\subsubsection{Hypotheses}

\subsubsection{Breakup Tactics: Avoidance/Withdrawal}

H1.1a: There will be a main effect for breakup strategy on avoidance/withdrawal tactics used during the breakup, such that relationships dissolved through ghosting will elicit higher proportions of avoidance/withdrawal strategies than relationships dissolved through direct conversations.

H1.1b: There will be a main effect for breakup role on use or perceived use of avoidance/withdrawal tactics such that disengagers will report higher proportions of use of avoidance/withdrawal tactics than recipients will report perceiving.

\subsubsection{Breakup Tactics: Open Confrontation}

H1.2: There will be a main effect for breakup strategy on open confrontation tactics used during the breakup, such that relationships dissolved through direct conversations will elicit higher proportions of open confrontation tactics than relationships dissolved through ghosting.

\subsubsection{Breakup Tactics: Distant/Mediated Communication}

\section{H1.3: There will be a main effect for breakup strategy on distant/mediated} communication tactics used during the breakup, such that relationships dissolved through ghosting will elicit higher proportions of distant/mediated communication tactics than relationships dissolved through direct conversations. 


\subsubsection{Breakup Tactics: De-escalation}

H1.4: There will be a main effect for breakup role on use or perceived use of $d e$ escalation tactics, such that breakup disengagers will report higher proportions of use of de-escalation tactics than breakup recipients.

\subsubsection{Breakup Tactics: Positive Tone/Self-blame}

H1.5: There will be a main effect for breakup strategy on positive tone/self-blame tactics used during the breakup, such that relationships dissolved through direct conversations will elicit higher proportions of positive tone/self-blame tactics than relationships dissolved through ghosting.

\subsubsection{Breakup Tactics: Cost Escalation}

H1.6: There will be an interaction between breakup strategy and breakup role on use or perceived use of cost escalation tactics, such that ghosting disengagers will report higher use than direct disengagers (H1.6a), but direct recipients will report greater perceived use than ghosting recipients $(\mathbf{H 1}$.6b).

\subsubsection{Breakup Tactics: Manipulation}

H1.7: There will be a main effect for breakup strategy on manipulation tactics used during the breakup, such that relationships dissolved through ghosting will elicit higher proportions of manipulation tactics than relationships dissolved through direct conversations.

\subsubsection{Breakup Motivations: Direct Conversation Strategy}

H2.1: A significant difference in motivations and perceived motivations is expected between direct disengagers and direct recipients for clarity and understanding, such that disengagers will report these motivations as more influential in their decision to end their relationships directly than recipients perceived. 


\subsubsection{Breakup Motivations: Ghosting Strategy}

H2.2a: A significant difference in motivations and perceived motivations is expected between ghosting disengagers and ghosting recipients for done with relationship, such that disengagers will report these motivations as more influential in their decision to end their relationships through ghosting than recipients perceived.

H2.2b: A significant difference in motivations and perceived motivations is expected between ghosting disengagers and ghosting recipients for anticipated a difficult breakup, such that disengagers will report these motivations as more influential in their decision to end their relationships through ghosting than ghosting recipients perceived it to be.

\subsubsection{Breakup Distress}

H3.1a: There will be a main effect for breakup role on reported amount of breakup distress, such that recipients will be more distressed than disengagers.

\subsubsection{Positive and Negative Affect}

H4.1a: There will be a main effect for breakup role on reported amount of positive and negative affect, such that recipients will report more negative affect than disengagers.

\subsubsection{Post-Breakup Personal Growth}

No confirmatory hypotheses were made.

\subsubsection{Participants}

Sample B contained 296 participants $\left(M_{\text {age }}=25.64, S D_{\text {age }}=4.08\right)$, with 122 identifying as male, 173 identifying as female, and one identifying otherwise. All four conditions had 74 participants. A large majority of the participants identified as heterosexual (82.8\%), with $17.2 \%$ identifying as lesbian, gay or bisexual.

Of the breakups that informed the participants' responses, 109 (36.8\%) ended between 3 and 6 months before the time of study completion, 110 (37.2\%) ended between a month and 3 months before, 68 (23\%) ended between a week and a month before, and $9(3 \%)$ ended within a week prior to completing the study. Online dating sites or applications 
were how $101(34.1 \%)$ participants met their partners, and 192 (64.9\%) met offline, either meeting by chance in person (67), being introduced through a friend or family member (65), or meeting at school or work (60). Two participants met their partners through social media, and another participant met their partner through a video game. The majority of relationships before the breakups were characterized as serious or exclusively dating relationships (65.2\%), with $26.4 \%$ being casual or non-exclusively dating relationships and $7.4 \%$ being friends-with-benefits or casual sex relationships. On average, participants self-reported commitment to their partners was relatively high $(M=$ $5.17, S D=1.51$ ), and the length of the relationships ranged from less than a week to more than a year $\left(M_{\text {weeks }}=32.13, S D_{\text {weeks }}=25.62\right)$.

\subsubsection{Results}

\subsubsection{Breakup Tactics: Avoidance/Withdrawal}

Main effects of breakup strategy (H1.1a) and breakup role (H1.1b) were hypothesized, however, results indicated support only for breakup strategy with a moderate effect size, such that avoidance/withdrawal tactics were more highly reported in ghosting breakups than direct conversation breakups. The interaction between role and strategy was not significant (see Table 23 for means and standard deviations, and Table 24 for ANOVA summary statistics).

Table 23. Proportion of use or perceived use of each breakup tactic in Sample B.

\begin{tabular}{llllllll}
\hline & \multicolumn{3}{c}{ Breakup Strategy } & \\
\cline { 2 - 6 } & \multicolumn{3}{c}{$\begin{array}{c}\text { Direct } \\
\text { Conversation }\end{array}$} & \multicolumn{1}{c}{ Ghosting } & \multicolumn{2}{c}{ Total } \\
\cline { 2 - 6 } Tactic & $M$ & $S D$ & $M$ & $S D$ & $M$ & $S D$ \\
\hline Avoidance/Withdrawal & & & & & & \\
Disengager & .449 & .289 & .654 & .279 & .551 & .301 \\
Recipient & .464 & .311 & .548 & .270 & .506 & .293 \\
Total & .457 & .299 & .601 & .279 & .529 & .298 \\
Open Confrontation & & & & & & \\
Disengager & .750 & .326 & .142 & .278 & .446 & .429 \\
Recipient & .726 & .318 & .118 & .231 & .422 & .412 \\
Total & .738 & .321 & .130 & .255 & .434 & .420 \\
Distant/Mediated Communication & & & & & & & \\
Disengager & .206 & .272 & .480 & .286 & .343 & .310
\end{tabular}




\begin{tabular}{lllllll} 
Recipient & .179 & .282 & .487 & .333 & .333 & .344 \\
Total & .193 & .277 & .483 & .310 & .338 & .327 \\
De-escalation & & & & & & \\
Disengager & .324 & .266 & .335 & .316 & .330 & .291 \\
Recipient & .346 & .309 & .265 & .281 & .305 & .297 \\
Total & .335 & .288 & .300 & .300 & .318 & .294 \\
Positive Tone/Self-Blame & & & & & & \\
Disengager & .497 & .296 & .234 & .274 & .366 & .314 \\
Recipient & .447 & .273 & .153 & .217 & .300 & .286 \\
Total & .472 & .285 & .194 & .250 & .333 & .302 \\
Cost Escalation & & & & & & \\
Disengager & .274 & .278 & .378 & .347 & .326 & .318 \\
Recipient & .395 & .346 & .292 & .284 & .344 & .320 \\
Total & .335 & .319 & .335 & .319 & .335 & .318 \\
Manipulation & & & & & & \\
Disengager & .219 & .267 & .208 & .268 & .214 & .267 \\
Recipient & .165 & .246 & .222 & .266 & .193 & .257 \\
Total & .192 & .258 & .215 & .266 & .203 & .262 \\
\hline
\end{tabular}

Note. Non-transformed means and standard deviations are shown for open confrontation, positive tone/self-blame, and cost escalation for ease of interpretation.

Table 24. Factorial ( 2 X 2) ANOVA results for use or perceived use of each breakup tactic as a function of breakup role $(R)$ and breakup strategy $(S)$ in Sample B.

\begin{tabular}{lcccccc}
\hline Tactic & $F_{\text {Role }}$ & $\omega^{2}$ & $F_{\text {Strategy }}$ & $\omega^{2}$ & $F_{R x S}$ & $\omega^{2}$ \\
\hline Avoidance/Withdrawal & 1.82 & .003 & $18.59 * * *$ & .055 & 3.29 & .007 \\
Open Confrontation $\dagger$ & 0.13 & -.001 & $345.59 * * *$ & .553 & 0.00 & -.002 \\
Distant/Mediated Communication & 0.08 & -.003 & $72.05 * * *$ & .201 & 0.02 & -.002 \\
De-escalation & 0.51 & -.002 & 1.06 & .000 & 1.81 & .003 \\
Positive Tone/Self-blame $\dagger$ & 3.49 & .006 & $90.03 * * *$ & .231 & 0.96 & .000 \\
Cost Escalation $\dagger$ & 0.22 & -.004 & 0.01 & -.005 & $4.84 *$ & .019 \\
Manipulation & 0.44 & -.002 & 0.57 & -.001 & 1.23 & .001 \\
\hline
\end{tabular}

Note. ${ }^{*} p<.05 . * * * p<.001 . \dagger$ A square root transformation was applied to the variable.

\subsubsection{Breakup Tactics: Open Confrontation}

Levene's test of homogeneity of variance was violated for open confrontation. In attempt to resolve this issue, a square root transformation was applied to the raw scores. When the analysis was re-run, Levene's test was still violated. At this point, the researcher deemed it appropriate to interpret the output considering that factorial ANOVAs are generally robust to violations of assumptions (Field, 2013), and this is especially the case, as there are equal sample sizes in each condition. The transformed scores are used in the analysis below. 
Breakups that ended directly were expected to elicit greater use and perceived use of open confrontation tactics than breakups that ended through ghosting (H1.2). This hypothesis was confirmed and was accompanied by a very large effect size. The main effect of breakup role and the interaction between strategy and role were not significant.

\subsubsection{Breakup Tactics: Distant/Mediated Communication}

A main effect of breakup strategy was predicted (H1.3), such that participants whose relationships ended through ghosting would report greater use or perceived use of distant/mediated communication tactics. The hypothesis was supported and demonstrated a large effect size. The main effect of breakup role and the interaction between strategy and role were not significant.

\subsubsection{Breakup Tactics: De-escalation}

Disengagers were expected to report greater use of de-escalation tactics that recipients reported perceiving (H1.4). The hypothesis was not supported. In addition, the main effect of breakup strategy and the interaction between strategy and role were not significant.

\subsubsection{Breakup Tactics: Positive Tone/Self-Blame}

Levene's test was violated for positive tone/self-blame. After a square root transformation was applied to account for the positive skew of the distribution, Levene's test remained significant. The analysis below was run with the transformed scores.

A main effect of breakup strategy was hypothesized (H1.5), such that positive tone/selfblame tactics would be used or perceived to be used more often in direct breakups compared to ghosting breakups. The hypothesis was supported in the expected direction, and the effect size was large. The main effect of breakup role and the interaction between strategy and role were not significant.

\subsubsection{Breakup Tactics: Cost Escalation}

Levene's test was violated but became non-significant after applying a square root transformation to the variable to alleviate the positive skew of the data. 
An interaction between breakup strategy and role was expected (H1.6) such that ghosting disengagers would report higher use of cost escalation tactics than direct disengagers, but direct recipients would report higher perceived use of cost escalation tactics than ghosting recipients. Although the interaction emerged statistically significant $(p<.05)$, it did not meet the respective threshold dictated by the Holm-Bonferroni method (see Table 32), so was not supported. The planned pairwise comparisons were conducted as planned and were found to be in the expected direction, but non-significant. In addition, the main effects of breakup role and breakup strategy were not significant.

\subsubsection{Breakup Tactics: Manipulation}

Relationships that ended through ghosting were expected to elicit greater reports of manipulation tactics than relationships that ended directly (H1.7). The hypothesis was not supported. The main effect of breakup role and the interaction between strategy and role were not significant.

\subsubsection{Breakup Motivations: Direct Conversation Strategy}

Preliminary data screening before a one-way MANOVA was conducted indicated that the intercorrelations between the factors ranged from -.102 to .444 and were deemed not sufficiently large enough to raise concern about multicollinearity (see Table 25). However, Box's $M$ test was significant, meaning the assumption of homogeneity of variance/covariance matrices across conditions was violated. Due to this violation, a series of one-way Welch's robust tests of equality of means were conducted instead (in line with what was planned in the pre-registered data analytic plan, https://osf.io/8r6t9/).

Table 25. Correlation coefficients for relations among the direct MBSC factors in Sample B.

\begin{tabular}{lcc}
\hline Factors & Clarity and Understanding & Done with Relationship \\
\hline Gentle Breakup & $.444^{* *}$ & .089 \\
Clarity and Understanding & -- & -.102 \\
\hline
\end{tabular}

Note. ${ }^{* *} p<.01$.

Direct disengagers reported that ensuring clarity and understanding during the breakup was a much more influential motivation for having a direct breakup conversation than 
recipients perceived it to be (H2.1), Welch's $F(1,139.02)=11.21, p=.001$, est. $\omega^{2}=$ .065 (see Table 26). Explorations of differences between the remaining two factors revealed a significant difference between disengagers and recipients in terms of motivations to have a direct breakup in order to facilitate a gentle separation, Welch's $F(1,143.96)=8.72, p=.004$, est. $\omega^{2}=.050$ (see Table 26). No significant difference emerged between disengagers and recipients in terms of disengagers being motivated to have a direct breakup because they felt the relationship was not going anywhere or became interested in other partners, Welch's $F(1,144.12)=0.04, p>.05$.

Table 26. Mean scores and standard deviations of the direct MBSC factors as a function of breakup role in Sample $B$.

\begin{tabular}{lcccccc}
\hline & \multicolumn{6}{c}{ Factors } \\
\cline { 2 - 7 } Role & \multicolumn{1}{c}{ Gentle Breakup } & \multicolumn{2}{c}{ Clarity and Understanding } & \multicolumn{2}{c}{ Done with Relationship } \\
\cline { 2 - 7 } & $M$ & $S D$ & $M$ & $S D$ & $M$ & $S D$ \\
\hline Disengagers & 4.47 & 1.32 & 5.51 & 1.12 & 3.41 & 1.60 \\
Recipients & 3.79 & 1.48 & 4.81 & 1.41 & 3.46 & 1.42 \\
\hline
\end{tabular}

\subsubsection{Breakup Motivations: Ghosting Strategy}

Preliminary data screening before a one-way MANOVA was conducted indicated that the intercorrelations between the factors ranged from .170 to .422 and were deemed not sufficiently large enough to raise concern about multicollinearity (see Table 27). However, Box's $M$ test was significant, meaning the assumption of homogeneity of variance/covariance matrices across conditions was violated. Due to this violation, a series of one-way Welch's robust tests of equality of means were conducted instead (in line with what was planned in the pre-registered data analytic plan).

Table 27. Correlation coefficients for relations among the ghosting MBSC factors in Sample B.

\begin{tabular}{lccc}
\hline Factors & $\begin{array}{c}\text { Done with } \\
\text { Relationship }\end{array}$ & Guilt & $\begin{array}{c}\text { Anticipated a } \\
\text { Difficult Breakup }\end{array}$ \\
\hline Avoidance & $.170^{*}$ & $.422^{* *}$ & $.254^{* *}$ \\
Done with Relationship & -- & $.332^{* *}$ & $.178^{*}$ \\
Guilt & -- & -- & $.321^{* *}$ \\
\hline
\end{tabular}

Note. $* p<.05 . * * p<.01$. 
Disengagers reported being done with the relationship as a more influential factor in their decision to ghost their partners than recipients believed $(\mathbf{H 2 . 2 a})$, Welch's $F(1,143.80)=$ $12.79, p<.001$, est. $\omega^{2}=.074$. Contrary to expectations, disengagers did not rate the anticipated a difficult breakup factor as more influential than recipients perceived $(\mathbf{H 2 . 2 b})$, Welch's $F(1,136.55)=3.32, p=.07$. Explorations of the remaining factors indicated no significant difference emerged between disengagers and recipients in terms of disengagers being motivated to ghost in order to avoid a breakup conversation, Welch's $F(1,145.28)=0.53, p>.05$. However, a significant difference did emerge for the factor guilt, such that disengagers reported feeling motivated to ghost to prevent hurting their partner's feelings more than recipients perceived, Welch's $F(1,143.74)=$ $7.95, p=.005$, est. $\omega^{2}=.045$, see Table 28 .

Table 28. Mean scores and standard deviations of the ghosting MBSC factors as a function of breakup role in Sample $B$.

\begin{tabular}{lcccccccc}
\hline & \multicolumn{8}{c}{ Factors } \\
\cline { 2 - 9 } & \multicolumn{9}{c}{$\begin{array}{c}\text { Done with } \\
\text { Rvoidance }\end{array}$} & \multicolumn{2}{c}{ Relationship } & \multicolumn{2}{c}{$\begin{array}{c}\text { Anticipated a } \\
\text { Rolfficult Breakup }\end{array}$} \\
\cline { 2 - 10 } & $M$ & $S D$ & $M$ & $S D$ & $M$ & $S D$ & $M$ & $S D$ \\
\hline Disengagers & 4.59 & 1.44 & 4.72 & 1.60 & 3.97 & 1.70 & 3.68 & 1.95 \\
Recipients & 4.76 & 1.34 & 3.83 & 1.42 & 3.22 & 1.50 & 3.16 & 1.49 \\
\hline
\end{tabular}

\subsubsection{Breakup Distress}

Breakup recipients were expected to report experiencing greater distress than breakup disengagers (H3.1). The hypothesis was supported with a large effect size (see Table 30). An unexpected main effect of breakup strategy also emerged, with relationships dissolved through direct conversations eliciting greater distress than breakups dissolved through ghosting (see Table 29). The effect size was moderate. The interaction between breakup role and breakup strategy was not significant.

\subsubsection{Positive and Negative Affect}

Breakup recipients were expected to report experiencing greater negative affect than breakup disengagers (H3.1). The hypothesis was supported with a large effect size. The main effect of breakup strategy and the interaction was not significant. 


\subsubsection{Post-Breakup Recovery and Personal Growth}

An exploration of post-breakup recovery and personal growth revealed a significant main effect of breakup strategy, such that participants in direct breakups reported significantly more personal growth than participants in relationships that ended through ghosting (see Table 29). In addition, the interaction between strategy and role was significant (see Table 30). Direct disengagers reported significantly more post-breakup personal growth than direct recipients. The difference between ghosting disengagers and ghosting recipients was not significant.

Table 29. Descriptive statistics of the BDS, BES, and PBRS in Sample B.

\begin{tabular}{|c|c|c|c|c|c|c|}
\hline \multirow[b]{3}{*}{ Measure } & \multicolumn{4}{|c|}{ Breakup Strategy } & & \\
\hline & \multicolumn{2}{|c|}{$\begin{array}{c}\text { Direct } \\
\text { Conversation }\end{array}$} & \multicolumn{2}{|c|}{ Ghosting } & \multicolumn{2}{|c|}{ Total } \\
\hline & $M$ & $S D$ & $M$ & $S D$ & $M$ & $S D$ \\
\hline \multicolumn{7}{|l|}{ BDS } \\
\hline Disengager & 2.03 & 0.75 & 1.69 & 0.67 & 1.86 & 0.73 \\
\hline Recipient & 2.89 & 0.83 & 2.62 & 0.75 & 2.76 & 0.80 \\
\hline Total & 2.46 & 0.90 & 2.15 & 0.85 & 2.31 & 0.89 \\
\hline \multicolumn{7}{|l|}{ BES } \\
\hline Disengager & -0.50 & 1.74 & -1.12 & 1.83 & -0.81 & 1.80 \\
\hline Recipient & 2.73 & 1.81 & 2.58 & 1.93 & 2.66 & 1.87 \\
\hline Total & 1.12 & 2.40 & 0.73 & 2.64 & 0.93 & 2.52 \\
\hline \multicolumn{7}{|l|}{ PBRS } \\
\hline Disengager & 3.80 & 1.11 & 3.10 & 1.12 & 3.45 & 1.16 \\
\hline Recipient & 3.21 & 1.29 & 3.27 & 1.23 & 3.24 & 1.26 \\
\hline Total & 3.50 & 1.23 & 3.19 & 1.18 & 3.34 & 1.21 \\
\hline
\end{tabular}

Note. BDS = Breakup Distress Scale, BES = Breakup Emotions Scale, PBRS = PostBreakup Recovery and Personal Growth Scale.

Table 30. Factorial (2 X 2) ANOVA results for the BDS, BES, and PBRS as a function of breakup role $(R)$ and breakup strategy $(S)$ in Sample B.

\begin{tabular}{lcccccc}
\hline Measure & $F_{\text {Role }}$ & $\omega^{2}$ & $F_{\text {Strategy }}$ & $\omega^{2}$ & $F_{R x S}$ & $\omega^{2}$ \\
\hline BDS & $104.71 * * *$ & .657 & $12.58 * * *$ & .073 & 0.18 & -.005 \\
BES & $264.89 * * *$ & .964 & 3.23 & .008 & 1.25 & .001 \\
PBRS & 2.21 & .004 & $5.27 *$ & .014 & $7.67 *$ & .022 \\
\hline
\end{tabular}

Note. ${ }^{*} p<.05 . * * * p<.001$. 


\subsubsection{Exploration of Covariates: Relationship Length and Commitment}

A significant main effect of breakup strategy emerged when relationship length was treated as a dependent variable, such that breakups that ended through ghosting $\left(M_{\text {weeks }}=\right.$ $26.03, S D_{\text {weeks }}=25.69$ ) were significantly shorter than relationships that ended directly $\left(M_{\text {weeks }}=38.23, S D_{\text {weeks }}=24.14\right), F(1,292)=17.62, p<.001, \omega^{2}=.053$.

When commitment was treated as a dependent variable a main effect of breakup strategy was found, such that relationships that ended through direct conversation $(M=5.52, S D=$ 1.35) had significantly higher reported commitment than relationships that ended through ghosting $(M=4.81, S D=1.58), F(1,292)=18.25, p<.001, \omega^{2}=.052$. In addition, a main effect of breakup role was significant, such that recipients $(M=5.47, S D=1.40)$ reported significantly greater commitment than disengagers $(M=4.86, S D=1.55), F(1$, 292) $=13.11, p<.001, \omega^{2}=.037$. The interaction between breakup strategy and breakup role was also significant, $F(1,292)=4.30, p=.039, \omega^{2}=.010$. Post hoc tests revealed ghosting recipients $(M=5.28, S D=0.17)$ to be significantly more committed than ghosting disengagers $(M=4.34, S D=0.17)$. No significant difference emerged between direct disengagers and direct recipients.

When relationship length and commitment were independently added as covariates to the 2 X 2 factorial ANOVAs for breakup tactics, breakup distress, positive and negative affect, and post-breakup recovery and personal growth, a few notable changes in statistical significance emerged.

The main effect of breakup role on positive tone/self-blame became significant when commitment was added as a covariate, such that disengagers reported using more of these tactics than recipients reported their partners to have used.

The significant main effect of breakup strategy on breakup distress became nonsignificant when commitment was added as a covariate.

The main effect of breakup role on post-breakup recovery and personal growth became significant when commitment was added as a covariate, such that disengagers reported 
greater growth than recipients. The significant main effect of breakup strategy on postbreakup personal growth became non-significant when relationship length and commitment were added independently as covariates.

All other main effects and interactions were not affected by adding relationship length or commitment as covariates (see Table 31 ).

Table 31. Factorial ( 2 X 2) ANOVA results without covariates and results with relationship length and commitment as covariates in Sample B.

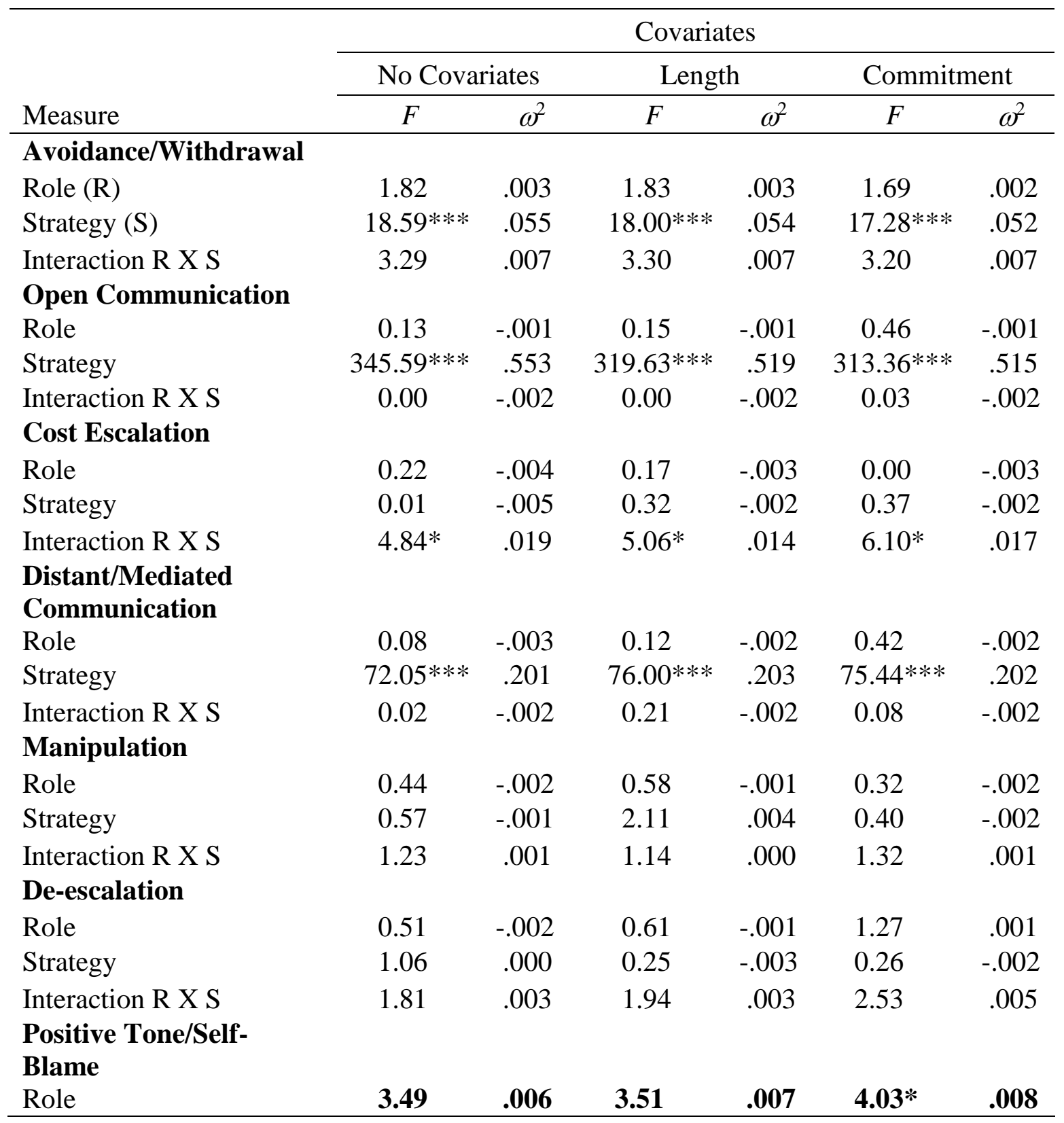




\begin{tabular}{lcccccc}
\hline Strategy & $90.03 * * *$ & .231 & $83.51^{* * *}$ & .216 & $80.84^{* * *}$ & .212 \\
Interaction R X S & 0.96 & .000 & 0.96 & -.000 & 1.15 & .000 \\
Breakup Distress & & & & & & \\
Role & $104.71^{* * *}$ & .253 & $112.81^{* * *}$ & .272 & $88.24 * * *$ & .227 \\
Strategy & $\mathbf{1 2 . 5 8} * * *$ & $\mathbf{. 0 7 3}$ & $\mathbf{5 . 0 1 *}$ & $\mathbf{. 0 1 0}$ & $\mathbf{3 . 2 6}$ & $\mathbf{. 0 0 6}$ \\
Interaction R X S & 0.18 & -.005 & 0.11 & -.002 & 0.29 & -.002 \\
Breakup Emotions & & & & & & \\
Role & $264.89^{* * *}$ & .469 & $268.94 * * *$ & .475 & $244.50^{* * *}$ & .453 \\
Strategy & 3.23 & .008 & 1.11 & .000 & 0.11 & -.002 \\
Interaction R X S & 1.25 & .001 & 1.16 & .000 & 0.18 & -.002 \\
Post-Breakup Personal & & & & & & \\
Growth & & & & & & \\
Role & $\mathbf{2 . 2 1}$ & $\mathbf{. 0 0 4}$ & $\mathbf{2 . 4 3}$ & $\mathbf{. 0 0 5}$ & $\mathbf{4 . 1 1} *$ & $\mathbf{. 0 1 0}$ \\
Strategy & $\mathbf{5 . 2 7 *}$ & $\mathbf{. 0 1 4}$ & $\mathbf{3 . 0 0}$ & $\mathbf{. 0 0 7}$ & $\mathbf{2 . 5 6}$ & $\mathbf{. 0 0 5}$ \\
Interaction R X S & $7.67 * *$ & .022 & $7.54 * *$ & .021 & $6.02 *$ & .016 \\
\hline
\end{tabular}

Note. $* p<.05 . * * p<.01 . * * * p<.001$. Bolded rows indicate a change in statistical significance with the addition of a covariate.

\subsubsection{Results Summary}

Like Sample A, relationships that ended through direct conversations were longer and had higher levels of reported commitment than those that ended through ghosting. Similarly, recipients reported higher levels of commitment than disengagers. A significant interaction emerged for commitment in Sample B that was not found in Sample A, such that levels of commitment did not significantly differ between disengagers and recipients of direct breakups, however, ghosting recipients reported being significantly more committed than ghosting disengagers.

Eight findings from Sample A were replicated in Sample B. Main effects of breakup strategy for avoidance/withdrawal and distant/mediated communication were found such that higher proportions of use were reported in ghosting breakups compared to direct conversation breakups. In addition, open confrontation and positive-tone/self-blame tactics were used more often in direct breakups than ghosting breakups. Main effects of breakup role replicated for breakup distress and negative affect, with recipients reporting significantly higher levels than disengagers. Discrepancies between disengagers and recipients also emerged for the motivation to achieve clarity and understanding during a direct breakup, and disenchantment with the relationship for ghosting breakups. 
Disengagers reported these motivations influenced their decision to choose the respective breakup strategy more significantly more strongly than recipients believed.

Five findings that demonstrated statistical significance below $p<.05$ in Sample A did not replicate when tested in a confirmatory way in Sample B. Most dramatically, the breakup tactics de-escalation, cost escalation, and manipulation along with ghosting MBSC factor anticipated a difficult breakup all originally had $p$ values less than .01 in Sample A but in Sample B, all had $p$ values above .05. In addition, the main effect of breakup role for avoidance/withdrawal which obtained a $p$ value of .027 in Sample A increased to a value of .179 in Sample B.

Table 32. Summary of Sample B hypothesis tests with Holm-Bonferroni adjusted alpha levels.

\begin{tabular}{llllll}
\hline Hypothesis & Dependent Variable & $\begin{array}{l}\text { Factor, } \\
\text { Interaction } \\
\text { or Group }\end{array}$ & $\begin{array}{l}\text { Obtained } \\
p \text { Value }\end{array}$ & $\begin{array}{c}\text { HB } \\
\alpha_{a d j}\end{array}$ & $H_{0}$ \\
\hline $1.1 \mathrm{a}$ & Avoidance/Withdrawal & Strategy & .000 & .0033 & Rejected \\
1.2 & Open Confrontation & Strategy & .000 & .0036 & Rejected \\
1.3 & Distant/Mediated & Strategy & & & \\
& Communication & & .000 & .0038 & Rejected \\
1.5 & Positive Tone/Self-blame & Strategy & .000 & .0042 & Rejected \\
$2.2 \mathrm{a}$ & MBSC-G: Done with & Role & & & \\
& Relationship & & .000 & .0045 & Rejected \\
3.1 & Breakup Distress & Role & .000 & .005 & Rejected \\
4.1 & Breakup Emotions & Role & .000 & .0056 & Rejected \\
2.1 & MBSC-D: Clarity and & Role & & & \\
& Understanding & & .001 & .0063 & Rejected \\
1.6 & Cost Escalation & Interaction & .029 & .0071 & Retained \\
$2.2 \mathrm{~b}$ & MBSC-G: Anticipated & Role & & & \\
& Difficult Breakup & & .07 & .0083 & Retained \\
$1.6 \mathrm{a}$ & Cost-Escalation Pairwise & Disengagers & & & \\
& Comparison & & .110 & .01 & Retained \\
$1.6 \mathrm{~b}$ & Cost-Escalation Pairwise & Recipients & & & \\
& Comparison & & .133 & .0125 & Retained \\
$1.1 \mathrm{~b}$ & Avoidance/Withdrawal & Role & .179 & .0167 & Retained \\
1.4 & Manipulation & Strategy & .451 & .025 & Retained \\
& De-escalation & Role & .477 & .05 & Retained \\
\hline
\end{tabular}


Note. $\alpha_{a d j} \mathrm{HB}=$ adjusted alpha level after Holm-Bonferroni correction. MBSC-G = Motivations for Breakup Strategy Choice-Ghosting. MBSC-D = Motivations for Breakup Strategy Choice-Direct Conversation.

A handful of significant $(p<.05)$ exploratory findings in Sample B did demonstrate differences from findings in Sample A. Specifically, the interactions between breakup role and strategy that emerged as significant for breakup distress and positive and negative affect in Sample A did not replicate in Sample B. A significant difference did emerge in Sample B but not Sample A between disengagers and recipients for the motivation to facilitate a gentle dissolution in direct breakups, such that disengagers reported this influenced their decision more heavily. In addition, ghosting disengagers reported that feeling guilty about hurting the recipients' feelings influenced their decision to ghost more than recipients perceived, but only in Sample B. Finally, a main effect of breakup strategy and an interaction between strategy and role emerged for post-breakup personal growth that was not found in Sample A.

\subsection{Discussion}

The cross-validation design of Study 2 allowed for results to be freely explored in the first half of the data set and for select hypotheses the researchers were willing to "bet on" to be confirmed in the second half of the data set. Results that emerged in both samples coupled with the use of the Holm-Bonferroni correction method to restrict the experiment-wise alpha rate to .05 in Sample B subjected the hypotheses to a more stringent test which allowed for greater confidence in the replicated findings.

Breakups that ended directly were found in both samples to have lasted longer and been characterized by greater commitment. This suggests that within relationships where partners have developed a close and intimate connection with each other, perhaps direct breakups are implemented during dissolution as an act of compassion and respect. However, it could also reflect Davis's (1973) suggestion that the longer partners are involved the more difficult it is to "untie" partners from each other, making fading away a less efficient breakup strategy. 
Relationships that ended through ghosting were shown to have significantly higher reported use of avoidance/withdrawal and distant/mediated communication, and significantly less open confrontation and positive tone/self-blame breakup tactics in both samples. In line with the defining features of each strategy, the lack of explanation involved with ghosting coincides with increased use of avoidance/withdrawal, while the existence of an explicit expression of dissolution characteristic of a breakup facilitated by a direct conversation aligns with greater use of open confrontation tactics. Similarly, the positive tone/self-blame tactics necessitate some sort of communication between partners, making use of such tactics highly unlikely in ghosting breakups. While these findings may not be surprising, the ability for the characteristic differences of each strategy to be documented quantitatively represents a novel contribution to this area of research.

Across both samples recipients experienced significantly greater amounts of distress and negative affect than disengagers regardless of strategy used during the breakup. The replicability of this finding in addition to the large effect sizes in both samples indicate that breakup role is a key factor in predicting distress-oriented experiences postdissolution. More salient than how the breakup occurred, being the rejected partner who did not have control over the breakup and did not desire to breakup contributed to much greater experiences of distress. With the addition of the assessment of positive affect, it was shown that disengagers from both ghosting and direct breakups actually reported more positive affect than negative affect. This suggests that a fuller spectrum of emotions should be assessed after romantic relationship dissolution in future research.

Direct disengagers reported desiring a breakup where their intent to dissolve could be clearly understood was a motivator for their decision to end their breakups directly, however, direct recipients perceived this as significantly less of an influence, and this was demonstrated in Sample A and Sample B. This discrepancy suggests that while disengagers may intend to give the recipients clarity and understanding during the breakup conversation, perhaps their approach was not successful, and the recipients were left confused or in want of further information or discussion. Alternately, recipients who might retain bitter or otherwise negative feelings post-dissolution may be less likely to attribute caring-oriented motivations to disengagers' decision to breakup with them. 
Ghosting disengagers reported that simply feeling disinterested in their relationships motivated their decision to ghost significantly more so than ghosting recipients perceived, which was demonstrated in both samples. Differences in the perceptions of disengagers and recipients in terms of how or why dissolution occurred is noteworthy as these inconsistencies may provide insight or explanatory power as to why differences in postbreakup outcome measures exist. While the current study did not involve partners from the same relationship, this would be an avenue for research to move towards in the future.

The findings that did not replicate across samples represent variables that need to be reevaluated and re-tested to relieve the current state of mixed results. While the interaction between strategy and role for cost escalation obtained $p$ values below .05 in both samples, each had minimal effect sizes, and did not withstand the significance cut off after the alpha level was adjusted for controlling Type I error in Sample B. However, the emergence of such an effect twice suggests that perhaps investigation of this variable with a higher-powered study might reveal stronger effects. Similarly, the interactions that emerged for breakup distress and positive and negative affect that did not replicate in Sample B may also emerge in a higher-powered study, as interactions often require more power to detect. Across both samples, the ghosting MBSC factors anticipated a difficult breakup and guilt and direct MBSC factor gentle breakup only demonstrated significant differences between disengagers and recipients in one of the two samples. In addition, divergent findings for de-escalation and manipulation across samples remain unexplained. While a main effect of breakup role for avoidance/withdrawal emerged in Sample A the $p$ value was close to .05 , therefore the non-significant finding in Sample B was not entirely unexpected. However, differing perceptions of use of certain breakup tactics may influence cognitive processing, emotional reactions and behavior both during and after the breakup and may be worthy of further exploration. Lastly, in Sample B only, participants who experienced direct breakups reported greater post-breakup personal growth than those in ghosting breakups, suggesting that the presence of a breakup conversation may facilitate more diverse or more intense positive life changes following relationship dissolution. Consideration of these findings should remain cautious because of the inconsistent support found across the samples, however, such findings should pique some interest and demonstrate that there is more to be uncovered about the 
processes, motivations and consequences of different breakup strategies and breakup role in romantic relationship dissolution.

Study 2 demonstrated that significant differences emerged in the breakup tactics used or perceived to be used between ghosting and direct breakups and that some findings were replicable across two independent samples. Similarly, differences in post-breakup distress and negative affect between disengagers and recipients were robust across samples. Investigations of the motivations for choosing certain breakup strategies indicated that disengagers and recipients have different perceptions of similar experiences, providing a potential explanation for differences in post-breakup outcomes. Finally, mixed results with some variables indicate that further research is needed to resolve these inconsistencies. 


\section{Chapter 4}

\section{General Discussion}

The two studies presented here represent the first broad scale investigation of the novel indirect breakup strategy of ghosting (Study 1), and the first study to compare the motivations, processes, and positive and negative consequences of ghosting to those of the direct strategy of having a breakup conversation (Study 2). With much existing research focused on how technologically-mediated communication is increasingly used to initiate and maintain relationships, not much research exists thus far that informs how technology influences processes of relationship dissolution. The present studies have demonstrated that clear differences exist between traditional, non-technologicallymediated breakup strategies and modern breakup strategies that are implemented through such technological use.

Results that were found consistently in Study 1 and Study 2 indicated that relationships ended through ghosting were more likely to be shorter and to be characterized by lower commitment, which supports the idea that this breakup strategy may be most commonly implemented before substantial commitment or intimacy has developed. Additionally, across both studies, breakup recipients experienced greater distress than breakup disengagers, and ghosting disengagers reported the least amount of breakup distress, perhaps alluding to the idea that ghosting could adaptive or self-protective, such that avoiding a breakup conversation and contact with the ex-partner may also make it easier for the disengager to avoid feelings of distress or negative affect post-dissolution.

\subsection{Limitations}

A notable limitation of Study 1 was that participants could report on relationships that occurred within the past 5 years. Accurately recalling detailed information regarding the breakup tactics used or the amount of breakup distress felt post-dissolution for a breakup that occurred so long ago is not ideal. This limitation was addressed in Study 2, where the breakup had to occur within the past 6 months of completing the study. As such, more confidence can be had in the accuracy of the data provided in Study 2. In general, the 
data gathered from these studies relied on self-report. While not an uncommon method in social and behavioral science, the results can only be trusted to the extent that participants were being honest about their personal feelings and perceptions while completing the surveys.

The participants in both studies were collected from MTurk. While age restrictions were set for both studies to target individuals most likely to use technologically-mediated communication (18-35 years old), the MTurk sample may differ from student or community samples in notable ways in terms of experiences with or attitudes towards ghosting. Future research may seek to replicate the present findings with participants who were not recruited from an online source.

While the priority of both studies was to accumulate information on ghosting because the phenomenon had not yet been studied in depth, in some instances this focus distracted from gathering similar information about direct breakups, preventing salient comparisons between the two to be made. For example, while retaliatory actions and negative perceptions of the ghosting disengagers were elicited from ghosting recipients in Study 1, such information would have been beneficial to obtain from direct recipients as well (however, coincidentally there were no direct recipients in Study 1). Similarly, while a clear definition of ghosting was provided to participants before they indicated how their relationships ended, a description or definition of a "direct breakup" was not given, which created ambiguity in terms of what that breakup may have involved. Like the ghosting strategy, direct breakup strategies can be nuanced, and may occur in a variety of ways. Future studies should seek to devote equal amounts of attention to the strategy types that are being compared.

\subsection{Implications and Future Directions}

These studies demonstrate that a distinct breakup strategy has evolved with the extensive infusion of technologically-mediated communication in the area of romantic relationships. Consequently, the assumption that relationship dissolution involves a communicative aspect has been challenged, suggesting that how breakup strategies have been conceptualized in past literature should be reevaluated. While the current research 
proposed the idea of two distinct breakup types, direct and indirect, which refer to whether or not an explicit indication of dissolution occurred, this conceptualization is preliminary and should be further developed. For example, a direct breakup in which a clear indication of dissolution occurs can take a variety of different forms. While one strategy may be to have a dialogue between partners, where detailed explanations can be given, questions can be asked, and feelings debriefed, another strategy could be sending a single text message that says, "it's over." Though a clear and direct indication is given in both scenarios, the nature of these breakups is obviously very different, and may result in different post-breakup consequences. This might indicate that a continuum may be a more appropriate model to represent a variety of breakup strategies that range between the direct and indirect poles.

Correspondingly, though Collins and Gillath (2012) recently updated the list of breakup tactics to reflect the relevant technological advances since Baxter's (1982) scale was created in the 1980s, now even newer tactics have been established that should be included in the scale. The speed at which technology is advancing, especially in terms of how SNSs are becoming an increasingly large part of how we connect with others (Quiroz, 2013), necessitates the continual revision of measures of breakup tactics and strategies in order to accurately assess how processes of relationship dissolution are evolving.

In agreement with Sprecher (1994), it is the opinion of the current researcher that there is great value in collecting information about the experiences of both partners within a relationship dyad. This research has shown that differences exist in post-breakup distress and positive and negative affect, along with perceptions of motivations for breakup strategy choice depending on whether an individual was the disengager or recipient. However, a striking limitation is that the recipients and disengagers were not from the same relationship. As such, agreement between relationship partners on the variables of interest in the current study could not be assessed. A longitudinal study that recruits couples and collects data leading up to relationship dissolution would offer unique insights into the cause of dissolution, the process leading up to (breakup tactics) the culmination of relationship termination (direct or indirect), and post-breakup outcomes, 
and provide the opportunity to compare self-reports and partner perceptions of these variables between both members of the dyad. Additionally, collecting detailed information about the dissolution process as it is unfolding using weekly or monthly diaries or surveys would allow participants to describe their breakup as it is occurring instead of having to rely on their memories to recount breakups that happened weeks, months or years ago. While recruitment and attrition represent unavoidable obstacles that would have to be strategically handled, dyadic data from partners who dissolved their relationships during the course of a study would allow researchers to add another level of inquiry and understanding to the area of relationship dissolution, specifically that of within-couple variation and between-couple variation, as opposed to one-sided recollections of relationship breakups.

\subsection{Conclusion}

Results of Study 1 demonstrated an indirect breakup strategy colloquially known as ghosting distinctly differed from traditional direct breakup strategies, where an explicit indication that the relationship is over is verbally communicated to the rejected partner. Preliminary findings demonstrated individual difference variables related to attachment style and the Dark Triad were associated with experiences with ghosting. Qualitative analyses provided descriptive information that increased our understanding of what ghosting is, how and why it is used, and the negative consequences of its use. Study 2 investigated differences in breakup tactics, motivations for breakup strategy choice, and various post-breakup outcomes as a function of breakup strategy and breakup role. Differences in tactics leading up to the culmination of relationship termination varied mostly between breakup strategies, while measures of breakup distress and negative affect were highly associated with breakup role. Going forward, as technology continues to advance empirical research must strive to keep up to identify any new benefits or consequences of the incorporation of such developments into our behavior in romantic relationship breakups. 


\section{References}

Ainsworth, M. D. S., Blehar, M. C., Waters, E., \& Wall, S. (1978). Patterns of attachment: A psychological study of the strange situation. Oxford, England: Lawrence Erlbaum.

Ali, F., \& Chamorro-Premuzic, T. (2010). The dark side of love and life satisfaction: Associations with intimate relationships, psychopathy and Machiavellianism. Personality and Individual Differences, 48(2), 228-233. doi:10.1016/j.paid.2009.10.016

Bakeman, R., \& Gottman, J. M. (1986). Observing behavior: An introduction to sequential analysis. Cambridge, England: Cambridge University.

Bakermans-Kranenburg, M. J., \& van IJzendoorn, M. H. (1997). Adult attachment and the break-up of romantic relationships. Journal of Divorce and Remarriage, 27(3/4), 121-139. doi:10.1300/j087v27n03_08

Banks, S. P., Altendorf, D. M., Greene, J. O., \& Cody, M. J. (1987). An examination of relationship disengagement: Perceptions, breakup strategies and outcomes. Western Journal of Speech Communication, 51(1), 19-41. doi:10.1080/10570318709374250

Baxter, L. A. (1982). Strategies for ending relationships: Two studies. Western Journal of Speech Communication, 46(3), 223-241. doi:10.1080/10570318209374082

Baxter, L. A. (1984). Trajectories of relationship disengagement. Journal of Social and Personal Relationships, 1(1), 29-48. doi:10.1177/0265407584011003

Braun, V., \& Clarke, V. (2006). Using thematic analysis in psychology. Qualitative Research in Psychology, 3(2), 77-101. doi:10.1191/1478088706qp063oa

Brewer, G., \& Abell, L. (2017). Machiavellianism and romantic relationship dissolution. Personality and Individual Differences, 106, 226-230. doi:10.1016/j.paid.2016.11.001

Boyatzis, C. J. (1998). A collaborative assignment on the role of culture in child development and education. Teaching of Psychology, 25(3), 195-198. doi:10.1207/s15328023top2503_7 
Buehler, C. (1987). Initiator status and the divorce transition. Family Relations, 36(1), 82-86. doi:10.2307/584653

Buss, D. M. (1989). Toward an evolutionary psychology of human mating. Behavioral and Brain Sciences, 12(1), 39-49. doi:10.1017/s0140525x00024274

Buss, D. M. (2003). Sexual strategies: A journey into controversy. Psychological Inquiry, 14(3), 219-226. doi:10.1207/s15327965pli1403\&4_7

Carter, G. L., Campbell, A. C., Muncer, S., \& Carter, K. A. (2015). A Mokken analysis of the Dark Triad 'Dirty Dozen': Sex and age differences in scale structures, and issues with individual items. Personality and Individual Differences, 83, 185-191. doi:10.1016/j.paid.2015.04.012

Carter, V. (2013, September 27). Stop trying to spare my feelings with a "slow fade" breakup. Retrieved from https://www.xojane.com/sex/do-this-dont-abandon-theslow-fade-meant-to-spare-my-feelings

Christie, R., \& Geis, F. L. (1970). Studies in Machiavellianism. London: Academic Press. Cody, M. (1982). A typology of disengagement strategies and an examination of the role intimacy, reactions to inequity, and relational problems play in strategy selection. Communication Monographs, 49(3), 148-170. doi:10.1080/03637758209376079

Coen, S. (2015, November 9). Ghosting: Have apps like Tinder killed off basic decency when it comes to dating. Retrieved from https://www.independent.co.uk/lifestyle/love-sex/ghosting-dating-tinder-added-to-dictionary-etiquettea6724096.html

Collins, T. J., \& Gillath, O. (2012). Attachment, breakup strategies, and associated outcomes: The effects of security enhancement on the selection of breakup strategies. Journal of Research in Personality, 46(2), 210-222. doi:10.1016/j.jrp.2012.01.008

Cramer, A. O. J., van Ravenzwaaij, D., Matzke, D., Steingroever, H., Wetzels, R., Grasman, R. P. P. P., ... Wagenmakers, E. J. (2016). Hidden multiplicity in exploratory multiway ANOVA: Prevalence and remedies. Psychonomic Bulletin \& Review, 23(2), 640-647. doi:10.3758/s13423-015-0913-5 
Crotty, N. (2014, July 11). Generation ghost: The facts behind the slow fade. Retrieved from https://www.elle.com/life-love/sex-relationships/advice/a12787/girlsghosting-relationships/

Cupach, W. R. (1992). Dialectical proceses in the disengagement of interpersonal relationships. Close Relationship Loss, 128-141. doi:10.1007/978-1-4613-91869_7

Davis, M. (1973). Intimate Relations. The Free Press: New York.

Davis, D., Shaver, P. R., \& Vernon, M. L. (2003). Personality and Social Psychology Bulletin, 29(7), 871-884. doi:10.1177/0146167203029007006

Drigotas, S. M., \& Rusbult, C. E. (1992). Should I stay or should I go? A dependence model of breakups. Journal of Personality and Social Psychology, 62(1), 62-87. doi:10.1037/0022-3514.62.1.62

Feeney, J. A., \& Noller, P. (1990). Attachment style as a predictor of adult romantic relationships. Journal of Personality and Social Psychology, 58(2), 281-291. doi:10.1037/0022-3514.58.2.281

Fraley, R. C., \& Shaver, P. R. (2000). Adult romantic attachment: Theoretical developments, emerging controversies, and unanswered questions. Review of General Psychology, 4(2), 132-154. doi:10.1037//1089-2680.4.2.132

Field, A. (2013). Discovering statistics using IBM SPSS statistics. Thousand Oaks, CA: SAGE.

Field, T., Diego, M., Pelaez, M., Deeds, O., \& Delgado, J. (2009). Breakup distress in university students. Adolescence, 44(176), 705-727. Retrieved from https://www.researchgate.net/publication/43531747_Breakup_distress_in_univers ity_students

Fine, M. A., \& Sacher, J. A. (1997). Predictors of distress following relationship termination among dating couples. Journal of Social and Clinical Psychology, 16(4), 381-388. doi:10.1521/jscp.1997.16.4.381

Fisher, H. (1989). Evolution of human serial pairbonding. American Journal of Physical Anthropology, 78(3), 331-354. doi:10.1002/ajpa.1330780303

Fiske, S., \& Taylor, S. (1984). Social Cognition. New York: Random. 
Frazier, P. A., \& Cook, S. W. (1993). Correlates of distress following heterosexual relationship dissolution. Journal of Social and Personal Relationships, 10(1), 5567. doi:10.1177/0265407593101004

Freedman, G., Powell, D. N., Le, B., \& Williams, K. D. (2018). Ghosting and destiny: Implicit theories of relationships predict beliefs about ghosting. Journal of Social and Personal Relationships, 1-20. doi:10.1177/0265407517748791

Ghosting. (2013, November 27). Urban Dictionary. Retrieved from https://www.urbandictionary.com/define.php?term=Ghosting

Hardwick, C. (n.d.). Is it ever okay to ghost someone? 9 times it makes sense to ice him out. Retrieved from https://www.bolde.com/is-it-ever-okay-to-ghost-someone/

Hartley, H. O. (1955). Some recent developments in analysis of variance. Communications on Pure and Applied Mathematics, 8, 47-72. doi:10.1002/cpa.3160080104

Hazan, C., \& Shaver, P. (1987). Romantic love conceptualized as an attachment process. Journal of Personality and Social Psychology, 52(3), 511-524. doi:10.1037/00223514.52.3.511

Helgeson, V. S. (1994). Relation of agency and communion to well-being: Evidence and potential explanations. Psychological Bulletin, 116(3), 412-428. doi:10.1037//0033-2909.116.3.412

Hill, C. T., Rubin, Z., \& Peplau, L. A. (1976). Breakups before marriage: The end of 103 affairs. Journal of Social Issues, 32(1), 147-168. doi:10.1111/j.15404560.1976.tb02485.x

Jonason, P. K., \& Kavanagh, P. (2010). The dark side of love: Love styles and the Dark Triad. Personality and Individual Differences, 49(6), 606-610. doi:10.1016/j.paid.2010.05.030

Jonason, P. K., \& Webster, G. D. (2010). The dirty dozen: A concise measure of the dark triad. Psychological Assessment, 22(2), 420-432. doi:10.1037/a0019265

Kajonius, P. J., Persson, B. N., Rosenberg, P., \& Garcia, D. (2016). The (mis)measurement of the Dark Triad Dirty Dozen: Exploitation at the core of the scale. PeerJ, 4, e1748. doi:10.7717/peerj.1748 
Knapp, M. L. \& Vangelisti, A. L. (2005). Stages of relationships. Interpersonal Communication and Human Relationships (pp. 36-49). Boston, MA: Allyn \& Bacon.

Knee, C. R. (1998). Implicit theories of relationships: Assessment and prediction of romantic relationship initiation, coping, and longevity. Journal of Personality and Social Psychology, 74(2), 360-370. doi:10.1037//0022-3514.74.2.360

Krahl, J. R., \& Wheeless, L. R. (1997). Retrospective analysis of previous relationship disengagement and current and current attachment style. Communication Quarterly, 45(3), 167-187. doi:10.1080/01463379709370059

Lakens, D. (2015, June 8). Why you should use omega-squared instead of eta-squared. [Blog post]. Retrieved from http://daniellakens.blogspot.com/2015/06/why-youshould-use-omega-squared.html

LeFebvre, L. (2017). Ghosting as a relationship dissolution strategy in the technological age. In N. M. Punyanunt-Carter \& J. S. Wrench (Eds.), The impact of social media in modern romantic relationships (pp. 219-235). New York, NY: Lexington Books.

Lilgendahl, J. P., \& McAdams, D. P. (2011). Constructing stories of self-growth: How individual differences in patterns of autobiographical reasoning relate to wellbeing in midlife. Journal of Personality, 79(2), 391-428. doi:10.1111/j.14676494.2010.00688.x

McEwan, B. (2013). Sharing, caring, and surveilling: An actor-partner interdependence model examination of Facebook relational maintenance strategies. Cyberpsychology, Behavior and Social Networking, 16, 863-869. doi:10.1089/cyber.2012.0717

McHoskey, J. (1995). Narcissism and Machiavellianism. Psychological Reports, 77(3), 755-759. doi:10.2466/pr0.1995.77.3.755

McLean, K. C., \& Pratt, M. W. (2006). Life's little (and big) lessons: Identity statuses and meaning-making in the turning point narratives of emerging adults. Developmental Psychology, 42(4), 714-722. doi:10.1037/0012-1649.42.4.714 
Metts, S., Cupach, W. R., \& Bejlovec, R. A. (1989). 'I love you too much to ever start liking you': Redefining romantic relationships. Journal of Social and Personal Relationships, 6(3), 259-274. doi:10.1177/0265407589063002_

Moore, P. (2014, October 28). Poll Results: Ghosting. Retrieved from https://today.yougov.com/topics/lifestyle/articles-reports/2014/10/28/poll-resultsghosting

Morris, C. E., \& Reiber, C. (2011). Frequency, intensity and expression of postrelationship grief. EvoS Journal: The Journal of the Evolutionary Studies Consortium, 3, 1-11. Retrieved from http://evostudies.org/wpcontent/uploads/2011/01/MorrisVol3Iss1.pdf

Morris, C. E., Reiber, C., \& Roman, E. (2015). Quantitative sex differences in response to the dissolution of a romantic relationship. Evolutionary Behavioral Sciences, 9(4), 270-282. doi:10.1037/ebs0000054

Papp, L. M., Danielewicz, J., \& Cayembeg, C. (2012). “Are we Facebook official?” implications of dating partners' Facebook use and profiles for intimate relationship satisfaction. Cyberpsychology, Behavior and Social Networking, 15(2), 85-90. doi:10.1089/cyber.2011.0291

Patton, M. Q. (1990). Qualitative evaluation and research methods (2 ${ }^{\text {nd }}$ ed.). Newbury Park, CA: Sage.

Paulhus, D. L, \& Williams, K. M. (2002). The Dark Triad of personality: Narcissism, Machiavellianism, and psychopathy. Journal of Research in Personality, 36(6), 556-563. doi:10.1016/s0092-6566(02)00505-6

Perilloux, C., \& Buss, D. M. (2008). Breaking up romantic relationships: Costs experienced and coping strategies deployed. Evolutionary Psychology, 6(1), 164181. doi:10.1177/147470490800600119

Pizzano, P. A., Sherblom, J. C., \& Umphrey, L. R. (2013). Being secure means being willing to say you're sorry: Attachment style and the communication of relational dissatisfaction and disengagement. Journal of Relationships Research, 4(7), 1-13. doi:10.1017/jrr.2013.7

Quiroz, P. A. (2013). From finding the perfect love online to satellite dating and 'lovingthe-one-you're near': A look at Grindr, skout, plenty of fish, meet moi, zoosk, and 
assisted serendipity. Humanity and Society, 37(2), 181-185.

doi:10.1177/0160597613481727

Random Lists. (n.d.). Random team generator. Retrieved from https://www.randomlists.com/team-generator

Rollie, S. S., \& Duck, S. (2006). Divorce and dissolution of romantic relationships: Stage models and their limitations. In M.A. Fine \& J. H. Harvey (Eds.), Handbook of divorce and relationship dissolution (pp. 223-240). Mahwah, NJ: Erlbaum.

Safronova, V. (2015, June 26). Exes explain ghosting, the ultimate silent treatment. The New York Times. Retrieved from https://www.nytimes.com/2015/06/26/fashion/exes-explain-ghosting-the-ultimatesilent-treatment.html

Samakow, J. (2014, October 30). 'Ghosting': The 21 $1^{\text {st }}$-century dating problem everyone talks about, but no one knows how to deal with. Retrieved from https://www.huffingtonpost.ca/entry/ghosting-dating-_n_6028958

Simpson, J. A. (1990). Influence of attachment styles on romantic relationships. Journal of Personality and Social Psychology, 59(5), 971-980. doi:10.1037//00223514.59.5.971

Smith, A. (2016). 15\% of American adults have used online dating site or mobile dating apps. Pew Research Center. Retrieved from http://www.pewinternet.org

Smith, C. (2016). By the numbers: 41 impressive Tinder statistics. DMR. Retrieved from http://expandedramblings.com/index.php/tinder-statistics/

Spira, J. (2016, October 28). Why ghosting has become a cultural phenomenon. Retrieved from https://www.huffingtonpost.com/entry/why-ghosting-has-become-a-culturalphenomenon_us_5813bfa0e4b08301d33e0956

Sprecher, S. (1994). Two sides to the breakup of dating relationships. Personal Relationships, 1(3), 199-222. doi:10.1111/j.1475-6811.1994.tb00062.x

Sprecher, S., \& Fehr, B. (1998). The dissolution of close relationships. In J. H. Harvey (Ed.), Perspectives on loss: A sourcebook (pp. 99-112). Washington, DC: Taylor \& Francis. 
Sprecher, S., Felmlee, D., Metts, S., Fehr, B., \& Vanni, D. (1998). Factors associated with distress following the breakup of a close relationship. Journal of Social and Personal Relationships, 15(6), 791-809. doi:10.1177/0265407598156005

Sprecher, S., Zimmerman, C., \& Abrahams, E. M. (2010). Choosing compassionate strategies to end a relationship. Social Psychology, 41(2), 66-75. doi:10.1027/1864-9335/a000010

Syed, M., \& Nelson, S. C. (2015). Guidelines for establishing reliability when coding narrative data. Emerging Adulthood, 3(6), 375-387. doi:10.1177/2167696815587648

Tabachnick, B. G., \& Fidell, L. S. (2007). Using multivariate statistics $\left(5^{\text {th }}\right.$ ed.). New York: Allyn and Bacon.

Tashiro, T., \& Frazier, P. (2003). "I'll never be in a relationship like that again": Personal growth following romantic relationship breakups. Personal Relationships, 10(1), 113-128. doi:10.1111/1475-6811.00039

Tedeschi, R. G., \& Calhoun, L. G. (1996). The Posttraumatic Growth Inventory: Measuring the positive legacy of trauma. Journal of Traumatic Stress, 9(3), 455471. doi:10.1002/jts. 2490090305

Vilhauer, J. (2015, November 27). This is why ghosting hurts so much. Retrieved from https://www.psychologytoday.com/ca/blog/living-forward/201511/is-whyghosting-hurts-so-much

Warner, R. M. (2013). Applied statistics: from bivariate through multivariate techniques ( $2^{\text {nd }}$ ed.). Thousand Oaks, CA: SAGE Publications.

Wei, M., Russell, D. W., Mallinckrodt, B., \& Vogel, D. L. (2007). The Experiences in Close Relationship Scale (ECR)-Short Form: Reliability, validity, and factor structure. Journal of Personality Assessment, 88(2), 187-204. doi:10.1080/00223890701268041 


\section{Appendices}

\section{Appendix A: Study 1 MTurk Recruitment Advertisement.}

Researchers are trying to explore, define and describe the phenomenon of "ghosting" as a breakup strategy in both online and offline romantic relationships. If you choose to participate, you will be asked to answer questions about your most recent relationship breakup with a romantic interest or partner (including dating site matches, friends-withbenefits, casual dating partners, serious partners, etc.) as well as several demographic questions. Please be aware that certain questions are of a very personal nature and could potentially bring minor discomfort. If this sounds interesting to you, and you have experienced at least one romantic relationship breakup within the past five years, are between the ages of 18-35, speak English fluently, reside in the United States or Canada, and have an active MTurk account with at least 95\% approval from previous experimenters in whose studies you have participated, please see the attached link to participate. This study should take between 30-60 minutes to complete and you will be compensated with $\$ 1.00$ for participation. 


\section{Appendix B: Study 1 Letter of Information.}

\section{Project Title:}

Ghosting: Relationship Dissolution in the $21^{\text {st }}$ Century

\section{Investigators:}

Lorne Campbell, Ph.D., Department of Psychology, University of Western Ontario (Principal investigator)

Rebecca Koessler, B.Sc., M.Sc. candidate, Department of Psychology, University of Western Ontario

Taylor Kohut, Ph.D., Department of Psychology, University of Western Ontario

\section{LETTER OF INFORMATION}

\section{Invitation to Participate}

We invite you to participate in a research study that examines ghosting experiences, conducted by Dr. Lorne Campbell ( Rebecca Koessler

( of Western Ontario. You have been invited to participate because you expressed an interest in participating through Amazon's Mechanical Turk (MTurk).

\section{Purpose of this Letter}

The purpose of this letter is to provide you with information in order to allow you to make an informed decision regarding participation in this research. Participation may involve exposure to sensitive questions, and it is advised that participants conduct the study in a private place. You have the option to decline to take part or to withdraw from the study at any time without threat of penalty.

\section{Purpose of this Study}

The purpose of the current study is to explore, define, and describe the phenomenon of "ghosting" in the context of romantic relationships initiated both online and offline. The findings from this study will be used in future studies to better understand the motivations behind and consequences of ghosting.

\section{Inclusion Criteria}

Individuals interested in joining the study must be between 18 and 35 years of age, speak English fluently, and reside in Canada or the United States. Interested individuals must also have had a romantic interest or partner who they are no longer involved with (including dating site/app matches, friends-with-benefits, casual dating partners, serious partners, etc.) within the past 5 years, and have an active MTurk account with at least $95 \%$ approval from previous experimenters in whose studies they have participated.

\section{Exclusion Criteria}

Individuals who are under 18 years of age or over 35 years of age, do not speak English fluently, do not reside in Canada or the United States, have not had a romantic interest or partner with whom they are no longer involved within the past 5 years, and/or do not have an active account with MTurk with at least a $95 \%$ approval rating are not eligible to participate in this study. 


\section{Study Procedures}

If you agree to participate, you will be asked to answer a short questionnaire that assesses demographic information. Next, you will be asked to answer questions about your relationship with the last person you were romantically interested in but are no longer involved with, including additional questions about ghosting if applicable. Then, you will be asked to complete several scales that assess various personal beliefs and attitudes. Once the questionnaire is complete, you will be forwarded to a debriefing page and will be assigned an anonymous code used to claim compensation. This study will take between 30-60 minutes to complete. Approximately 500 people will participate in this research.

\section{Possible Risks and Harms}

Please be aware that certain questions are of a very personal nature and could potentially bring minor discomfort. If you experience discomfort for any reason, you are free to withdraw at any time.

\section{Possible Benefits}

You may not directly benefit from participating in this study, but your participation will contribute meaningfully to the body of knowledge in psychology, and will also benefit society by providing greater understanding of ghosting experiences within the context of romantic relationships.

\section{Compensation}

You will receive $\$ 1.00$ for participating in this study. If you should choose to withdraw from the study prior to submitting, you can still receive full compensation for your participation if you contact the researchers.

\section{Voluntary Participation}

Participation in this study is voluntary. You may refuse to participate, refuse to answer any questions, or withdraw from the study at any time.

\section{Confidentiality}

All data collected will remain confidential and will be accessible by the authorized investigator as well as the broader psychology scientific community. The data will be posted on the Open Science Framework website (OSF; https://osf.io) so that data may be inspected and analyzed by other researchers. The data that will be shared on the OSF website will not contain any information that can identify a participant. If you choose to withdraw from this study before its completion, your data will be removed and deleted from our database. If you choose to withdraw from the study after its completion we will be unable to remove your data from the database because we are not collecting any information that would allow us to identify your particular responses in the database. Representatives of the University of Western Ontario Non-Medical Research Ethics Board may contact you or require access to your study-related records to monitor the conduct of this research.

\section{Contacts for Further Information}

After you complete this study you will receive a debriefing sheet explaining the nature of the research. If you would like any further information regarding this research project or your participation in the study, you may contact Rebecca Koessler by email (—) or Dr. Lorne Campbell by email (_). If you have any questions about your rights as a research participant or the conduct of this study, you may contact the University of Western Ontario Office of Research Ethics by phone ) or email 


\section{Publication}

If the results of the study are published your name will not be used. If you would like to receive a copy of any potential study results, you may contact Rebecca Koessler by email ( ).

\section{Consent}

Please indicate your consent by clicking "I have read the letter of information and I agree to participate" at the bottom of the screen. If you select "I have read the letter of information and I DO NOT agree to participate," you will exit the survey. 


\section{Appendix C: Study 1 Survey. \\ Demographics}

Instructions: Please provide some basic information about yourself. This information will be used for statistical purposes only and will be treated confidentially.

What is your age in years?

What is your gender?

a. Male

b. Female

c. If you feel that your gender cannot be represented by one of the above check boxes we invite you to write in how you identify your gender in the space provided below.

Are you fluent in English?
a. Yes
b. No

Which best describes your current sexual orientation?

a. Heterosexual

b. Lesbian/Gay

c. Bisexual

d. If you feel that your sexual orientation cannot be represented by one of the above check boxes we invite you to write in how you identify your sexual orientation in the space provided below.

What is your current relationship status?
a. Single
b. Casually dating
c. Exclusively dating (monogamous)
d. Engaged
e. Married
f. Separated
g. Divorced
h. Widowed
i. None of these describe my relationship status. My relationship status can be described as:

What is your race?
a. Indigenous (North America)
b. Asian
c. East Asian 
d. South Asian

e. African American/Canadian or Black

f. Caucasian or White

g. Hispanic or Latinx

h. If you feel that your race cannot be represented by one of the above check boxes we invite you to write in how you identify your race in the space provided below.

Which of the following best describes your current religious affiliation (if any)?
a. Agnostic
b. Atheist
c. Buddhist
d. Christian
e. Hindu
f. Jewish
g. Muslim
h. None
i. If you feel that your religion cannot be represented by one of the above check boxes we invite you to write in how you identify your religion in the space provided below.

Have you ever used online dating sites or dating applications to find a potential romantic partner?
a. Yes
b. No

Please place a check mark next to the dating sites or applications that you have used previously.
a. Tinder
b. Bumble
c. Coffee meets bagel
d. OkCupid
e. Grindr
f. Match.com
g. eHarmony.com
h. PlentyOfFish
i. Other(s), please specify:

Are you currently using an online dating site or application to find a potential romantic partner?
a. Yes
b. No

If yes, what dating site(s) or application(s) are you using currently?
a. Tinder
b. Bumble 
c. Coffee meets bagel

d. OkCupid

e. Grindr

f. Match.com

g. eHarmony.com

h. PlentyOfFish

i. Other(s), please specify:

\section{Ghosting Questions}

Have you heard the term "ghosting" in the context of dating?
a. Yes
b. No

How would you define "ghosting" a romantic partner in the context of dating?

Please answer the following questions about ghosting using the following definition: Ghosting is the act of ending a relationship with a partner with whom romantic interest and attraction once existed by avoiding any type of communication and/or contact with that partner.

How many people have you "ghosted"?
a. 0
b. 1
c. 2
d. 3
e. 4
f. 5
g. More than 5

How many people have "ghosted" you?
a. 0
b. 1
c. 2
d. 3
e. 4
f. 5
g. More than 5

Some people believe that if you have explicitly expressed disinterest to a partner before avoiding contact with them, it is not considered ghosting because you provided them with an explanation. Do you agree or disagree with this view?
a. I agree
b. I disagree

Please explain why you agree or disagree with this view. 


\section{Relationship Dissolution Questions}

Please answer the following questions about your most recent romantic interest or partner who you are no longer involved with (including online dating site/app matches, one night stands, casual dating partners and monogamous partners, etc.)

How long ago did this relationship end?

a. Less than a week ago

b. Between a week and a month ago

c. Between a month and 3 months ago

d. Between 3 and 6 months ago

e. Between 6 months to a year ago

f. More than a year ago

g. More than 5 years ago

What was this person's gender?
a. Male
b. Female
c. Other, please specify:

How did you meet this partner?

a. Online dating site, please specify name of site:

b. Online dating app, please specify name of app:

c. By chance in person

d. Through a friend or family member

e. At school or on the school campus

f. Other, please specify:

What type of contact did you have with this partner? (check all that apply)

a. Communicated within a dating site/app

b. Exchanged phone numbers

c. Became friends or followed each other on social media (Facebook, Twitter, Snapchat, etc.)

d. Met in person

e. Met that person's friends or family

Approximately how long were you in a relationship with this partner before your relationship ended? Please specify unit of time (e.g. days, weeks, months, years).
a. Year(s):
b. Month(s):
c. Week(s):
d. $\operatorname{Day}(\mathrm{s})$ :

How committed were you to this partner?

Not at all 
$\begin{array}{lllllll}1 & 2 & 3 & 4 & 5 & 6 & 7\end{array}$

How would you characterize your relationship with this partner?

a. No relationship

b. Just friends

c. Friend with benefits (hook-ups, casual sex partner)

d. Casually (non-exclusively) dating

e. Seriously (exclusively) dating

f. Engaged

g. Other. Please describe:

How did your relationship end? Note: Ghosting is the act of ending a relationship with a partner with whom romantic interest and attraction once existed by avoiding any type of communication and/or contact with that partner.

a. I "ghosted" my partner

b. My partner "ghosted" me

c. I broke up with my partner, I did not "ghost" them

d. My partner broke up with me, they did not "ghost" me

e. I broke up with my partner, then I "ghosted" them

f. My partner broke up with me, then they "ghosted" me

g. The breakup was mutual

\section{**Participants who indicated they broke up with their partners (answered a, c, or e above) or indicated their breakups were mutual (answered g above) were shown the breakup tactics questionnaire below (adapted from Collins \& Gillath, 2012)}

Instructions: Please estimate the frequency with which you used the following strategies to facilitate the breakup with your partner.

Never Rarely Occasionally Sometimes Frequently Usually Extremely Often
1
2
3
4
5
6
7

1. I disclosed little about my personal activities and interests whenever we talked.

2. I avoided scheduling future meetings with my partner whenever possible.

3. I tried to prevent my partner from having any "hard feelings" about the breakup.

4. I tried to prevent us leaving on a "sour note" with one another.

5. I verbally explained to my partner my reasons for desiring the breakup.

6. I became unpleasant to my partner in the hopes that $\mathrm{s} /$ he would make the first move.

7. I picked an argument with my partner as an excuse to breakup.

8. I gave hints of my desire to breakup to people who knew the other person.

9. I terminated the relationship indirectly (through e-mail, text-messaging, or other unidirectional methods of communication)

10. I "waited it out" until conditions were conducive to breakup (e.g. until vacation time) 
**Participants who indicated they were broken up with by their partners (answered b, $\mathbf{d}$, or $\mathbf{f}$ above) or indicated their breakups were mutual (answered $\mathrm{g}$ above) were shown the breakup tactics questionnaire below (adapted from Collins \& Gillath, 2012)

Instructions: Please estimate the frequency with which you noticed your partner using the following strategies to facilitate the breakup with you.

Never Rarely Occasionally Sometimes Frequently Usually Extremely Often

$\begin{array}{lllllll}1 & 2 & 3 & 4 & 5 & 6 & 7\end{array}$

1. My partner disclosed little about their personal activities and interests whenever we talked.

2. My partner avoided scheduling future meetings with me whenever possible.

3. My partner tried to prevent me from having any "hard feelings" about the breakup.

4. My partner tried to prevent us leaving on a "sour note" with one another.

5. My partner verbally explained to me their reasons for desiring the breakup.

6. My partner became unpleasant to me in the hopes that I would make the first move.

7. My partner picked an argument with me as an excuse to breakup.

8. My partner gave hints of their desire to breakup to people who knew me.

9. My partner terminated the relationship indirectly (through e-mail, text-messaging, or other unidirectional methods of communication)

10. My partner "waited it out" until conditions were conducive to breakup (e.g. until vacation time)

**Participants who indicated they ghosted a partner in the past were asked the following questions:

How did you ghost this partner? Please explain in detail.

Why did you ghost this partner? Please explain in detail.

**Participants who indicated they had been ghosted by a partner in the past were asked the following questions:

How did this partner ghost you? Please explain in detail.

Why do you believe this partner ghosted you? Please explain in detail. 
What action(s) did you take, if any, in response to being ghosted?

How did your perceptions of this partner change after you realized they ghosted you?

\section{Breakup Distress (Field et al., 2009)}

Instructions: This scale consists of statements that describe different feelings and emotions. Indicate to what extent you felt this way when your relationship ended.

$\begin{array}{cccc}\text { Not at All } & \text { A Little } & \text { Moderately } & \text { Very Much So } \\ 1 & 2 & 3 & 4\end{array}$

1. I think about this person so much that it's hard for me to do things I normally do.

2. Memories of the person upset me.

3. I feel I cannot accept the breakup I've experienced.

4. I feel drawn to places and things associated with the person.

5. I can't help feeling angry about the breakup.

6. I feel disbelief over what happened.

7. I feel stunned or dazed over what happened.

8. Ever since the breakup it is hard for me to trust people.

9. Ever since the breakup I feel like I have lost the ability to care about other people or I feel distant from people I care about.

10. I have been experiencing pain since the breakup.

11. I go out of my way to avoid reminders of the person.

12. I feel that life is empty without the person.

13. I feel bitter over this breakup.

14. I feel envious of others who have not experienced a breakup like this.

15. I feel lonely a great deal of the time since the breakup.

16. I feel like crying when I think about the person.

\section{Dark Triad (Jonason \& Webster, 2010)}

Instructions: Here are a number of characteristics that may or may not apply to you. Please indicate the extent to which you agree or disagree with that statement.

$\begin{array}{ccccccc}\begin{array}{c}\text { Disagree } \\ \text { strongly }\end{array} & \begin{array}{c}\text { Disagree } \\ \text { moderately }\end{array} & \begin{array}{c}\text { Disagree a } \\ \text { little }\end{array} & \begin{array}{c}\text { Neither } \\ \text { agree nor } \\ \text { disagree }\end{array} & \begin{array}{c}\text { Agree a } \\ \text { little }\end{array} & \begin{array}{c}\text { Agree } \\ \text { moderately }\end{array} & \begin{array}{c}\text { Agree } \\ \text { strongly }\end{array} \\ 1 & 2 & 3 & 4 & 5 & 6 & 7\end{array}$

1. I tend to manipulate others to get my way.

2. I tend to lack remorse.

3. I tend to want others to admire me.

4. I have used deceit or lied to get my way. 
5. I tend to be unconcerned with the morality of my actions.

6. I tend to want others to pay attention to me.

7. I have used flattery to get my way.

8. I tend to be callous or insensitive.

9. I tend to seek status or prestige.

10. I tend to exploit others towards my own end.

11 . I tend to be cynical.

12. I tend to expect special favors from others.

\section{Attachment Style (Wei et al., 2007)}

Instructions: The following statements concern how you feel in romantic relationships. We are interested in how you generally experience relationships, not just in what is happening in a current relationship. Respond to each statement by indicating how much you agree or disagree with it. Mark your answer using the following rating scale:

$\begin{array}{ccccccc}\begin{array}{c}\text { Strongly } \\ \text { disagree }\end{array} & \text { Disagree } & \begin{array}{c}\text { Slightly } \\ \text { disagree }\end{array} & \text { Neutral } & \begin{array}{c}\text { Slightly } \\ \text { agree }\end{array} & \text { Agree } & \begin{array}{c}\text { Strongly } \\ \text { agree }\end{array} \\ 1 & 2 & 3 & 4 & 5 & 6 & 7\end{array}$

1. It helps to turn to my romantic partner in times of need.

2. I need a lot of reassurance that I am loved by my partner.

3. I want to get close to my partner, but I keep pulling back.

4. I find that my partner(s) don't want to get as close as I would like.

5. I turn to my partner for many things, including comfort and reassurance.

6. My desire to be very close sometimes scares people away.

7. I try to avoid getting too close to my partner.

8. I do not often worry about being abandoned.

9. I usually discuss my problems and concerns with my partner.

10. I get frustrated if romantic partners are not available when I need them.

11. I am nervous when partners get too close to me.

12. I worry that romantic partners won't care about me as much as I care about them. 


\section{Appendix D: Study 1 Debriefing Form.}

\section{Western :}

\section{Project Title:}

Ghosting: Relationship Dissolution in the $21^{\text {st }}$ Century

\section{Investigators:}

Lorne Campbell, Ph.D., Department of Psychology, University of Western Ontario (Principal investigator)

Rebecca Koessler, B.Sc., M.Sc. candidate, Department of Psychology, University of Western Ontario

Taylor Kohut, Ph.D., Department of Psychology, University of Western Ontario

\section{Debriefing Form}

Thank you for participating in this research. You have made an important contribution to a developing body of knowledge in psychology. Now that your participation is complete, we can tell you more about the study you have just participated in.

The current study was conducted to explore, define, and describe the phenomenon of "ghosting" as a relationship dissolution strategy in the context of romantic relationships initiated both online and offline, as well as to uncover any associations between "ghosting" and a variety of dispositional and situational measures. In addition, information about the frequency of and motivations behind ghosting experiences were collected for the purpose of furthering the field's knowledge of relationship dissolution in the modern dating world. The findings from this study will be used to develop an empirically-based definition of ghosting and guide predictions for future studies.

Your responses and participation are much appreciated. Without your involvement, it would not be possible to conduct this research. Thank you.

If you have any further questions about this research you may contact Rebecca Koessler by email ( or Dr. Lorne Campbell by email (_). If you have any questions about your rights as a research participant or the conduct of this study, you may contact The Office of Research Ethics , email:

\section{HIT CODE:}

Please be sure to copy this code to receive compensation for this study. Please print this letter for your future reference. 


\section{Appendix E: Study 2 MTurk Recruitment Advertisements.}

\section{Direct Disengager Advertisement:}

Researchers at Western University are interested in investigating whether different outcomes result from the use of certain breakup strategies during romantic relationship dissolution. Individuals interested in joining the study must be between 18 and 25 years of age, speak English fluently, reside in Canada or the United States and have an active MTurk account with at least $97 \%$ approval from previous experimenters in whose studies you have participated. Interested individuals must also have experienced a non-mutual breakup with a romantic partner whom they were casually or exclusively dating within the past 6 months. Participants who broke up with their partners by having a direct conversation are of primary interest (no mutual breakups). Please be aware that certain questions are of a very personal nature and could potentially bring minor discomfort. This study should take between 15-20 minutes to complete and you will be compensated with $\$ 0.50$ for your participation. Please contact Rebecca Koessler, B.Sc. or Dr. Lorne Campbell (_ with questions or concerns.

\section{Ghosting Disengager Advertisement:}

Researchers at Western University are interested in investigating whether different outcomes result from the use of certain breakup strategies during romantic relationship dissolution. Individuals interested in joining the study must be between 18 and 25 years of age, speak English fluently, reside in Canada or the United States and have an active MTurk account with at least $97 \%$ approval from previous experimenters in whose studies you have participated. Interested individuals must also have experienced a non-mutual breakup with a romantic partner whom they were casually or exclusively dating within the past 6 months. Participants who broke up with their partners by ghosting them are of primary interest (no mutual breakups). Please be aware that certain questions are of a very personal nature and could potentially bring minor discomfort. This study should take between 15-20 minutes to complete and you will be compensated with $\$ 0.50$ for your participation. Please contact Rebecca Koessler, B.Sc. ( or Dr. Lorne Campbell (_) with questions or concerns.

\section{Direct Recipient Advertisement:}

Researchers at Western University are interested in investigating whether different outcomes result from the use of certain breakup strategies during romantic relationship dissolution. Individuals interested in joining the study must be between 18 and 25 years of age, speak English fluently, reside in Canada or the United States and have an active MTurk account with at least $97 \%$ approval from previous experimenters in whose studies you have participated. Interested individuals must also have experienced a non-mutual breakup with a romantic partner whom they were casually or exclusively dating within the past 6 months. Participants who were broken up with by their partners through a

direct conversation are of primary interest (no mutual breakups). Please be aware that certain questions are of a very personal nature and could potentially bring minor discomfort. This study should take between 15-20 minutes to complete and you will be 
compensated with $\$ 0.50$ for your participation. Please contact Rebecca Koessler, B.Sc.

(1) or Dr. Lorne Campbell (—) with questions or concerns.

\section{Ghosting Recipient Advertisement:}

Researchers at Western University are interested in investigating whether different outcomes result from the use of certain breakup strategies during romantic relationship dissolution. Individuals interested in joining the study must be between 18 and 25 years of age, speak English fluently, reside in Canada or the United States, and have an active MTurk account with at least $97 \%$ approval from previous experimenters in whose studies you have participated. Interested individuals must also have experienced a non-mutual breakup with a romantic partner whom they were casually or exclusively dating within the past 6 months. Participants who were broken up with by their partners through ghosting are of primary interest (no mutual breakups). Please be aware that certain questions are of a very personal nature and could potentially bring minor discomfort. This study should take between 15-20 minutes to complete and you will be compensated with $\$ 0.50$ for your participation. Please contact Rebecca Koessler, B.Sc.

or Dr. Lorne Campbell (_) with questions or concerns. 


\section{Appendix F: Study 2 Survey. \\ Demographics}

Instructions: Please provide some basic information about yourself. This information will be used for statistical purposes only and will be treated confidentially.

What is your age in years?

What is your gender?

a. Male

b. Female

c. If you feel that your gender cannot be represented by one of the above check boxes we invite you to write in how you identify your gender in the space provided below.

Are you fluent in English?
a. Yes
b. No

Which best describes your current sexual orientation?

a. Heterosexual

b. Lesbian/Gay

c. Bisexual

d. If you feel that your sexual orientation cannot be represented by one of the above check boxes we invite you to write in how you identify your sexual orientation in the space provided below.

What is your current relationship status?
a. Single
b. Casually dating
c. Exclusively dating (monogamous)
d. Married
e. Divorced
f. None of these describe my relationship status. My relationship status can be described as:

What is your race?
a. Indigenous (North America)
b. Asian
c. South Asian
d. Middle Eastern
e. African European or Black
f. Caucasian or White 
g. Hispanic or Latinx

h. If you feel that your race cannot be represented by one of the above check boxes we invite you to write in how you identify your race in the space provided below.

Which of the following best describes your current religious affiliation (if any)?
a. Agnostic
b. Atheist
c. Buddhist
d. Christian
e. Hindu
f. Jewish
g. Muslim
h. Spiritual
i. None
j. If you feel that your religion cannot be represented by one of the above check boxes we invite you to write in how you identify your religion in the space provided below.

\section{Relationship Dissolution Questions}

Please answer the following questions about a recent romantic partner who you stopped being involved with in the past 6 months. All the following questions should be answered keeping the same breakup with the same partner in mind.

How long ago did this relationship end?

a. Less than a week ago

b. Between a week and a month ago

c. Between a month and 3 months ago

d. Between 3 and 6 months ago

e. More than 6 months ago

What was this person's gender?
a. Male
b. Female
c. Other, please specify:

How did you meet this partner?
a. Online dating site/app
b. By chance in person
c. Through a friend or family member
d. At school or at work
e. Other, please specify:

What type of contact did you have with this partner? (check all that apply)

a. Communicated online or within a dating site/app 
b. Exchanged phone numbers

c. Became friends or followed each other on social media (Facebook, Twitter, Snapchat, Instagram, etc.)

d. Met in person

e. Met that person's friends or family

Approximately how long were you in a relationship with this partner before your relationship ended? Please specify unit of time (e.g. days, weeks, months, years).
a. Year(s):
b. Month(s):
c. Week(s):
d. $\operatorname{Day}(\mathrm{s})$ :

How committed were you to this partner?

How would you characterize the relationship you had with this partner at the time of your breakup?
a. Friend with benefits (hook-ups, casual sex partner)
b. Casually (non-exclusively) dating
c. Seriously (exclusively) dating
d. Other. Please describe:

How did your relationship end?

a. I broke up with my partner

b. My partner broke up with me

c. The breakup was mutual

\section{**Participants who selected a) I broke up with my partner, were shown the following questions:}

How did you break up with your partner? **Note: Ghosting is the act of ending a relationship with a partner with whom romantic interest and attraction once existed by avoiding any type of communication and/or contact with that partner.

a. I had a direct conversation with my partner

b. I ghosted my partner

c. None of the above, I broke up with my partner in a different way

\section{**Ghosting and Direct Disengagers completed the questionnaire below (adapted from Collins \& Gillath, 2012)}

Instructions: The following are various strategies that can be employed during a romantic relationship breakup. Please indicate whether or not you used each strategy when you broke up with your partner. 


\begin{tabular}{|c|c|c|c|}
\hline \# & Breakup Tactic & \begin{tabular}{|l|} 
Yes, I \\
used \\
this \\
strategy
\end{tabular} & $\begin{array}{l}\text { No, I } \\
\text { did not } \\
\text { use this } \\
\text { strategy }\end{array}$ \\
\hline 1 & I dropped subtle "hints" that things had changed between us & & \\
\hline 2 & $\begin{array}{l}\text { I made the relationship more costly for my partner by being bitchy, } \\
\text { demanding, etc. }\end{array}$ & & \\
\hline 3 & $\begin{array}{l}\text { I procrastinated in saying or doing anything in the hopes that things } \\
\text { would improve }\end{array}$ & & \\
\hline 4 & I maintained our conversations on a superficial level & & \\
\hline 5 & $\begin{array}{l}\text { I tried to prevent my partner from having any "hard feelings" about } \\
\text { the breakup }\end{array}$ & & \\
\hline 6 & I used Caller ID to avoid calls on my cell phone from my partner & & \\
\hline 7 & $\begin{array}{l}\text { I tried to find reasons for the breakup other than things about our } \\
\text { relationship (e.g., a job offer, graduation, etc.) }\end{array}$ & & \\
\hline 8 & I honestly conveyed my wishes to my partner & & \\
\hline 9 & $\begin{array}{l}\text { I terminated the relationship indirectly (through e-mail, text- } \\
\text { messaging, or other unidirectional methods of communication) }\end{array}$ & & \\
\hline 10 & $\begin{array}{l}\text { I started dating someone else in the hopes my partner would learn } \\
\text { about my desire to breakup through my actions }\end{array}$ & & \\
\hline 11 & I avoided contact with my partner as much as possible & & \\
\hline 12 & $\begin{array}{l}\text { I tried to put my partner in a "good frame of mind" before breaking } \\
\text { the news to them }\end{array}$ & & \\
\hline 13 & $\begin{array}{l}\text { I took total blame for why the breakup was needed, even if I thought I } \\
\text { was not the only cause }\end{array}$ & & \\
\hline 14 & $\begin{array}{l}\text { I "waited it out" until conditions were conducive to breakup (e.g., } \\
\text { until vacation time) }\end{array}$ & & \\
\hline 15 & I kept our conversations brief whenever we talked & & \\
\hline 16 & I verbally explained to my partner my reasons for breaking up & & \\
\hline 17 & $\begin{array}{l}\text { I terminated the relationship without letting my partner know about it } \\
\text { directly, by changing my relationship status on my webpage } \\
\text { (Facebook, myspace, Friendster, other webpages) }\end{array}$ & & \\
\hline 18 & I reduced overt displays of liking and affection towards my partner & & \\
\hline 19 & $\begin{array}{l}\text { I disclosed little about my personal activities and interests whenever } \\
\text { we talked }\end{array}$ & & \\
\hline 20 & I avoided hurting my partner's feelings at all costs & & \\
\hline 21 & $\begin{array}{l}\text { I found a time and place when we could talk face to face about my } \\
\text { desire to breakup }\end{array}$ & & \\
\hline 22 & I picked an argument with my partner as an excuse to breakup & & \\
\hline 23 & I "eased into" the breakup by saying it was just a "temporary thing" & & \\
\hline 25 & I tried to prevent us leaving on a "sour note" with one another & & \\
\hline 26 & $\begin{array}{l}\text { I tried to convince my partner that the breakup was in both our } \\
\text { interests }\end{array}$ & & \\
\hline 27 & $\begin{array}{l}\text { I emphasized to my partner the good things gained from the } \\
\text { relationship in the past }\end{array}$ & & \\
\hline 28 & I ceased doing favors for my partner & & \\
\hline 29 & $\begin{array}{l}\text { I terminated the relationship avoiding confrontation (i.e., not "face to } \\
\text { face") by calling, writing, or Instant Messaging my partner how I felt }\end{array}$ & & \\
\hline
\end{tabular}




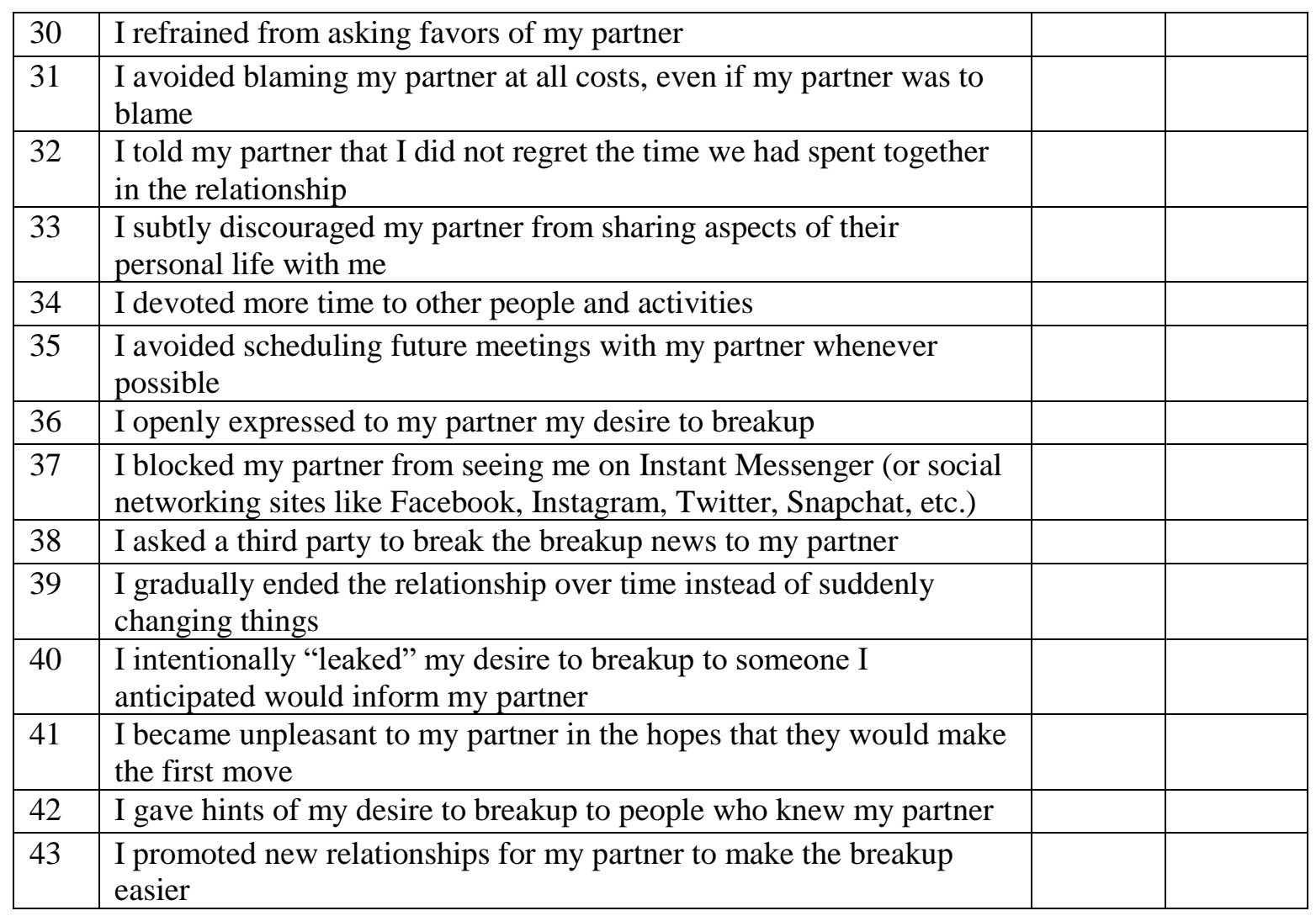

Please describe any other strategies you used when breaking up with your partner that were not listed above.

\section{**Participants who selected b) My partner broke up with me, were shown the following questions:}

How did you your partner break up with you? **Note: Ghosting is the act of ending a relationship with a partner with whom romantic interest and attraction once existed by avoiding any type of communication and/or contact with that partner.

a. My partner had a direct conversation with me

b. My partner ghosted me

c. None of the above, my partner broke up with me in a different way

\section{**Ghosting and Direct Recipients completed the questionnaire below (adapted from Collins \& Gillath, 2012)}

Instructions: The following are various strategies that can be employed during a romantic relationship breakup. Please indicate whether or not your partner used each strategy when they broke up with you.

\begin{tabular}{|c|c|c|c|}
\hline$\#$ & Breakup Tactic & $\begin{array}{c}\text { Yes, } \\
\text { my }\end{array}$ & $\begin{array}{c}\text { No, my } \\
\text { partner }\end{array}$ \\
\hline
\end{tabular}




\begin{tabular}{|c|c|c|c|}
\hline & & $\begin{array}{l}\text { partner } \\
\text { used } \\
\text { this } \\
\text { strategy }\end{array}$ & $\begin{array}{l}\text { did not } \\
\text { use this } \\
\text { strategy }\end{array}$ \\
\hline 1 & $\begin{array}{l}\text { My partner dropped subtle "hints" that things had changed between } \\
\text { us }\end{array}$ & & \\
\hline 2 & $\begin{array}{l}\text { My partner made the relationship more costly for me by being bitchy, } \\
\text { demanding, etc. }\end{array}$ & & \\
\hline 3 & $\begin{array}{l}\text { My partner procrastinated in saying or doing anything in the hopes } \\
\text { that things would improve }\end{array}$ & & \\
\hline 4 & My partner maintained our conversations on a superficial level & & \\
\hline 5 & $\begin{array}{l}\text { My partner tried to prevent me from having any "hard feelings" about } \\
\text { the breakup }\end{array}$ & & \\
\hline 6 & My partner used Caller ID to avoid calls on their cell phone from me & & \\
\hline 7 & $\begin{array}{l}\text { My partner tried to find reasons for the breakup other than things } \\
\text { about our relationship (e.g., a job offer, graduation, etc.) }\end{array}$ & & \\
\hline 8 & My partner honestly conveyed their wishes to me & & \\
\hline 9 & $\begin{array}{l}\text { My partner terminated the relationship indirectly (through e-mail, } \\
\text { text-messaging, or other unidirectional methods of communication) }\end{array}$ & & \\
\hline 10 & $\begin{array}{l}\text { My partner started dating someone else in the hopes I would learn } \\
\text { about their desire to breakup through their actions }\end{array}$ & & \\
\hline 11 & My partner avoided contact with me as much as possible & & \\
\hline 12 & $\begin{array}{l}\text { My partner tried to put me in a "good frame of mind" before breaking } \\
\text { the news to me }\end{array}$ & & \\
\hline 13 & $\begin{array}{l}\text { My partner took total blame for why the breakup was needed, even if } \\
\text { they thought they was not the only cause }\end{array}$ & & \\
\hline 14 & $\begin{array}{l}\text { My partner "waited it out" until conditions were conducive to } \\
\text { breakup (e.g., until vacation time) }\end{array}$ & & \\
\hline 15 & My partner kept our conversations brief whenever we talked & & \\
\hline 16 & My partner verbally explained to me their reasons for breaking up & & \\
\hline 17 & $\begin{array}{l}\text { My partner terminated the relationship without letting me know about } \\
\text { it directly, by changing their relationship status on their webpage } \\
\text { (Facebook, myspace, Friendster, other webpages) }\end{array}$ & & \\
\hline 18 & My partner reduced overt displays of liking and affection towards me & & \\
\hline 19 & $\begin{array}{l}\text { My partner disclosed little about their personal activities and interests } \\
\text { whenever we talked }\end{array}$ & & \\
\hline 20 & My partner avoided hurting my feelings at all costs & & \\
\hline 21 & $\begin{array}{l}\text { My partner found a time and place when we could talk face to face } \\
\text { about their desire to breakup }\end{array}$ & & \\
\hline 22 & My partner picked an argument with me as an excuse to breakup & & \\
\hline 23 & $\begin{array}{l}\text { My partner "eased into" the breakup by saying it was just a } \\
\text { "temporary thing" }\end{array}$ & & \\
\hline 25 & $\begin{array}{l}\text { My partner tried to prevent us leaving on a "sour note" with one } \\
\text { another }\end{array}$ & & \\
\hline 26 & $\begin{array}{l}\text { My partner tried to convince me that the breakup was in both our } \\
\text { interests }\end{array}$ & & \\
\hline 27 & $\begin{array}{l}\text { My partner emphasized to me the good things gained from the } \\
\text { relationship in the past }\end{array}$ & & \\
\hline
\end{tabular}




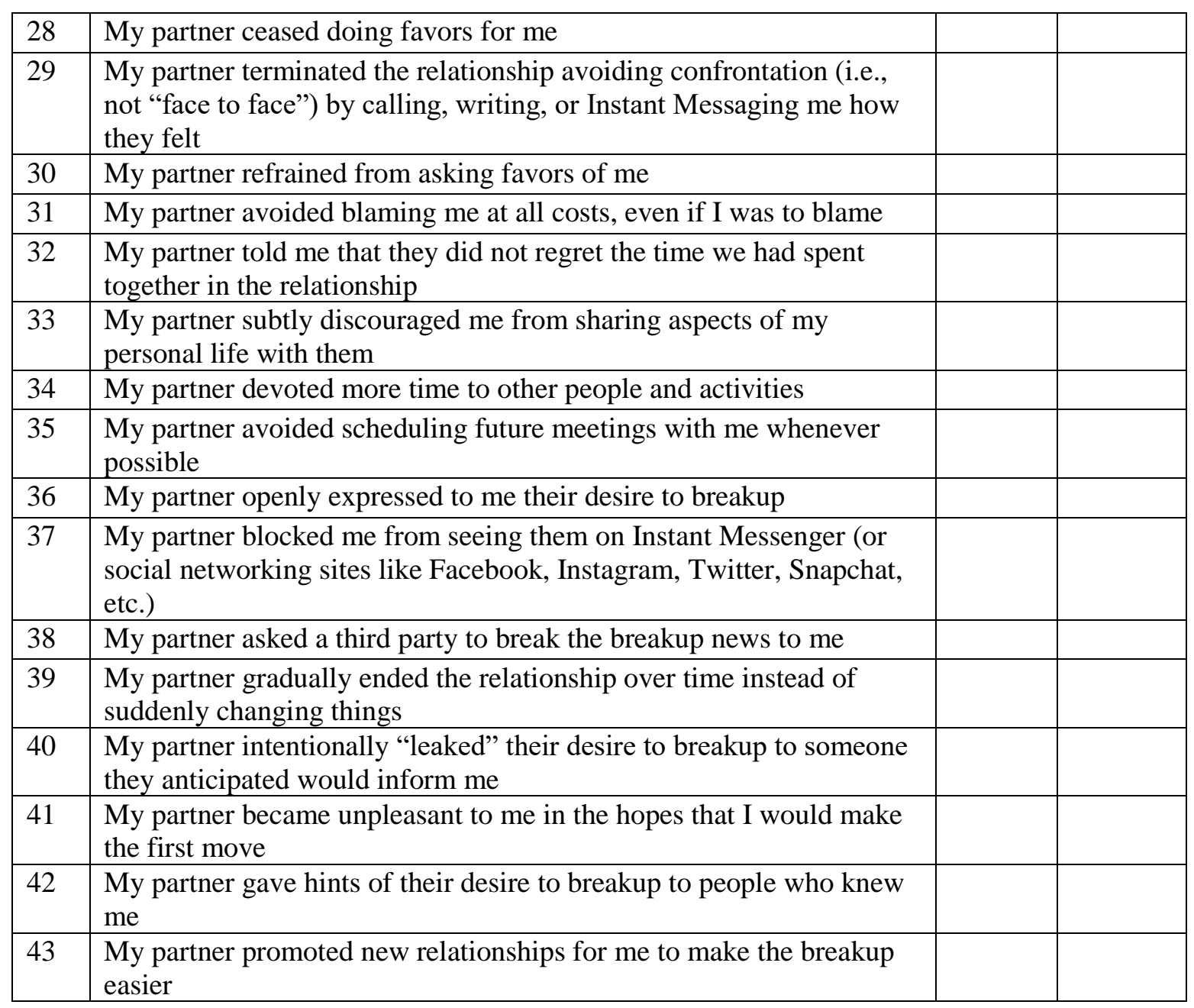

Please describe any other strategies your partner used when breaking up with you that were not listed above.

\section{**Direct Disengagers completed this questionnaire (Motivation for Breakup Strategy Choice Questionnaire, created by the researchers)}

Instructions: You indicated previously that you broke up with your last partner by having a direct conversation with them. Please indicate to what extent each of the motivations below affected your decision to break up with your partner directly. Please focus on what motivated your decision to break up with your partner in the way that you did, rather than why you wanted to no longer be in a relationship with your partner in general.

Did not affect my decision at all
Somewhat

affected

my

decision
Extremely

affected my decision 
$\begin{array}{lllllll}1 & 2 & 3 & 4 & 5 & 6 & 7\end{array}$

1. I did not think my partner and I were compatible

2. I wanted to have control over the breakup

3. I wanted to make my intentions/desire for separation clear

4. I did not want to hurt my partner's feelings

5. I became interested in someone else

6. Our relationship was not very serious

7. I became bored with the relationship

8. I wanted to explain why I wanted to breakup

9. I did not want my partner to be confused

10. I wanted to be honest with my partner

11. I wanted to show my partner I respect them

12. I wanted to tell my partner that I valued the time we shared together

13. I wanted to try and support my partner even though I was breaking up with them

14. I wanted to try and be friends with my partner after we broke up

15. I knew I would encounter my partner in the future and did not want it to be awkward

16. I wanted to tell my partner that the breakup was because of me ("It's not you, it's me)

If there was a motivation not listed above that affected your decision to break up with your partner directly, please describe and explain below.

\section{**Ghosting Disengagers completed this questionnaire (Motivation for Breakup Strategy Choice Questionnaire, created by the researchers)}

Instructions: You indicated previously that you broke up with your last partner by ghosting them. Please indicate to what extent each of the motivations below affected your decision to break up with your partner through ghosting. Please focus on what motivated your decision to break up with your partner in the way that you did, rather than why you wanted to no longer be in a relationship with your partner in general.

Did not affect

my decision at

all
Somewhat

affected my

decision

$4 \quad 5$
Extremely

affected my

decision

1

2

3

5

6

7

1. I did not think my partner and I were compatible

2. I wanted to have control over the breakup

3. I wanted to make my intentions/desire for separation clear

4. I did not want to hurt my partner's feelings

5. I became interested in someone else

6. Our relationship was not very serious

7. I became bored with the relationship 
8. I felt it would be too painful to break up in person

9. I wanted to avoid an argument with my partner

10. I did not want my partner to ask me for another chance

11. It was too much effort to explain why I wanted to breakup

12. I felt bad telling them I wanted to breakup

13. I was anxious about telling them I wanted to break up

14. I did not want to deal with a breakup

15. I just wanted to get away from my partner

16. I could not face my partner

17. I did not want to have a confrontation with my partner

18. I was unsure how to tell them directly that I wanted to break up

19. I had tried to break up with my partner directly first, but it failed

20. My partner would overreact/be dramatic about the breakup

21. My partner deserved to be ghosted

If there was a motivation not listed above that affected your decision to break up with your partner through ghosting, please describe and explain below.

\section{**Direct Recipients completed this questionnaire (Motivation for Breakup Strategy Choice Questionnaire, created by the researchers)}

Instructions: You indicated previously that your last partner broke up with you by having a direct conversation. Please indicate to what extent you believe each of the motivations below affected your partner's decision to break up with you directly. Please focus on what you believe motivated your partner's decision to break up with you in the way that they did, rather than why you believe your partner no longer wanted to be in a relationship with you in general.

Did not affect my decision at all

1

\author{
Somewhat \\ affected my \\ decision
}

4
Extremely affected my decision

1. My partner did not think we were compatible

2. My partner wanted to have control over the breakup

3. My partner wanted to make their intentions/desire for separation clear

4. My partner did not want to hurt my feelings

5. My partner became interested in someone else

6. Our relationship was not very serious

7. My partner became bored with the relationship

8. My partner wanted to explain why they wanted to breakup

9. My partner did not want me to be confused

10. My partner wanted to be honest with me

11. My partner wanted to show they respect me

12. My partner wanted to tell me that they valued the time we shared together 
13. My partner wanted to try and support me even though they were breaking up with me

14. My partner wanted to try and be friends with me after we broke up

15. My partner knew they would encounter me in the future and did not want it to be awkward

16. My partner wanted to tell me that the breakup was because of them ("It's not you, it's me)

If there was a motivation not listed above that you believe affected your partner's decision to break up with you directly, please describe and explain below.

\section{**Ghosting Recipients completed this questionnaire (Motivation for Breakup Strategy Choice Questionnaire, created by the researchers)}

Instructions: You indicated previously that your last partner broke up with you by ghosting you. Please indicate to what extent you believe each of the motivations below affected your partner's decision to break up with you through ghosting. Please focus on what motivated your partner's decision to break up with you in the way that they did, rather than why you believe your partner no longer wanted to be in a relationship with you in general.

Did not affect

my decision

at all

\author{
Somewhat \\ affected my \\ decision
}

Extremely

affected my

decision
1
2
3
4
5
6
7

1. My partner did not think we were compatible

2. My partner wanted to have control over the breakup

3. My partner wanted to make their intentions/desire for separation clear

4. My partner did not want to hurt my feelings

5. My partner became interested in someone else

6. Our relationship was not very serious

7. My partner became bored with the relationship

8. My partner felt it would be too painful to break up in person

9. My partner wanted to avoid an argument with me

10. My partner did not want me to ask them for another chance

11. My partner thought it was too much effort to explain why they wanted to breakup

12. My partner felt bad telling me they wanted to breakup

13. My partner was anxious about telling me they wanted to break up

14. My partner did not want to deal with a breakup

15. My partner just wanted to get away from me

16. My partner could not face me

17. My partner did not want to have a confrontation with me

18. My partner was unsure how to tell me directly that they wanted to break up 
19. My partner had tried to break up with me directly first, but it failed

20. My partner thought I would overreact/be dramatic about the breakup

21. My partner thought I deserved to be ghosted

If there was a motivation not listed above that you believe affected your partner's decision to break up with you through ghosting, please describe and explain below.

**All participants completed the following scales.

\section{Breakup Distress (BDS; Field et al, 2009)}

Instructions: This scale consists of statements that describe different feelings and emotions. Indicate which extent you felt this way when your relationship ended.

$\begin{array}{cccc}\text { Not at all } & \text { A Little } & \text { Moderately } & \text { Very Much So } \\ 1 & 2 & 3 & 4\end{array}$

1. I thought about this person so much that it was hard for me to do things I normally did

2. Memories of the person upset me

3. I felt I could not accept the breakup I experienced

4. I felt drawn to places and things associated with the person

5. I couldn't help feeling angry about the breakup

6. I felt disbelief over what happened

7. I felt stunned or dazed over what happened

8. Ever since the breakup it was hard for me to trust people

9. Ever since the breakup I felt like I had lost the ability to care about other people or I felt distant from people I care about

10. I had been experiencing pain since the breakup

11. I went out of my way to avoid reminders of the person

12. I felt that life was empty without the person

13. I felt bitter over this breakup

14. I felt envious of others who had not experienced a breakup like this

15. I felt lonely a great deal of the time since the breakup

16. I felt like crying when I thought about the person

\section{Breakup Emotions (BES; Sprecher, 1994)}

Instructions: Please indicate the degree to which you experienced each emotion initially after the breakup.

Not at all

1
2
Somewhat

3
4
5
Extremely

6

7 
1. Depression

2. Guilt

3. Anger

4. Hate

5. Frustration

6. Resentment

7. Loneliness

8. Jealousy

9. Hurt

10. Contentment

11. Joy

12. Happiness

13. Satisfaction

14. Love

15. Relief

Post-Breakup Recovery (PBR; Tedseschi \& Calhoun, 1996)

Instructions: How much life change have you experienced in different areas as a result of your breakup?

$\begin{array}{cccccc}\begin{array}{c}\text { I did not } \\ \text { experience } \\ \text { this }\end{array} & \begin{array}{c}\text { I experienced } \\ \text { this to a very } \\ \text { small degree }\end{array} & \begin{array}{c}\text { I experienced } \\ \text { this to a small } \\ \text { degree }\end{array} & \begin{array}{c}\text { I experienced } \\ \text { this to a } \\ \text { moderate } \\ \text { degree }\end{array} & \begin{array}{c}\text { I experienced } \\ \text { this to a great } \\ \text { degree }\end{array} & \begin{array}{c}\text { I experienced } \\ \text { this to a very } \\ \text { great degree }\end{array} \\ 1 & 2 & 3 & 4 & 5 & 6\end{array}$

1. Knowing that I can count on people in times of trouble

2. A sense of closeness with others

3. A willingness to express my emotions

4. Having compassion for others

5. Putting effort into my relationships

6. I learned a great deal about how wonderful people are

7. I accept needing others

8. Developed new interests

9. I established a new path for my life

10. I'm able to do better things with my life

11. New opportunities are available which wouldn't have been otherwise

12. I'm more likely to try to change things which need changing

13. A feeling of self-reliance

14. Knowing I can handle difficulties

15. Being able to accept the way things work out

16. I discovered that I'm stronger than I thought I was

17. A better understanding of spiritual matters

18. I have stronger religious faith

19. My priorities about what is important in life

20. An appreciation for the value of my own life

21. Appreciating each day 


\section{Appendix G: Study 2 Eligibility Screening Questionnaire.}

The following questions are included in the present survey. If a participant indicates any of the answers below they will be excluded from future data analysis. All participants will still receive compensation even if they provided any of the answers below if they submit the survey (MTurk), withdraw during the study (SONA), or contact the researchers after withdrawing from the study (MTurk).

DEM_AGE: What is your age in years?

In-eligible answer: below 18, over 25

DEM_ENG: Are you fluent in English?

In-eligible answer: No

MRR_01: How long ago did this relationship end?

In-eligible answer: more than 6 months ago

MRR_08: How did your relationship end?

In-eligible answer: The breakup was mutual

MRR_09_Dis: How did you break up with your partner?

In-eligible answer: None of the above, I broke up with my partner in a different way

MRR_09_Rec: How did your partner break up with you?

In-eligible answer: None of the above, my partner broke up with me in a different way 


\section{Appendix H: Study 2 Letter of Information.}

\section{Project Title:}

Romantic Relationship Dissolution and Breakup Strategy Use

\section{Investigators:}

Lorne Campbell, Ph.D., Department of Psychology, University of Western Ontario (Principal investigator)

Rebecca Koessler, B.Sc., M.Sc. candidate, Department of Psychology, University of Western Ontario

Taylor Kohut, Ph.D., Department of Psychology, University of Western Ontario

\section{LETTER OF INFORMATION}

\section{Invitation to Participate}

We invite you to participate in a research study that examines romantic relationship breakup experiences, conducted by Dr. Lorne Campbell ( $)$, Rebecca Koessler ( the University of Western Ontario. You have been invited to participate because you expressed an interest in participating through Prolific Academic.

\section{Purpose of this Letter}

The purpose of this letter is to provide you with information in order to allow you to make an informed decision regarding participation in this research. Participation may involve exposure to sensitive questions, and it is advised that participants conduct the study in a private place. You have the option to decline to take part or to withdraw from the study at any time without threat of penalty.

\section{Purpose of this Study}

The purpose of the current study is to investigate the differences in motivations for choosing certain breakup strategies and the consequences of those choices with regard to post-breakup outcomes like distress and personal growth.

\section{Inclusion Criteria}

Individuals interested in joining the study must be between 18 and 35 years of age, speak English fluently, and reside in Canada or the United States and have an active MTurk account with at least $97 \%$ approval from previous experimenters in whose studies you have participated. Interested individuals must also have experienced a non-mutual breakup with a romantic partner whom they were casually or exclusively dating within the past 6 months.

\section{Exclusion Criteria}

Individuals who are under 18 years of age or over 35 years of age, do not speak English fluently, do not reside in Canada or the United States, do not have an active MTurk account with at least $97 \%$ approval from previous experimenters in whose studies you have participated, and who have not experienced a non-mutual breakup with a romantic partner whom they were casually or exclusively dating within the past 6 months are not eligible to participate in this study. 


\section{Study Procedures}

If you agree to participate, you will be asked to answer a short questionnaire that assesses demographic information. Next, you will be asked to answer questions about your relationship with the romantic partner whom you are no longer involved with, including details about how your breakup occurred, and the feelings you experienced after the breakup. Once the questionnaire is complete, you will be forwarded to a debriefing page and will be assigned an anonymous code used to claim compensation. This study will take approximately 20 minutes to complete. The researchers intend to recruit 300 people from MTurk to participate in this research in addition to approximately 400 participants from an undergraduate university sample.

\section{Possible Risks and Harms}

Please be aware that certain questions are of a very personal nature and could potentially bring minor discomfort. If you experience discomfort for any reason, you are free to withdraw at any time.

\section{Possible Benefits}

You may not directly benefit from participating in this study, but your participation will contribute meaningfully to the body of knowledge in psychology, and will also benefit society by providing greater understanding of the motivations behind utilizing certain breakup strategies and the differences in post-breakup outcomes like distress and personal growth depending on the type of breakup strategy used during relationship dissolution.

\section{Compensation}

You will receive $\$ 0.50$ for participating in this study. If you should choose to withdraw from the study prior to submitting, you can still receive full compensation for your participation if you contact the researchers.

\section{Voluntary Participation}

Participation in this study is voluntary. You may refuse to participate, refuse to answer any questions, or withdraw from the study at any time.

\section{Confidentiality}

All data collected will remain confidential and will be accessible by the authorized investigator as well as the broader psychology scientific community. The data will be posted on the Open Science Framework website (OSF; https://osf.io) so that data may be inspected and analyzed by other researchers. The data that will be shared on the OSF website will not contain any information that can identify a participant. If you choose to withdraw from this study before its completion, your data will be removed and deleted from our database. If you choose to withdraw from the study after its completion we will be unable to remove your data from the database because we are not collecting any information that would allow us to identify your particular responses in the database. Representatives of the University of Western Ontario Non-Medical Research Ethics Board may contact you or require access to your study-related records to monitor the conduct of this research.

\section{Contacts for Further Information}

After you complete this study you will receive a debriefing sheet explaining the nature of the research. If you would like any further information regarding this research project or your participation in the study, you may contact Rebecca Koessler by email 
or Dr. Lorne Campbell by email (
). If you have any questions about your rights as a research participant or the conduct of this study, you may contact the University of Western Ontario Office of Human Research Ethics by phone ( (1).

\section{Publication}

If the results of the study are published your name will not be used. If you would like to receive a copy of any potential study results, you may contact Rebecca Koessler by email ( $)$.

\section{Consent}

Please indicate your consent by clicking "I have read the letter of information and I agree to participate" at the bottom of the screen. If you select "I have read the letter of information and I DO NOT agree to participate," you will exit the survey. 


\section{Appendix I: Study 2 Debriefing Form.}

\section{Western :}

Project Title:

Romantic Relationship Dissolution and Breakup Strategy Use

\section{Investigators:}

Lorne Campbell, Ph.D., Department of Psychology, University of Western Ontario (Principal investigator)

Rebecca Koessler, B.Sc., M.Sc. candidate, Department of Psychology, University of Western Ontario

Taylor Kohut, Ph.D., Department of Psychology, University of Western Ontario

\section{Debriefing Form}

Thank you for participating in this research. You have made an important contribution to a developing body of knowledge in psychology. Now that your participation is complete, we can tell you more about the study you have just participated in.

The current study was conducted to explore whether motivations for use of certain breakup strategies, specifically "ghosting" versus having a direct conversation, differ in a meaningful way. In addition, differences in post-breakup outcomes like distress, positive and negative emotions, and personal growth will be compared between participants who experienced a breakup through ghosting and participants who experienced a breakup through a direct conversation. Comparisons between participants who initiated their breakups and participants who were broken up with will also be made using the post-breakup outcome measures. The information collected from this study will help further the field's knowledge of relationship dissolution in the modern dating world, as ghosting is a rather new phenomenon that has not yet been investigated in depth. The findings from this study will be used to determine whether post-breakup outcomes (distress and growth) differ depending on the breakup strategy used (ghosting vs direct conversation) and whether the individual was the disengager (desired the breakup) or the recipient (did not desire the breakup). Additionally, the findings will be used to identify specific motivations which may predict the use of certain breakup strategies.

Your responses and participation are much appreciated. Without your involvement, it would not be possible to conduct this research. Thank you.

If you have any further questions about this research you may contact Rebecca Koessler by email or Dr. Lorne Campbell by email ( If you have any questions about your rights as a research participant or the
conduct of this study, you may contact The Office of Human Research Ethics email:

HIT CODE:

Please be sure to copy this code to receive compensation for this study. Please print this letter for your future reference. 


\section{Appendix J: Exploratory Factor Analyses of the Motivations for Breakup Strategy Choice (MBSC) Questionnaires.}

Exploratory factor analyses (EFA) of the direct MBSC and ghosting MBSC were conducted to reduce and classify the motivation items that were drawn from Study 1 and created by the researchers to identify differences in motivations or perceived motivations that exist between disengagers and recipients for each breakup type. The purpose of this factor analysis was not to create and validate an MBSC scale, but rather to assess the extent to which the collated items can be interpreted as underlying motivations that cause individuals to choose a certain breakup strategy to dissolve their relationships. These EFAs were data-driven, meaning the researchers did not make predictions about which items may group together into certain factors before the EFAs were conducted. The full sample $(N=595)$ was used to conduct both EFAs.

Before the direct MBSC EFA was conducted the items were screened for violations of assumptions. Each item was quantitative, and histograms along with skewness and kurtosis values were obtained to assess the normality of the distribution of scores for each item. Skewness and kurtosis values for all items fell within the range of 1.5 to 1.5 (Tabachnick \& Fiddell, 2007), and thus were considered normal. Scatterplots for each pair of items were obtained to confirm the relations between each pair were linear in nature. A correlation matrix of the 16 items was obtained and examined for acceptable amounts of correlations that differed significantly from zero and were at or above 3 in absolute magnitude (Warner, 2013). This assumption being satisfied indicated the correlation matrix would be factorable. Once the assumptions of factor analysis were demonstrated to be satisfied, the EFA was conducted.

To assess the dimensionality of the 16-item direct MBSC scale, an EFA was conducted using principal axis factoring utilizing the program SPSS (Version 25.0.0.0). Four factors were extracted with eigenvalues of 4.96, 2.37, 1.80, and 1.13. Item 2 ("I wanted to have control over the breakup/ "My partner wanted to have control over the breakup") was removed, as the corrected item-total correlation statistics indicated that item 2 showed a negative and low magnitude correlation (-.015). The EFA was run again, and three factors emerged with a pattern of eigenvalues over 1 (first factor $=4.95$, second factor $=2.37$, third factor $=1.66$ ). The oblimin rotated factor loadings and cross loadings for the retained factors from the second EFA that are used in the Sample A and Sample B analyses are shown in Table J1. Criteria deemed acceptable were factor loadings over (or approaching) .5 that did not have any cross loadings over .4. As such, items 1 and 11 ("I wanted to show my partner I respect them"/ "My partner wanted to show they respect me") did not meet these criteria and were not considered as part of any of the retained factors. The rotated three-factor solution demonstrated the three factors were not substantially correlated, ranging from $r=-0.16$ to $r=.13$. 
Table J1. Rotated factor loadings and cross-loadings for the final EFA of the direct MBSC scale.

\begin{tabular}{lccc}
\hline Item & Gentle Breakup & $\begin{array}{c}\text { Clarity and } \\
\text { Understanding }\end{array}$ & $\begin{array}{c}\text { Done with } \\
\text { Relationship }\end{array}$ \\
\hline MBSC 4 & $\mathbf{0 . 6 4}$ & -0.24 & 0.03 \\
MBSC 12 & $\mathbf{0 . 7 7}$ & -0.25 & -0.10 \\
MBSC 13 & $\mathbf{0 . 8 5}$ & -0.07 & -0.06 \\
MBSC 14 & $\mathbf{0 . 6 4}$ & 0.16 & 0.05 \\
MBSC 15 & $\mathbf{0 . 5 0}$ & 0.06 & 0.01 \\
MBSC 16 & $\mathbf{0 . 4 9}$ & 0.13 & 0.25 \\
MBSC 3 & -0.09 & $\mathbf{- 0 . 6 3}$ & -0.13 \\
MBSC 8 & 0.22 & $\mathbf{- 0 . 7 0}$ & -0.09 \\
MBSC 9 & 0.31 & $\mathbf{- 0 . 6 9}$ & -0.37 \\
MBSC 10 & 0.35 & $\mathbf{- 0 . 6 6}$ & -0.17 \\
MBSC 5 & 0.06 & 0.12 & $\mathbf{0 . 5 5}$ \\
MBSC 6 & 0.13 & 0.06 & $\mathbf{0 . 6 3}$ \\
MBSC 7 & -0.06 & -0.18 & $\mathbf{0 . 6 9}$ \\
\hline Note. Bold
\end{tabular}

Note. Bolded numbers represent primary factor loadings with non-bolded numbers representing cross loadings. Numbers following the scale name represent original item numbers.

The first factor, labeled gentle breakup contained six items $\left(\alpha_{\text {disengager }}=.79\right.$, $\left.\alpha_{\text {recipient }}=.83\right)$ and is characterized by concern of the disengager for the recipient's feelings during the breakup, for example, item 4, "I did not want to hurt my partner's feelings." In addition, two items reflected the possibility of encountering the recipient in the future or desiring to maintain a friendship with the recipient after the breakup (e.g., item 15, "I knew I would encounter my partner in the future and did not want it to be awkward"). The second factor, labeled clarity and understanding, contained four items $\left(\alpha_{\text {disengager }}=.82, \alpha_{\text {recipient }}=.81\right)$ and was characterized by the desire of the disengagers to be clear, honest, and explain why they desired to separate from their partners (e.g., item 9, "I did not want my partner to be confused"). The third factor, labeled done with relationship, contained three items ( $\left.\alpha_{\text {disengager }}=.70, \alpha_{\text {recipient }}=.55\right)$ and is characterized by dwindling interest in the relationship or relationship partner (e.g., item 7, "I became interested in someone else").

Before the ghosting MBSC EFA was conducted the items were screened for violations of assumptions The distributions of each item were acceptably normally distributed, as none elicited inflated values of skewness and kurtosis that exceeded -1.5 or 1.5 (Tabachnick \& Fiddell, 2007). Scatterplots for each pair of items were obtained to confirm the relations between each pair were linear in nature. The correlation matrix of all 21 items was found to have a variety of correlation magnitudes and correlations that differed significantly from zero (Warner, 2013). The EFA was conducted after the assumptions were considered to be satisfied. 
Using principal axis factoring with an oblimin rotation, six factors were initially extracted with eigenvalues over 1 (first factor $=5.23$, second factor $=2.12$, third factor $=$ 2.01 , fourth factor $=1.54$, fifth factor $=1.13$, sixth factor $=1.02$ ). After examining the pattern matrix, item 2 ("I wanted to have control over the breakup/ "My partner wanted to have control over the breakup") was removed because it was the only item that loaded strongly on the fifth factor without any large cross loadings (greater than .3). The EFA was run again without item 2 and revealed a five-factor structure with eigenvalues of $5.15,2.12,1.93,1.53$, and 1.03. The pattern matrix revealed that item 21 ("My partner deserved to be ghosted"/ "My partner thought I deserved to be ghosted") was the only item that loaded strongly onto the fifth factor without any large cross loadings. This item was removed, and the EFA was run a third and final time. The retained four-factor structure of the ghosting MBSC with oblimin rotated factor loadings and cross loadings that were used in the Sample A and Sample B analyses are shown in Table J2. Criteria deemed acceptable were factor loadings over (or approaching) .5 that did not have any cross loadings over .4. As such, items 3, 5, 8, 10, 13 and 15 did not meet these criteria and were not considered part of any of the retained factors. The rotated four-factor solution demonstrated slight correlations between the three factors, ranging from $r=-$ 0.10 to $r=.29$.

Table J2. Rotated factor loadings and cross-loadings for the final EFA of the ghosting MBSC scale.

\begin{tabular}{|c|c|c|c|c|}
\hline Item & Avoidance & $\begin{array}{l}\text { Done with } \\
\text { Relationship }\end{array}$ & Guilt & $\begin{array}{c}\text { Anticipated a } \\
\text { Difficult } \\
\text { Breakup }\end{array}$ \\
\hline MBSC 9 & 0.68 & -0.04 & 0.02 & 0.18 \\
\hline MBSC 11 & 0.50 & 0.16 & 0.02 & -0.01 \\
\hline MBSC 14 & 0.69 & 0.08 & -0.06 & -0.14 \\
\hline MBSC 16 & 0.69 & -0.16 & -0.14 & -0.06 \\
\hline MBSC 17 & 0.80 & -0.03 & 0.05 & 0.02 \\
\hline MBSC 18 & 0.51 & 0.18 & -0.37 & -0.02 \\
\hline MBSC 1 & 0.10 & 0.55 & 0.03 & 0.19 \\
\hline MBSC 6 & -0.17 & 0.69 & -0.16 & -0.12 \\
\hline MBSC 7 & 0.04 & 0.69 & 0.07 & -0.03 \\
\hline MBSC 4 & -0.07 & 0.12 & -0.52 & 0.21 \\
\hline MBSC 12 & 0.27 & 0.11 & -0.67 & 0.02 \\
\hline MBSC 19 & -0.19 & -0.02 & -0.10 & 0.70 \\
\hline MBSC 20 & 0.19 & -0.06 & 0.07 & 0.68 \\
\hline
\end{tabular}

Note. Bolded numbers represent primary factor loadings with non-bolded numbers representing cross loadings. Numbers following the scale name represent original item numbers. 
The first factor, labeled avoidance contained six items $\left(\alpha_{\text {disengager }}=.84, \alpha_{\text {recipient }}=\right.$ .81 ) and was characterized by the unwillingness or hesitancy on the part of the disengager to facilitate a breakup conversation, for example, item 18, "I was unsure how to tell them directly that I wanted to break up." The second factor, labeled done with relationship, contained three items ( $\left.\alpha_{\text {disengager }}=.76, \alpha_{\text {recipient }}=.45\right)$ and was characterized by the belief of the disengager that the relationship with the recipient was not working out (e.g., item 9, "I did not think my partner and I were compatible"). The third factor, labeled guilt, contained two items $\left(\alpha_{\text {disengager }}=.62, \alpha_{\text {recipient }}=.48\right)$ and was characterized by guilt or concern about potentially hurting the recipients' feelings (e.g., item 12, "I felt bad telling them I wanted to breakup"). Finally, the fourth factor, labeled anticipated a difficult breakup, contained two items $\left(\alpha_{\text {disengager }}=.68, \alpha_{\text {recipient }}=.51\right)$ characterized by the expectation that the recipient would not accept the breakup easily (e.g., item 20, "My partner would overreact/be dramatic about the breakup"). 


\section{Curriculum Vitae}

Name:

Post-secondary Education and Degrees:

\section{Honors and} Awards:

Related Work Experience
Rebecca B. Koessler

University of Oregon Eugene, Oregon, USA 2010-2014, B.Sc. Psychology and Anthropology

The University of Western Ontario

London, Ontario, Canada

2016-2018, M.Sc. Social Psychology

General Development Scholarship (\$1000), University of Oregon 2010-2011

Dean's List, University of Oregon 2010-2013

Resident Dean's Scholarship (\$8000), University of Oregon 2010-2014

Edith Chambers Scholarship (\$1000), University of Oregon 2013-2014

Laurel Scholars Award (\$1250), University of Oregon 2013-2014

Mortar Board Scholar, University of Oregon

2013-2014

Undergraduate Teaching Assistant, Evolutionary Psychology University of Oregon

2015

Teaching Assistant, Research Methods and Statistics The University of Western Ontario 2016-2018

Private Tutor, Research Methods and Statistics The University of Western Ontario 2018 